\title{
Community decision-making and privatised spaces: a case study of suburban shopping malls in the Wellington Region
}

\section{Chantal Mawer}

Thesis

ENVIRONMENTAL STUDIES 591
A 120 point thesis submitted to Victoria University of Wellington in partial fulfilment of the requirements for the degree of Masters of Environmental Studies

School of Geography, Environment and Earth Sciences

Victoria University of Wellington

April 2018 



\section{Abstract \\ Community decision-making and privatised spaces: a case study of suburban shopping malls in the Wellington Region}

Chantal Mawer

Shopping malls are a widely disparaged urban form, particularly when these have been built in favour of traditional public spaces. Critiques have ranged from their aesthetic to the impact they have on civic life and broader democracy. However, despite being in private ownership, they have been found to play crucial community functions. This is particularly true in suburban communities which often lack alternative forms of community infrastructure. Concurrently, across the globe, a number of malls are in decline and some communities are losing the only form of community space available to them. Moreover, they are often unable to contribute to decision-making regarding these spaces due to their private ownership.

This thesis examines the role that suburban shopping malls, in Aotearoa New Zealand can, and do play as community spaces. It assesses decision-making mechanisms, questioning how communities can participate in the development of what they conceive of as their community spaces. Two cases of declining malls in the Wellington Region- the Johnsonville Shopping Centre and the Wainuiomata Mall were selected and 12 semi-structured interviews and three focus groups were conducted.

This research found that these malls played an important role as spaces where communities were built and members socially engaged in often ad-hoc, but significant ways. However, due to the private nature of these spaces, community members often felt powerless and unable to participate in decisions relating to this space. This thesis demonstrates the ways in which the legal binary of public and private fails to encapsulate the nature of modern spaces, which in reality, typically exist as a socially constructed hybrid of both. It challenges the existing framework of property rights based on this binary, and subsequent wider community exclusion from decision-making. In response, this thesis offers policy recommendations around community decision-making in order to stimulate vital suburban community space into the future.

Key words: public space, shopping malls, community space, privatisation, community decision-making 


\section{Acknowledgements}

There are a number of people who need to be recognised for their contribution to this research. I would not have been able to do this without your support, guidance and generosity.

Firstly I would like to acknowledge the Wainuiomata and Johnsonville community members who have contributed to this research. Thank you for your hospitality and openness, this research would not have been possible without your help.

This thesis has been funded by the National Science Challenge 11 and contributes to the Shaping Places project within this. I am very grateful to have been involved with this project and for the financial assistance given to me.

To my supervisor Rebecca Kiddle, I cannot fully express my gratitude for everything you have done for me over this past year. Your ability to bring people together and create a sense of community and belonging in our department is a valuable gift, one which has substantially improved my postgraduate experience. Thank you for always believing in me and for providing a number of incredible opportunities which would not have been available otherwise. I am so grateful for your unwavering support and enthusiasm regarding this research. Your comments, feedback and recommendations provided invaluable inputs into this thesis, and I could not have imagined a better supervision experience. I am endlessly grateful for your mentorship.

To my fellow post grads, particularly my office mates in CO102A, I don't know if I would have gotten through this year without you. You have all contributed to an office environment and wider thesis experience which has been full of friendship, laughs, and encouragement. Thank you for your inspiring conversations, unwavering support and patience as well as daily quizzes and Tuesday baking. I feel so lucky to have gotten to know you all over the last year and I am going to miss working so closely with you.

I also want to thank my wider friend group, for being so understanding and providing encouragement and support when I most needed it. Thank you for keeping 
me connected to the outside world, for always being there and being so understanding during times of thesis pressure. I can't wait to go on adventures with you soon.

Finally to my family, thank you for helping me to get to this point and trusting in my life decisions thus far. You have taught me the value of hard work and also the importance of following my passions. Thank you for being a source of ongoing support and encouragement. I particularly want to acknowledge my mum, Katrina Jackson. Thank you for constantly seeking to engage in and understand 'my world', this means everything to me. 


\section{Table of Contents}

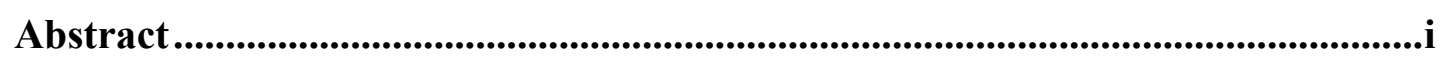

Acknowledgements...........................................................................................

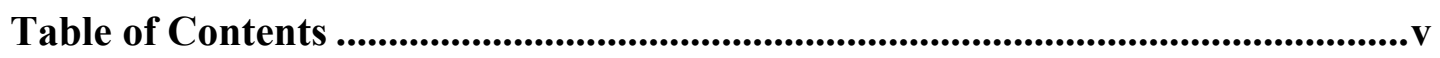

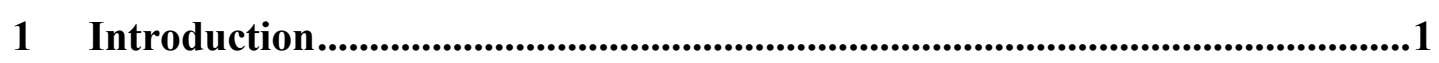

1.1 Origins and significance of this research...............................................

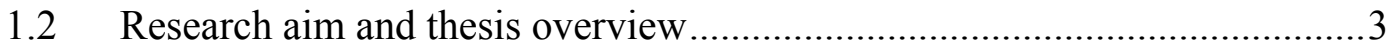

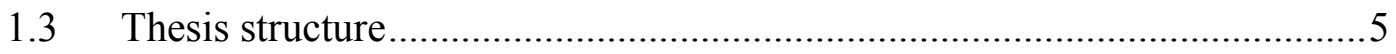

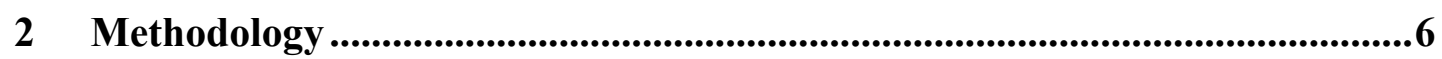

2.1 The epistemological underpinning of this research ..................................6

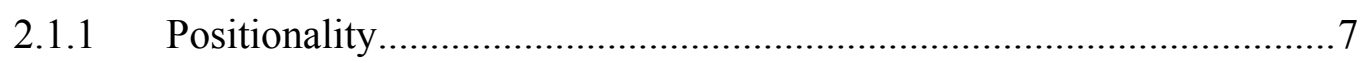

2.2 Qualitative Research methods ............................................................. 10

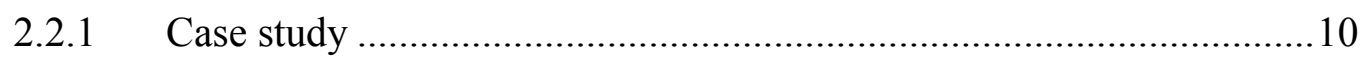

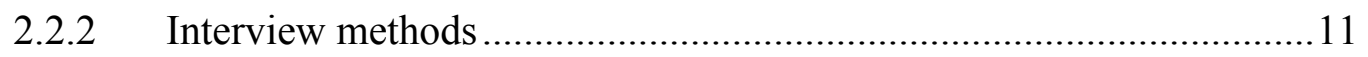

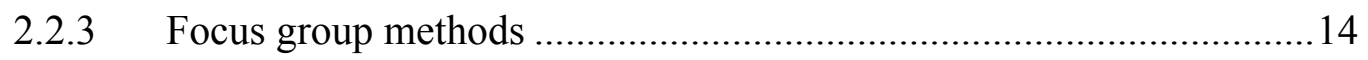

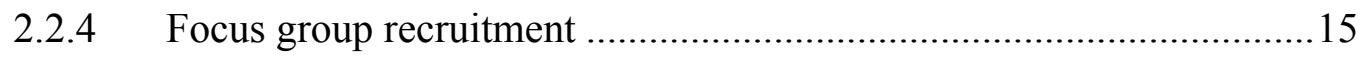

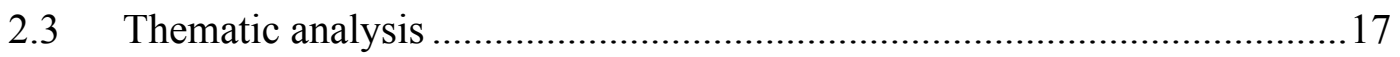

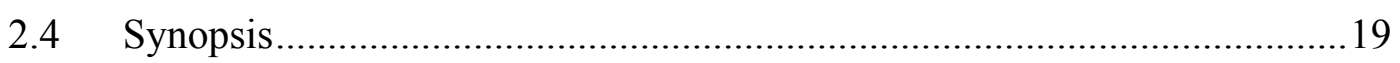

3 Wainuiomata Mall \& Johnsonville Shopping Centre ..................................20

3.1 Characteristics of the suburb of Wainuiomata ...........................................20

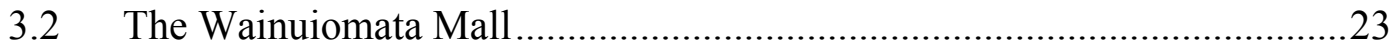

3.3 Characteristics of the suburb of Johnsonville...........................................25

3.4 The Johnsonville Shopping Centre ..........................................................28

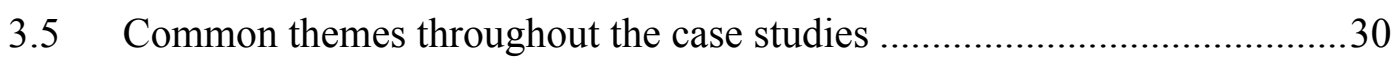

4 Conceptions of public and private space in relation to shopping malls........32

4.1 Public and private space and the growing trend of privatisation..................32

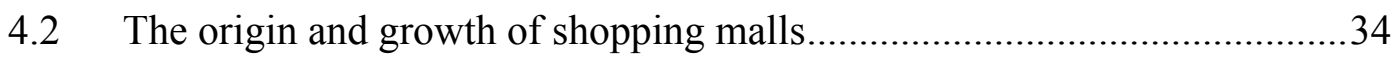

4.3 Critiques of shopping malls as an urban form ............................................36

4.4 Community functions of shopping malls ................................................. 37

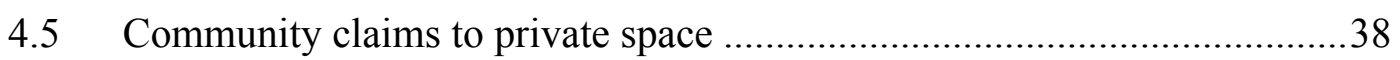

4.6 The age of 'dead malls' and the loss of community space ..........................39

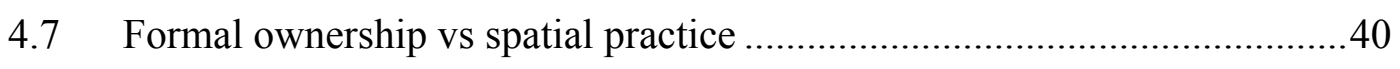

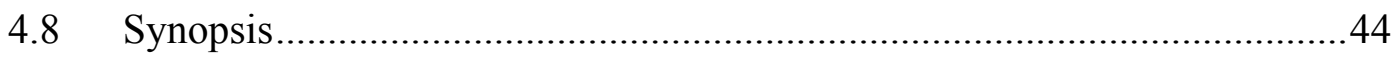

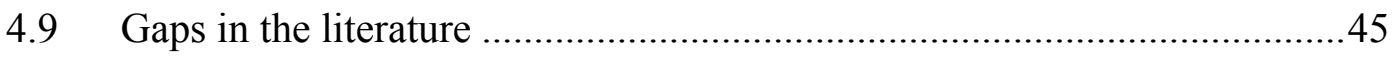

5 Shopping malls as community space and the impact of their decline...........46

5.1 Wainuiomata Mall as a site for socialisation and community building ......46 
5.2 Wainuiomata Mall decline and the loss of this socialisation role ...............49

5.3 Johnsonville Shopping Centre as a source of suburb identity .....................51

5.4 Suburban shopping malls as a source of community pride .........................53

5.5 The importance of local shopping malls for specific populations ...............55

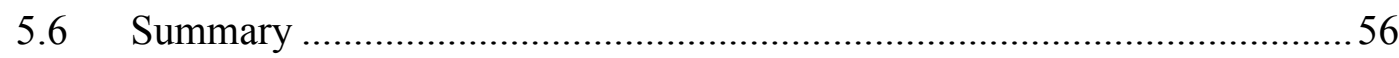

6 Contextualising this community function within the literature ...................58

6.1 The notion of a shopping mall as a community space ..............................5 58

6.2 Potential reasons for differing conceptions of community space ...............59

6.3 The community function of the mall relied on the success of its retail

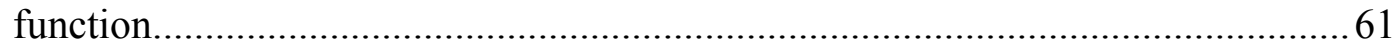

6.4 Community identity and pride as represented by a local shopping mall ....62

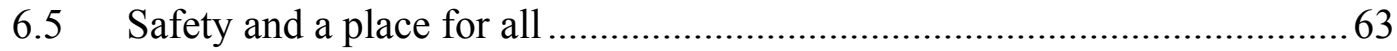

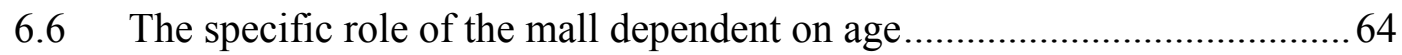

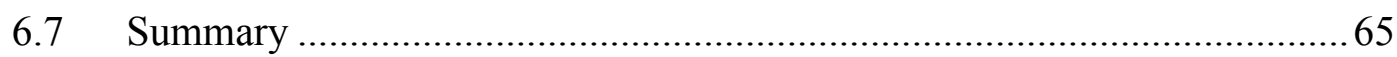

7 Community decision-making in privately owned commercial spaces ..........66

7.1 The failure of the mall owners to sufficiently engage with the affected communities

7.2 Community desire to be recognised as key stakeholders by mall owners .. 69

7.3 Private ownership as a limiting factor to community engagement and input

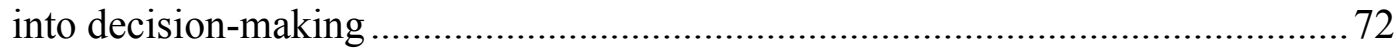

7.4 Community frustration over councils lack of influence............................ 75

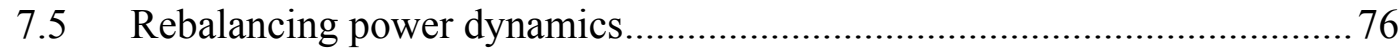

7.6 Public provision of community spaces.................................................. 77

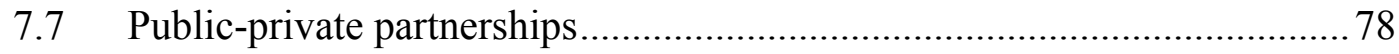

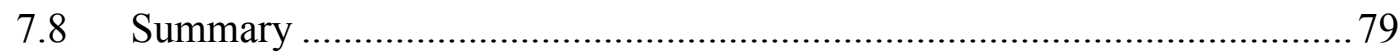

8 Property rights vs community rights in privatised 'public' spaces ..............80

8.1 Disempowered suburban communities in decision-making......................8 80

8.2 'Public' and 'private' spaces and the impact of this designation .................82

8.3 Spatial justice, property rights and democracy ...................................... 84

8.4 Moving toward 'just' community spaces .................................................. 89

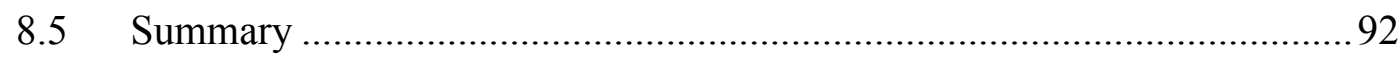

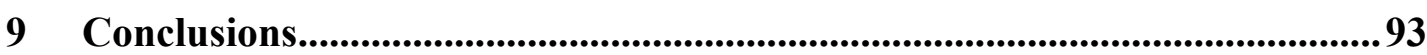

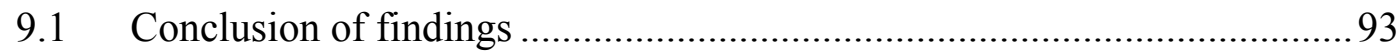

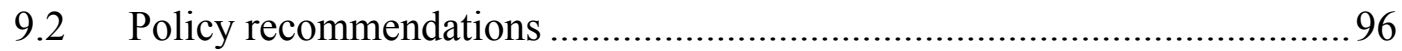

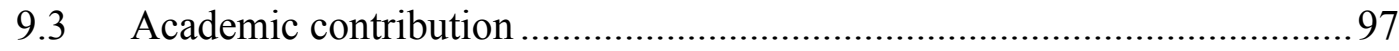

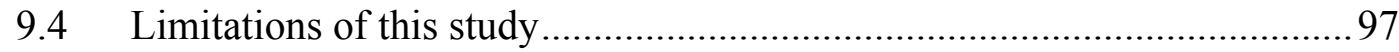

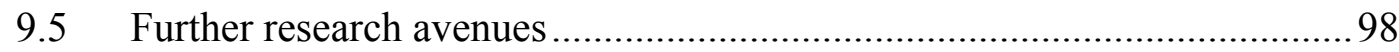

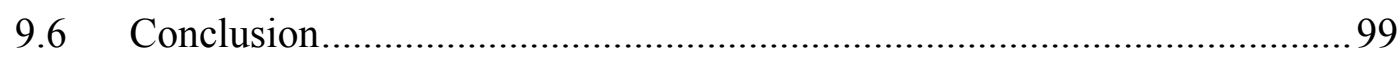


References ..............................................................................................................100

Appendices ..............................................................................................................112

Appendix 1: General interview guide for both case study locations.....................112

Appendix 2: General interview participant recruitment email ..............................113

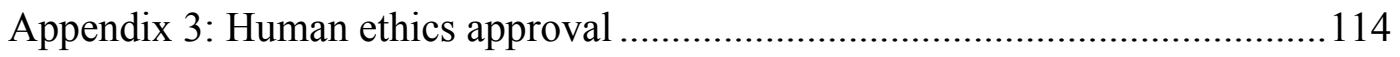

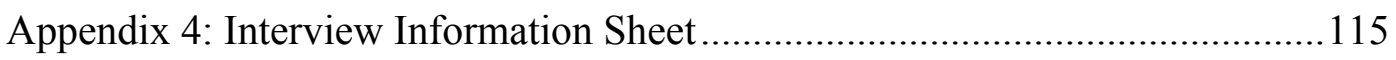

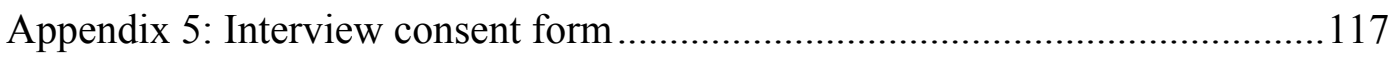

Appendix 6: Johnsonville general focus group recruitment advertisement .........118

Appendix 7 Focus group information sheet .......................................................119

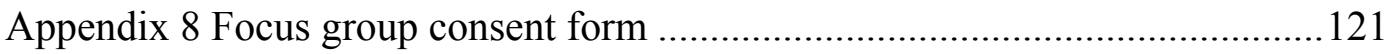

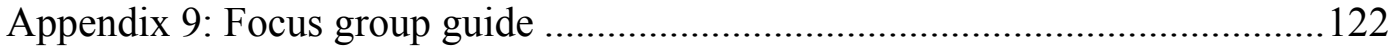





\section{Introduction}

Shopping malls are a widely disparaged urban form, with critiques ranging from their aesthetic, to their impact on civic life and broader democracy. However, in some cases, shopping malls play crucial community functions, particularly in areas such as suburban communities, which are lacking alternative public spaces.

Traditional conceptions of public and private space that relate to legal ownership fail to take account of the way in which communities have made claims to these spaces. These claims have often resulted in community uses which are well beyond the designed function of the mall as a space of consumption.

Currently, a number of malls across the globe are in decline. For those communities for whom the local mall is their only form of community or 'public' space, this decline has had a negative impact. This impact has been felt in relation to their ability to access retail but also other intangible benefits such as opportunities to meet others in the community. In addition, due to the private ownership of these malls, surrounding community members are often unable to contribute to decision-making regarding this space. This exclusion relates to the way in which, we as a society conceptualise space within the binary of 'public' or 'private'. This categorisation has far-ranging impacts, particularly in terms of legal rights to space and who has the ability to contribute to decision-making with respect to space design and function.

This thesis aims to interrogate the concept of ownership with respect to shopping malls, in order to understand how the categorisation of a space as public or private impacts on the social life of suburban communities. It demonstrates the ways in which the legal binary of public and private fails to encapsulate the nature of modern spaces, which in reality typically exist as a socially constructed hybrid of both. In support of vital communities and associated local economies, I argue that the way in which space is used, or its 'spatial practice', as opposed to the status of a space's legal ownership should be the underpinning principle of suburban mall development and maintenance policy and practice. This reconceptualisation recognises community members as important stakeholders, while also setting a scene for their involvement in decision-making regarding these spaces. 
Inherent within this argument are ideas relating to the right to the city, as conceptualised by Lefebvre (1996) and further developed by (Harvey, 2016). At the root of this argument is the right for citizens to be able to shape the urban environments they live in, in recognition of the ways in which these environments shape those who live within them. This topic feeds into broader ideas of community self-determination, spatial justice and democracy.

\subsection{Origins and significance of this research}

While undertaking research work in Wainuiomata over the summer of 2016, a visit to the mall and conversations with residents demonstrated the severity of the decline of the local shopping centre and the impact it was having on the community. At the time of this visit, five shops remained in the mall. There were also frequent media articles detailing the decline of this mall. Despite the impact that the mall's decline had on the community, it appeared they had little ability to change the situation. The only apparent course of action was for local politicians to attempt to pressure the owners to either sell the mall or redevelop it. Further research discovered that the situation was not unique to Wainuiomata, and communities which hosted declining suburban malls across the Wellington Region appeared to be experiencing similar issues.

Initially, while recognising the importance of these malls as a community space, I struggled to conceptualise this thesis argument. This was mainly due to the fact that the majority of the literature spoke about malls in ways that were not applicable to the experience of Wainuiomata. In fact, very little literature existed about malls within New Zealand. The literature emphasised the negative sides of shopping malls, often explaining how bad they were for community and public life. However, this did not seem to be the case for Wainuiomata. From conversations with community members, it was apparent that this space was understood to be crucial to their community cohesion and pride, and they lamented its decline.

To reconcile what I was reading in the literature with the case study I had chosen, I drove to Wainuiomata and spent time wandering around the mall and chatting with people who I came across. I even parked up on a bench with my books and laptop to try and link some element of the literature to the location to see if anything clicked. 
When I began to read a Parlette and Cowen (2011) article about the Morningside Mall in Scarborough, Ontario and the community activism that resulted due to its closure, I realised that their case study and argument encapsulated what was occurring in Wainuiomata.

Parlette and Cowen (2011) describe the closure of the Morningside Mall and the community response to this announcement. Hundreds of community members took to the street to protest, arguing that it was the 'heart of the community' and the only form of enclosed community space within the area (Parlette \& Cowen, 2011). However, despite this active claim to space, the mall was still demolished. Parlette and Cowen (2011) argue that we need to conceptualise spaces differently in order to recognise the significance of these spaces for suburban communities. Brill (2001) argued that while western societies are mourning the loss of 'pure public life', we fail to recognise any public life which is occurring in non-publically owned spaces. Suburban shopping malls provide an insightful opportunity to investigate these ideas.

This thesis provides an analysis of the role that suburban shopping malls play in New Zealand. This is an area previously under-researched. Mall literature is often North American centric, however, malls are an important and prevalent urban form across New Zealand and it is essential to understand the role they play within their surrounding communities. Several authors have addressed the link between shopping malls and democracy, however few have examined the formal decision-making mechanisms regarding these spaces. A topic which is of particular relevance due to the increasing private provision of public goods. This thesis examines the impact of this trend on local decision-making within the case studies of suburban shopping malls.

\subsection{Research aim and thesis overview}

The overarching research objective of this thesis is to understand the role that suburban shopping malls can play as community spaces and to examine the extent to which communities are able to shape decisions regarding these spaces. More specifically, there are four research questions which contribute to this overarching objective. 
The related research questions are as follows:

- What role can shopping malls play as community spaces and what are the elements within them which facilitate this role?

- What are the impacts on the community when the local mall declines?

- To what extent are community members able to influence decision-making regarding this space?

- What strategies might be employed to enable stronger community engagement in decision-making processes?

To answer these research questions I used a series of methods (for a detailed explanation see the methodology chapter below). This thesis is based on two case studies in the Wellington Region; Wainuiomata Mall and the Johnsonville Shopping Centre. The mall has played an important role as a community space for both these locations, and their decline has caused controversy within their respective communities. Despite this, it appears community members in both locations have had little ability to influence decisions relating to this space.

Within these case study inquiries, key informant interviews and focus groups were the methods selected for data collection. A range of perspectives were sought including those from council members, community leaders, retailers, wider community members and also the mall owners. This research, unfortunately, does not include the perspective of the mall owners or management. In both case studies, they declined to take part in this research after repeated attempts to engage with them. In total 37 people contributed to this research, 12 through semi-structured interviews while the remaining 26 participated in focus groups in their respective communities. One participant was both an interviewee and focus group participant. They have been counted in both number breakdowns, but only once in the total number of participants hence the discrepancy in numbers. This data was then analysed using a thematic analysis, while a social constructivist epistemology underpinned and guided this thesis. 


\subsection{Thesis structure}

The second chapter of this thesis details the methodology by which these research questions will be answered, and the manner in which the wider research will be conducted. The third chapter will provide a comprehensive background and context in relation to the two case study locations. It will discuss why these case studies were chosen, their significance, key characteristics of both communities and the history of the mall and its decline. The subsequent chapter provides a description of the theoretical framework that underpins this research inquiry, highlighting key authors and theories, and identifying the research gap that this thesis aims to fill. This chapter acts to provide a theoretical framework for answering these research questions.

The following chapters are split into two sections. Chapters five and six seek to answer research questions one and two. The fifth chapter discusses the results of the thematic analysis, while the sixth chapter correlates these findings to the broader literature examining key similarities and differences.

Chapters seven and eight address research questions three and four. Chapter seven examines the ways in which community members are able to contribute to decisionmaking regarding these spaces and the potential ways this could be improved. While chapter eight combines these findings, and in relation to the literature, argues for improved community decision-making mechanisms. The findings from research question four, in relation to the literature were used to identify policy and practice recommendations to encourage vital community decision-making. These can be found in the concluding chapter of this thesis accompanied with suggestions for future research avenues. 


\section{Methodology}

Through a qualitative study, this research examines the role that shopping malls can play in suburban communities and the impact of their decline on community agency, assessing decision-making mechanisms regarding this space. This thesis is based on two case studies in the Wellington Region; Wainuiomata Mall and the Johnsonville Shopping Centre. The terms shopping mall and shopping centre will be used interchangeably throughout this thesis, as they are within the case studies. As stated in the previous chapter, these sites have been selected as the mall has played an important role as a community space and their decline has caused controversy within their respective communities. The epistemological framework which underpins and guides this thesis is social constructivism. In line with this epistemological underpinning, qualitative research methods have been selected in order to answer the research objectives. Within this case study inquiry, key informant interviews and focus groups were the methods selected for data collection. A range of perspectives were sought including those from council members, community leaders, retailers, wider community members and also the mall owners. Unfortunately, the two owners decided not to be involved in this research. This data was then analysed using a thematic analysis. This chapter outlines the detailed research approach and its associated methods.

\subsection{The epistemological underpinning of this research}

It is important to highlight the philosophies and ideological assumptions which underpin this research as they act to determine its design and execution (Flowerdew \& Martin, 2005). Social constructivism is the epistemological stance that this research is based upon. This term refers to the idea that knowledge is constructed through an individual's experiences and the subjective meanings they place upon these (Creswell, 20144). The role that culture and context play in our understanding of a phenomenon is a key concern for social constructivism, particularly how this relates to knowledge construction (B. Kim, 2012). This epistemology is based on relativist ontology which denies the existence of an absolute truth and states that individual truths are relative (Creswell, 20144). Instead of attempting to explain a phenomenon, this research paradigm focuses on understanding " from the 
perspective of those experiencing it" (Costantino, 2008, p. 119). It acknowledges the varying worldviews of differing people and seeks to recognise the ways in which individuals understand the world (Creswell, 2013). It also concerns itself with understanding the ways in which knowledge is constructed as a result of social interactions and exchanges (B. Kim, 2012).

\subsubsection{Positionality}

Hegemonic knowledges have been based in positivist epistemologies and methodologies, emphasising neutrality and objectivity, where the researcher is perceived as being entirely separate from those researched (England, 1994; Mohammad, 2001). However, social constructivism denies the existence of this objectivity. Instead, the researcher is understood to be part of the social world and therefore it is impossible to achieve objectivity or neutrality (Costantino, 2008; Mohammad, 2001). In fact, Mohammad (2001) argues "the claim to objectivity and neutrality serves only to make invisible the biases and subjectivity of the information that is collected and coded as knowledge"(p. 103). Therefore, in line with critical reflexivity, I must acknowledge my social position in this research.

As a researcher I agree with Ley and Mountz (2001) sentiment that "we are all caught up in a web of contexts - class, age, gender, nationality, intellectual tradition and others- that shape our capacity to tell the story of others" (p. 235). My personal characteristics influence the interactions I have and therefore my research outcomes due to this research not occurring in a vacuum (Dowling, 2010; Phoenix, 1991; Valentine, 2005). The very nature of my research methods required that I engage socially with my participants. Thus our exchanges must be understood within the context of 'societal structures and behaviours' (Dowling, 2010).

Some of the factors which may have influenced or informed my research include the fact that I am a 25-year-old female, from a middle-class family and am university educated. I am an $8^{\text {th }}$ generation New Zealander of European descent. An example of these characteristics impacting on my research outcomes can be exemplified in a dialogue with a local Johnsonville retailer. I had approached them off the street to speak about my research and ask if they would be interested in participating in this study. They responded that normally they would not want to be involved, due to 
concerns regarding confidentiality. However, they decided to participate, linking their willingness to be involved to my personal attributes that I looked like a "nice, young, trustworthy person" (participant D). Based on societal views of what a "nice, young trustworthy person' looks like, I was able to gain access to valuable research knowledge which would not have been available to a different researcher.

Another characteristic which influenced my research was the fact that I do not live in either of the case study locations nor do I have strong connections to these communities. As explained by Dowling (2010) as an outsider it can be difficult to establish rapport with research participants, and it may be possible that I interpret data differently than those who are from the local context (Dowling, 2010). Conversely, some advantages also exist as an outsider, Dowling (2010) suggests that participants may explain ideas, contexts and feelings in more detail to enhance the comprehension to an outside researcher who is not aware of the subtleties of the context. Yet, these two categories are recognised as not being mutually exclusive (Dowling, 2010). There are a number of characteristics such as ethnicity, gender and socio-economic status which can create similarities between the researcher and participants, often leading to a semi-insider status (Dowling, 2010).

There are also mechanisms within the research process which can help to engage this semi -insider status. Sixsmith, Boneham, and Goldring (2003) discuss the issues relating to accessing research participants as an outsider, finding that they were able to do so by engaging in the community in other ways. Through this engagement, they built credibility and trust within the community and were able to recruit participants for their research more easily (Sixsmith et al., 2003). While my community engagement was far less comprehensive than theirs, the basic premise worked the same. Through attending a Northern Suburbs Liaison Meeting in Johnsonville, I was able to make a number of contacts, who acted to support my research in a myriad of ways. Including these contacts agreeing to be research participants, passing on names of potential interviewees and one even helped to recruit focus group participants. It was through my attendance at this meeting and from walking around the communities chatting with residents that I feel like I gained a little bit of insider status and was able to find participants easier. A detailed description of my recruitment process can be found later in this chapter. 
As a result of this semi insider status and a range of other factors, my interactions with participants cannot be seen as uniform. Based on my positionality and that of participants, some interactions were easier than others and naturally differing levels of connections were made. Kobayashi (2001) noted this discrepancy while researching employment equity in Canada. Naturally, she found that the research team had greater rapport with some participants than others and this is a factor which influenced their research outcomes (Kobayashi, 2001).

The influence of my positionality permeates all aspects of this thesis. Beginning from the selection of a research topic through to the methods through which this data is analysed. As Waitt (2010) explains "the researcher shapes the analysis as much as the analysis shapes the researcher" (p. 238). The impact of positionality can influence on both one's research but also the broader exchange and production of knowledge (Chacko, 2004). While acknowledging my positionality helped to make these influences visible, they also provided an opportunity through which I was able to try and minimise some of these influences when possible. One example of this can be seen by an awareness of power differentials during certain interviews, within which I was perceived to have more power. In a couple of instances, some participants were hesitant to speak about certain topics, we quickly moved on instead of me pushing for answers or information which would have been valuable to this research.

Another factor which has influenced the direction of this thesis is the funded nature of this research. This thesis has been funded by the National Science Challenge 11, Building Better Homes, Towns and Cities. It forms a part of a wider project called Shaping Places which examines the ways in which a range of social factors such as decision-making and population growth shape the design of our cities and the wider built environment. The remit of this funding was wide, only requiring that my research addressed an aspect of urban space and its link to community, however, it did act to shape my research. 


\subsection{Qualitative Research methods}

Qualitative research methods were used in this study in order to answer the research objectives. This is in line with the social constructivist epistemology guiding this research, as qualitative research provides a way in which to analyse an issue or situation holistically and in relation to its context (Byrne, 2001). The use of qualitative methods also symbolises a challenge to the hierarchical power structures within knowledge systems, instead recognising the voices, perspectives and opinions of lay people and highlighting their everyday realities (Smith, 2001). Through the use of qualitative methods, these perspectives and voices are given a platform, which would traditionally be confined to 'experts' (Smith, 2001). Case studies have been used to provide a comprehensive understanding of this phenomenon, and key informant interviews and focus groups were the methods used to obtain this data. Overall, 37 participants contributed to this research, 12 through semi-structured interviews while the remaining 26 participated in focus groups in their respective communities. One participant contributed to both, hence a discrepancy in the overall number of participants. A thematic analysis was used to analyse this data, where a number of themes were produced which will be discussed in subsequent chapters.

\subsubsection{Case study}

As mentioned previously, two case studies have been selected in order to answer the research questions of this thesis. These are the Wainuiomata Mall and the Johnsonville Shopping Centre. These two case studies were chosen due to a number of differing factors. In both of these case studies, it appears that the malls play an important social function. These two malls are set in different socio-economic contexts, geographical contexts, as well as being at differing levels of decline and redevelopment negotiations. They provide a chance to compare and contrast across these spaces to find similarities.

Case studies have been chosen as a method of inquiry as they provide an opportunity to examine a phenomenon in depth. Their emphasis on context and relativity, closely aligns to the social constructivist epistemology underpinning this research. Yin (2013) provides a detailed definition of a case study. He proposes that case study inquiry is a mechanism through which to understand a series of variables and how these collectively impact on a phenomenon. They aid in understanding a 
phenomenon "in depth and within its real-world context, especially when the boundaries between phenomenon and context may not be clearly evident”(Yin, 2013, p. 16). When seeking to understand 'how' or 'why' in research, then the use of case studies is a suitable research method (Yin, 2013).

Baxter and Jack (2008) explain that case studies are suitable to be used in research when the phenomenon studied cannot be understood without examining the context through which it is located. The use of a case study within this research topic is critical as this topic has come out of the situations that both of these sites are experiencing. The nature of Wainuiomata and Johnsonville, their community, and what is occurring nearby are all essential elements which allow for an understanding of the role these malls play in their communities and the impact of their decline. Case studies also allow for a phenomenon to be understood holistically and not through just one lens but from a variety of perspectives (Baxter \& Jack, 2008). Rather than attempting to generalise a theory for a wide range of settings, this method seeks to achieve an in-depth inquiry (Stark \& Torrance, 2005). In line with the constructivist epistemology guiding this research, case study as a method aims to understand and describe rather than theorise and analyse (Stark \& Torrance, 2005). The use of multiple case studies allows for these contexts to be compared and contrasted (Baxter \& Jack, 2008), illuminating different elements relating to the research questions. As Baxter and Jack (2008) explain, a case study provides a method for understanding how and why a situation is occurring, as well as allowing for an understanding in how the context influences the phenomenon studied (Baxter \& Jack, 2008).

\subsubsection{Interview methods}

As previously mentioned, 12 semi-structured interviews were conducted in both of the case study locations. Seven interviews were conducted with participants from Wainuiomata, while five were undertaken in Johnsonville. A wide range of perspectives were sought for this research. Table 1.1 below, demonstrates the grouping that these interview participants belonged to and how the total number of participants was divided amongst these. 
Table 1.1: Interview participant breakdown

\begin{tabular}{|l|l|l|r|l|}
\hline $\begin{array}{l}\text { Case study } \\
\text { location }\end{array}$ & $\begin{array}{l}\text { Community } \\
\text { leaders }\end{array}$ & $\begin{array}{l}\text { Council } \\
\text { members }\end{array}$ & Retailers & $\begin{array}{l}\text { Total } \\
\text { interviewees }\end{array}$ \\
\hline Wainuiomata & & 3 & 3 & \\
\hline & & 1 & 2 & $\mathbf{7}$ \\
\hline Johnsonville & 2 & 1 & & $\mathbf{5}$ \\
\hline
\end{tabular}

Semi-structured interviews were chosen to provide an in-depth analysis of each interviewee's perspective on the research issue. This method of interviews allow for a basic structure, often guided by an interview guide. However, they retain significant flexibility for both the researcher and interviewee (Dunn, 2010). An interview guide was used for these interviews and can be found in Appendix 1. As Dunn (2010) explains, this guide had the fundamental questions for the interview but doesn't account for questions that came up in conversations with interviewees. The benefits of this flexibility is that it allows interviewees to "construct their own accounts of their experiences by describing and explaining their lives in their own words" (Valentine, 2005, p. 111). It also allows for information and insights that might not have been envisioned in the research design. This method adheres to this thesis's guiding philosophy of constructivism as this method acknowledges the interviewee as the holder of knowledge and allows them to shape the interview (Valentine, 2005).

Due to my lack of connections within these two case study communities, interviewees were initially selected based on their media visibility relating to this research topic. The numerous articles relating to both case studies provided an insight into some of the principal actors within this issue. An email was sent to request participation in this research, a standard copy of which can be found in Appendix 2. Other participants were found through snowball sampling based on these initial interviewees. Snowball sampling refers to "using one contact to help you recruit another contact, who can, in turn, put you in touch with someone else" (Valentine, 2005, p. 117). Through contacting the major political actors regarding this issue, I was able to gain contacts of community members who were also heavily involved in these issues but who were not visible to an outside researcher. As rationalised by Valentine (2005) the selection of interviewees was not chosen to be 
representative of the population in either of these case studies, it was instead focussed on providing illustrative examples of individuals within these case studies.

The most challenging participants to recruit were retailers, particularly in Johnsonville. The participants who were recruited, discussed their hesitation in being involved in this research due to concerns that it may compromise their relationship with the mall owners. In order to recruit participants, I approached retailers face to face and discussed my research asking if they would like to participate. Previous efforts of attempting to contact them by phone and email had been unsuccessful. I was able to establish rapport and trust with participants by meeting face to face. This method of recruitment is not unique. In their article Sixsmith et al. (2003) speak about the process of street interviewing, where community members were approached on the street for a short interview. They found this often led to people being willing to participate in more in-depth interviews (Sixsmith et al., 2003). While I did not carry out street interviews, informal meet and greets provided avenues for making contacts with participants.

In total 12 participants were interviewed, these interviews lasted between 30 minutes to 90 minutes. These were all conducted face to face and were held at a time and location convenient for participants. This was typically in private rooms at their places of work. The Victoria University Ethics Committee approved this research on the $15^{\text {th }}$ of August 2017 as shown in Appendix 3. Prior to the interview, participants were given an information sheet as can be found in Appendix 4. This was to ensure participants were fully informed about the nature of the study and their ability to abstain from answering questions or withdraw from the study if they chose. They were also given a consent form which was signed before the interview took place and is shown in Appendix 5. This form provided permission to be able to use the content from the interview for this thesis. Within this form, participants also agreed to have the interview recorded and this recording was later transcribed ad verbum. Participants were also offered a copy of the audio recording, a summary of their interview and also a copy of the final thesis if they chose.

Informed consent, permission and confidentiality are key ethical issues when undergoing qualitative research (Hennik, Hutter, \& Bailey, 2011; Piper \& Simons, 
2005). It was ensured that consent and permission were given freely before any research took place. Confidentiality was guaranteed throughout the entire process if the participants chose to not be identified. They were also made aware that they could stop the interview anytime or choose not to answer certain questions. As shown in the interview guide, again a copy of which can be found in Appendix 1, the initial questions were broad and sought to create a rapport with interviewees as well as to understand their role within this topic. These then built to larger questions with specific focuses such as the community role of the mall and opportunities to contribute to decision-making. At the conclusion of the interview, participants were presented with a small koha (gift) typically of locally manufactured chocolate to compensate them for their time and participation.

Despite some participants agreeing to be named, in order to ensure confidentiality and uniformity, interview participants will be referred to as participants A, B , C ,D ,E, F, G, H, I, J, K, L.

\subsubsection{Focus group methods}

Key informant interviews provided an overall explanation of the issue and each informant supplied their specialised knowledge and perspectives. Focus groups were then used to canvas broader community member's perspectives on their declining malls. A focus group as defined by Bedford and Burgess (2001) is "a one-off meeting of between four and eight individuals who are brought together to discuss a particular topic chosen by the researcher (s) who moderate or structure the discussion" (p. 121). The number of participants varies across authors, however, most suggest between 6-10 (Cameron, 2010). Focus groups are a useful research method in order to understand a range of views on a particular issue, while also enabling the researcher to understand the ways in which individuals interact and create a dialogue about this issue (Bedford \& Burgess, 2001; Conradson, 2005; Flowerdew \& Martin, 2005). They not only allow for an understanding of the range of views but can also provide an understanding of why certain views are held by individuals or groups (Conradson, 2005). Focus groups are also seen by Cameron (2010) to be an effective method to explore "the nuances and complexities associated with people - place relations"(p. 157). They have also been understood to allow for 
an insight into all elements of an issue from the social, cultural, economic and political due to the conversational nature (Bedford \& Burgess, 2001).

In total 26 community members participated in these focus groups, two of which were held in Johnsonville and one which was held in Wainuiomata. The breakdown of numbers and the self-identified gender of these participants can be found in table 1.2 below. Initially, it was decided that two focus groups in both case studies would be conducted. This would split participants into a general category (those aged 1855 ) and an older group (65 years + ). This separation acknowledged that these two groups may have differing experiences of this situation based on their age group. Nevertheless, due to the nature of my recruitment, the older category and general category was merged in Wainuiomata. This meant that this focus group was larger than usual.

Table 1.2: Focus group participant breakdown

\begin{tabular}{|l|r|l|r|}
\hline Focus group & $\begin{array}{l}\text { Number of } \\
\text { participants }\end{array}$ & $\begin{array}{l}\text { Self-identified } \\
\text { female }\end{array}$ & Self-identified male \\
\hline $\begin{array}{l}\text { General } \\
\text { Wainuiomata }\end{array}$ & 13 & 12 & 1 \\
\hline General & 9 & & \\
Johnsonville & 4 & 7 & 3 \\
\hline Older Johnsonville & $\mathbf{2 6}$ & $\mathbf{2 0}$ & $\mathbf{6}$ \\
\hline Total participants & & & 3 \\
\hline
\end{tabular}

\subsubsection{Focus group recruitment}

The recruitment for these focus groups took various forms. For the general Johnsonville focus group, an advertisement was placed on the Johnsonville Community Noticeboard Facebook page. This is a very active community page which had 3,647 members when I advertised my research in October 2017. My advertisement was posted twice on this page and can be found in Appendix 6. I was overwhelmed with the response and had almost double the applicants that I needed for this focus group. The initial 10 were selected, and unfortunately, one member had to pull out on the day.

A community leader was used for recruitment in both the Johnsonville older focus group and the Wainuiomata focus group. Due to my outsider status and the well- 
publicised trouble of finding participants for focus groups (Barbour \& Schostak, 2005; Bedford \& Burgess, 2001) I sought to use gatekeepers when recruitment through social media was not appropriate or possible. As noted by Sixsmith et al. (2003) these participants added credibility to my research within the case study locations. They also provided access to participants which would not have been available without their help.

My initial recruitment plan within Wainuiomata was to advertise through the community Facebook page as I had done in Johnsonville. However, this page was closed to those who do not belong to the community, and I was unable to gain access. It was advised by Wainuiomata locals that I would need to try alternative methods of recruitment. Instead, a connection was made with one participant, who was a key informant interviewee and also a contact of my supervisor. After our initial interview, I asked about the best way to recruit Wainuiomata community members for focus groups. She instead offered to recruit the community members as she felt that this was the best way of approaching the issue due to community politics. Their position within the community meant that 12 participants were interested in the focus group (excluding herself). It also meant that all ages were mixed into this group, and all participants were acquaintances of the organiser. They were from similar backgrounds, which is a disadvantage of snowball sampling as identified by (Sixsmith et al., 2003), nevertheless, this was the only recruitment method which was deemed feasible by the community members approached.

In the case of the Johnsonville older focus group, I was unable to recruit these participants online through the community Facebook page, due to the acknowledgement that older people are less represented in these forums (Duggan \& Brenner, 2013). Instead, I met an appropriate gatekeeper at the Northern suburbs liaison meeting I attended. They were heavily involved in a local community organisation and offered to advertise the focus group within their monthly meeting. From this advertisement four people, inclusive of this contact took part.

These three focus groups were held between the $11^{\text {th }}$ and $23^{\text {rd }}$ of November 2017. The two Johnsonville focus groups were held at the local community centre. The general focus group was held on a Saturday morning due to availability, while the 
older focus group was held midweek. The Wainuiomata focus group was held during the week at a local organisations meeting room.

These focus groups lasted approximately 90 minutes and a morning tea was provided. Participants were also compensated for their time in the form of a $\$ 25$ supermarket voucher. As with the interviews, participants were provided with an information sheet prior to the focus group. Signed consent forms were also required before the focus group began. A copy of the information sheet and consent form can be found in Appendices 7 and 8 respectively. The focus group guide can be found in Appendix 9 demonstrating the structure of this event and the questions which were asked of the group.

Confidentiality and informed consent were guiding principles throughout this process. Confidentiality within focus groups is particularly important as Barbour and Schostak (2005) explain that often interactions within focus groups can cross the boundary of normal interactions. There is also a risk that information shared by participants will be shared with community members outside of the focus groups. The rules for the focus group explained that participants were not to disclose the contributions of others from the group. Again as with the interview participants, some agreed to be recognised while others wished to have their identity kept confidential. As with the interviews, all names have been removed to ensure uniformity and confidentiality. Focus group participants are referred to throughout this thesis based on their category. Participants from the general Wainuiomata focus group are referred to as GWF participant 1,2...Within Johnsonville, participants from the general focus group are referred to as GJF participant 1, 2... For the older group, these participants are referred to as OJF participant $1,2 \ldots$

\subsection{Thematic analysis}

A thematic analysis was used in order to analyse the data generated from this research. This method of analysis is understood by Braun and Clarke (2006) to be a foundational method of qualitative analysis for "identifying, analysing and reporting patterns (themes) within data" (Braun \& Clarke, 2006, p. 79). A thematic analysis is a 'widely used' method for qualitative analysis and is seen to be an "accessible and theoretically flexible approach" (Braun \& Clarke, 2006, p. 77). I have chosen to use 
this method of analysis because this thesis is exploratory, particularly the first section which seeks to understand the broader role of these shopping malls as community spaces.

One of the stipulated benefits of thematic analysis is its flexibility. It is seen to provide "a rich and detailed, yet complex, account of data" (Braun \& Clarke, 2006, p. 78). However, Braun and Clarke (2006) argue that the issue with thematic analysis is that it is not clearly conceptualised or distinguished from other forms of qualitative analysis. In their work, they set out a framework through which to conduct a thematic analysis. My analysis has been guided by this framework.

The first step of this framework involves immersing oneself in the research. This includes the transcription process and requires repeated readings of the data set in order to become familiar with the scope of the data and to begin to identify reoccurring concepts (Braun \& Clarke, 2006). Despite the availability of computer analysis software such as NVIVO, I chose to analyse this data by hand as I found that I was better able to be immersed in the data and find connections by working with hard copies of the transcripts.

After the initial familiarisation process, I then began to generate preliminary codes or labels for different ideas within the data. I coded interesting features across the data set and collated the data under each of these codes. Once a list of codes was generated, these were assimilated under broader thematic headings. Themes were produced through an inductive approach, where the themes identified in the research were closely tied to the data (Braun \& Clarke, 2006). These themes were selected for a variety of reasons, not simply based on prevalence. Some themes provided an interesting insight into the nature of the research or my chosen case study contexts, and therefore these have been included. When speaking about themes, I acknowledge these have been produced rather than 'emerging' from the data. Braun and Clarke (2006) argue to talk about these themes passively ignores the active role that I as a researcher play, linking back to my positionality.

While the initial themes were constructed inductively, these were also analysed at a latent level due to the differing nature of the two sections of this thesis. This meant 
that I sought to identify and examine the assumptive elements underlying the data and responses (Braun \& Clarke, 2006). This was particularly prevalent in the second section of this thesis which delves into ideas of private property and understanding the discourses related to this. This analysis was an iterative process, where I constantly reviewed and defined themes based on the findings in the data set. The final step of this analysis included writing the findings and discussion sections of this thesis.

\subsection{Synopsis}

Overall this study was underpinned by a constructivist epistemology. This thesis used case study inquiry, semi-structured interviews and focus groups in order to answer the research questions of this thesis. Differing recruitment strategies were used based on what was deemed the most appropriate in both locations, while a range of perspectives were sought to provide greater insights into this topic. These insights were then analysed by using a thematic analysis, the framework through which was guided by Braun and Clarke (2006). In line with the social constructivist philosophy guiding this research, themes were created through an inductive process giving precedence to individual's perceptions rather than pre-established theories. 


\section{Wainuiomata Mall and Johnsonville Shopping Centre}

This thesis is based on two case studies in the Wellington Region; Wainuiomata Mall and Johnsonville Shopping Centre. These sites have been selected as the mall has played an important role as a community space and their decline has caused controversy within their respective communities. These two case studies are both areas characterised by a high proportion of their residents travelling outside of their respective suburbs daily and have malls that are in varying levels of decline. However, these two case studies have key important differences which help to provide a comprehensive insight into this phenomenon. In this chapter, the salient characteristics of each suburb and its community will be discussed. A brief history of the local mall for both case studies is also detailed, accompanied with the context of their respective decline.

\subsection{Characteristics of the suburb of Wainuiomata}

In order to contextualise the decline of the Wainuiomata mall, it is important to understand the nature of Wainuiomata, often referred to as Wainui. As can be seen in figure 1, Wainuiomata is situated to the east of Wellington harbour, over the hill from Seaview (White, Dougall, Mawer, Meachen, \& Kiddle, 2017) and nestled in a basin between the Eastern Hutt hills and the Orongorongo hills (Te Ara, 2016). Wainuiomata is a large suburb of Lower Hutt and makes up part of the larger Wellington Region (White et al., 2017). 


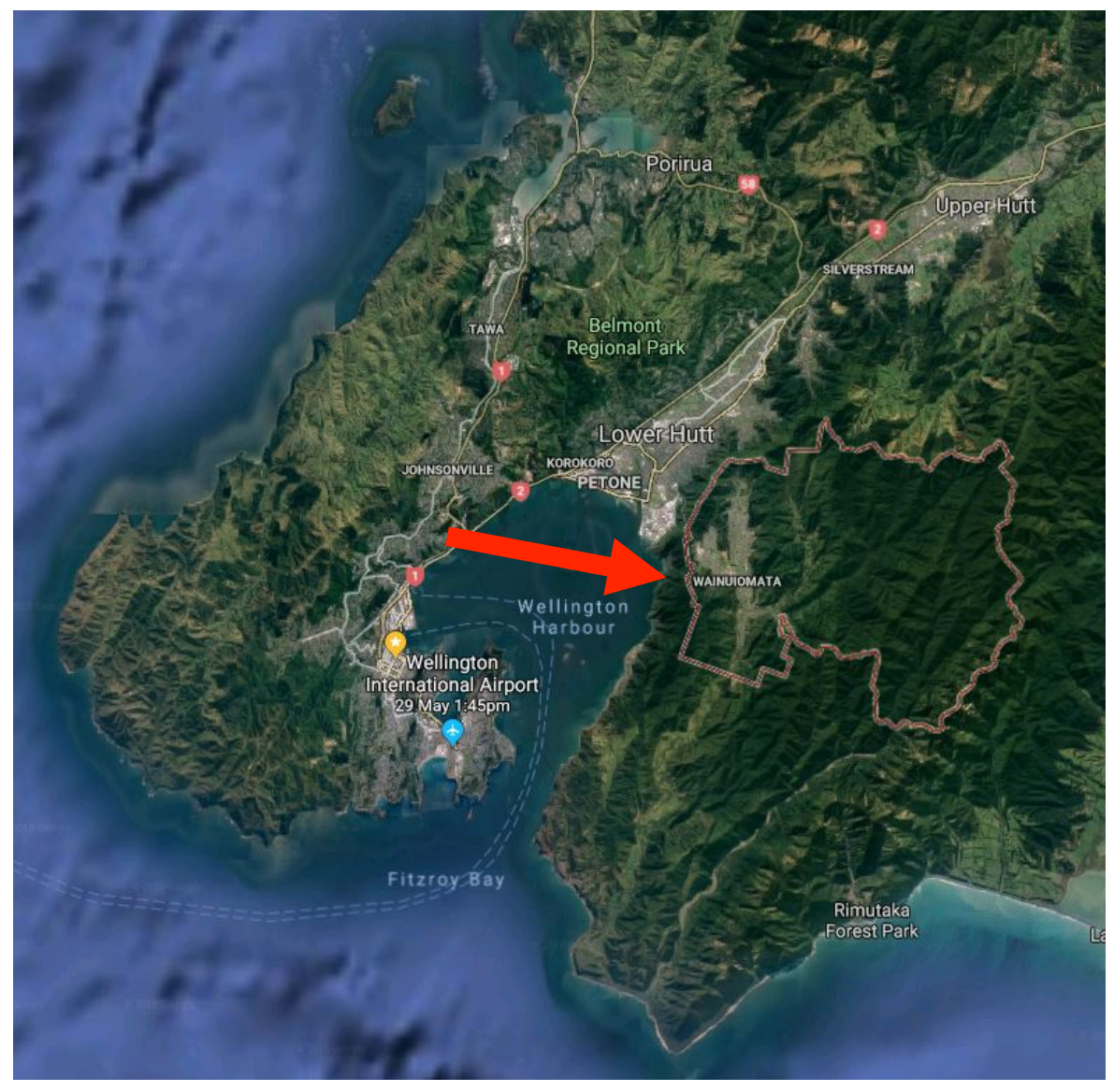

Figure 1: Map of Wainuiomata (as indicated by the red arrow) in relation to the wider Wellington Region (Google Maps, 2018).

There is only one access and exit point for Wainuiomata, requiring commuters to travel up the steep Wainuiomata Road. While an alternative route began to be constructed in 1932, the great depression halted this project leaving only one access route (White et al., 2017). The access to this suburb has been hypothesised to have been detrimental to the "growth and vitality of the suburb" (White et al., 2017, p. 5).

Wainuiomata was the settlement where Wellington's earliest Māori inhabitants lived, around the time of the moa (White et al., 2017). In 1844 the area was occupied by British settlers, and later became a site for timber mills (White et al., 2017). Its growth was seen to have originated as a result of 'The Company' also known as Wainuiomata Development Limited, which sold and developed land in the area (Alexander, 2000). From its sawmilling and farming origins, after the second world war, new housing "soon transformed it into a working-class suburb of Lower Hutt" (Te Ara, 2016, p. 1). 
As of 2013, Wainuiomata's resident population was 17,124 people living in 5,988 dwellings (Statistics New Zealand, 2013). The age structure of this population is changing with fewer young people (those between 0-17 years) and increasing numbers of older people (those between 70-84 years) (Statistics New Zealand, 2013). The predominant ethnicity in Wainuiomata are those who identify as European, making up 65\%, while those who identify as Māori made up 26\%, (Statistics New Zealand, 2013). The unemployment rate in Wainuiomata is $10 \%$ including those aged 15 years and over, while in Lower Hutt this rate is $8 \%$ (Statistics New Zealand, 2013).

Income levels are also lower than in Lower Hutt. As of 2013, 39.2\% of those 15 years and older in Wainuiomata had an annual income of $\$ 20,000$ or less, in Lower Hutt this number is $35.7 \%$ (Statistics New Zealand, 2013). In the higher income brackets, only $21.4 \%$ of Wainuiomata's population earned more than $\$ 50,000$ in comparison to $29.9 \%$ earning compared to Lower Hutt (Statistics New Zealand, 2013). Wainuiomata also has several areas which rate highly on the deprivation index (Statistics New Zealand, 2013). 43.5\% of families in Wainuiomata are made up of couples with children, where $25 \%$ of families are 'one parent with children' families (Statistics New Zealand, 2013). This is higher than Lower Hutt by 4.7\% (Statistics New Zealand, 2013). The most common transport method was by private car, truck or van, where $51.2 \%$ had travelled to work using this on census day (Statistics New Zealand, 2013).

Wainuiomata is characterised by a high commuting population, where the number of those employed within Wainuiomata is continuing to decrease (Statistics New Zealand, 2013). This has fallen by 7\% from 2010, and in 2013, 1,525 people were paid employees in Wainuiomata (Statistics New Zealand, 2013). The main employment destination for Wainuiomata residents was Parkway, followed by areas of Lower Hutt and then within the wider Wellington Region (Statistics New Zealand, 2013). The top industries in terms of employment numbers within the suburb were education and training (402 employees), retail trade (238 employees), and 195 were employed in the construction industry (Statistics New Zealand, 2013).

A community needs survey conducted in Wainuiomata over the summer of 2016 aimed to understand what elements of the area were of most importance to its 
residents and what were some of the strengths, opportunities and areas of concern (White et al., 2017). The results found that the area was characterised by a strong sense of community, as well as 'quality open spaces such as green spaces and parks'. Interviews were conducted along with this survey and respondents confirmed the strong sense of community in Wainuiomata, where some participants suggested this may be a result of the suburb's geographical isolation leading to a "us vs them" mentality (White et al., 2017, p. 8). While known for its strong sense of community, a number of ongoing concerns plague the suburb such as a "lack of affordable and quality housing, environmental issues such as arsenic soil contamination, a lack of local employment opportunities and disinvestment in local facilities such as the mall" (White et al., 2017, p. 1). Nearly a quarter of survey participants stated that the lack of job opportunities was the biggest challenge for the suburb (White et al., 2017). This was followed by the challenge of "meeting basic needs such as food and heating, access to affordable and quality housing and access to quality primary and secondary schools" (White et al., 2017, p. 13).

\subsection{The Wainuiomata Mall}

Both surveys and interviews conducted by White et al. (2017) "highlighted ongoing concerns including divestment in the local mall, which for many locals, acted as a proxy community space" (p. 9). This survey found of all the facilities in Wainuiomata, the shops were the ones most frequently used. When asked what four facilities were most important participants identified "shops, healthcare, public transport and free parks and recreation"(White et al., 2017, p. 9). Many interview participants highlighted the importance of the mall for locals, where it was once the focal point of the community in the 70s and 80s (White et al., 2017).

The Wainuiomata Mall was constructed by the Fletcher Trust and Investment Company in 1970, which was a time of growing mall development across New Zealand (Laurenson, 2018b). It played a significant role in the Wainuiomata community acting as a focal point of the area and a community hub, where residents socialised and shopped locally (White et al., 2017). Its physical prominence at the centre of the suburb can be seen below in figure 2 . Wainuiomata road is the only road into the suburb, and Queen Street is the other main source of retail within 
Wainuiomata. Again, as demonstrated by the blue shading in figure 2, the mall takes up a significant part of this retail centre.

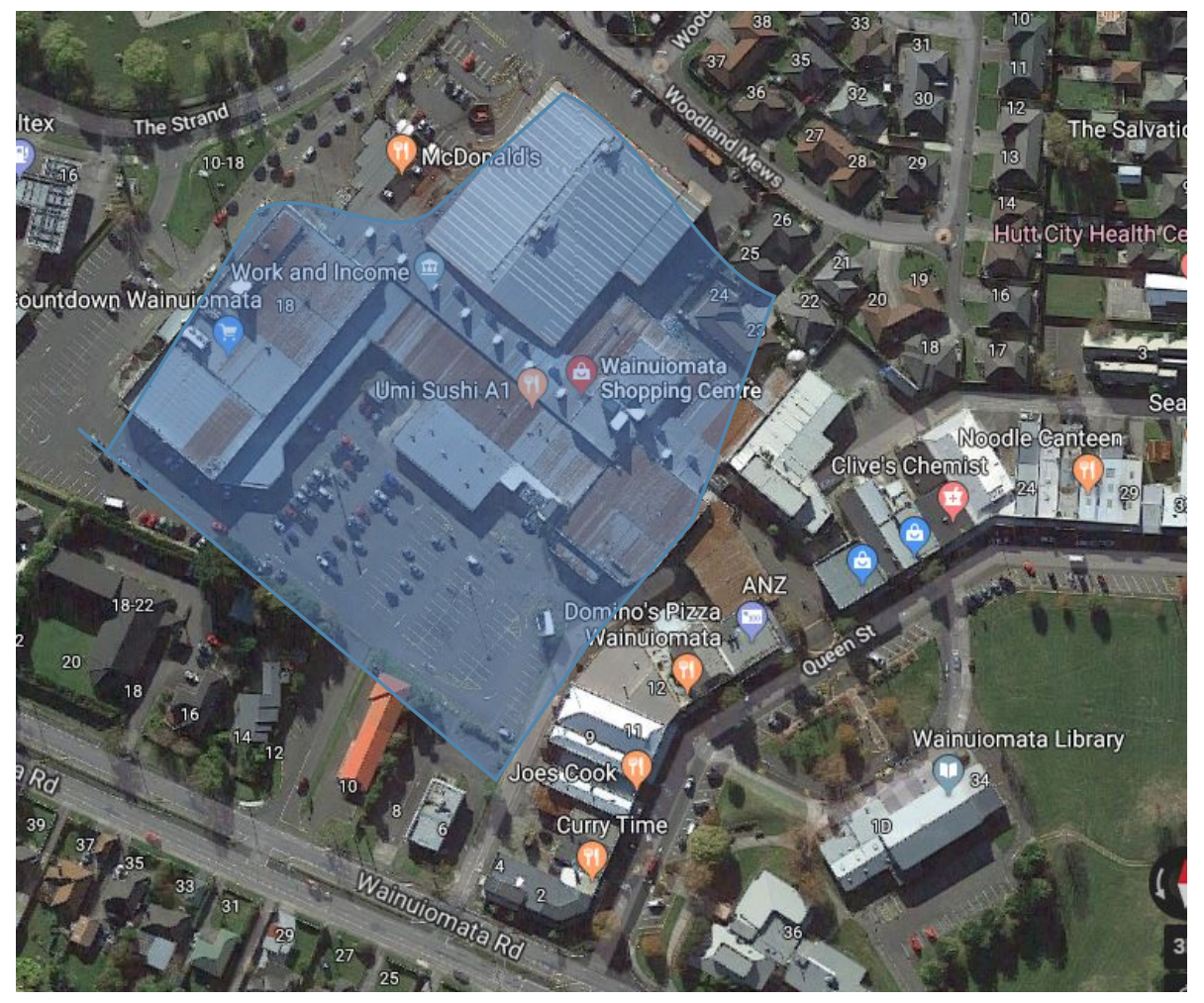

Figure 2. Map of Wainuiomata Mall retail area highlighting the size of the mall (Google Maps, 2018).

However, over the last decade or so, the Wainuiomata mall had begun to slowly decline, where according to Edwards and Shadwell (2016) nearly half of the mall's retail sites are empty. During my initial visit to the mall in December 2016, I observed that there were only five stores in operation. One of the last major tenants, The Warehouse, left the mall in 2016. With its departure, community members expressed their concern regarding the impact that the decline of the mall was having on the community (Edwards \& Shadwell, 2016). Campbell Barry, Wainuiomata Ward Councillor said the news of The Warehouse departing was a "real blow to the community" and stressed that the Hutt City Council had done everything possible to work with the mall owners to find a solution, however, in the end, he believed the community had been let down (Crayton-Brown, 2016).

Concerns have been raised about how the state of the mall impacts on the community and the mall has been named the communities biggest hurdle by a local councillor (White et al., 2017). They claimed that difficult owners had made it hard for 
anything to be done with the mall, whether it was to be sold or redeveloped (White et al., 2017). Another councillor appeared to echo this sentiment, stating that the current situation was detrimental to the community itself and the challenge was to get the owners working alongside the Council (White et al., 2017). This councillor asserted "you can't just sit there and say it's okay to have a 90\% um vacancy rate anymore, it is simply not acceptable for you to be using this as a tax write off, because they own about 6 malls" (White et al., 2017, p. 1). This comment implied that the owners were benefitting indirectly from the mall's decline and the subsequent financial losses from the mall as they were able to use those losses to pay less tax on the profits from their other properties. However, Campbell Barry, the Councillor for the Wainuiomata Ward is explicit that the issues affecting the Wainuiomata mall, are not specific to the mall itself and is instead an issue with malls in general (Barry, 2016). He advocated for the community to focus on things that could be changed, in the hope that the mall would follow suit (Barry, 2016).

A deal has recently been brokered, where in March 2017, media outlets reported that the mall had been sold to Progressive Enterprises, who were set to redevelop the site (Jolliff, 2017; Nicoll, 2017a). Local politicians and community members have expressed their excitement about the future of the mall (Jolliff, 2017; Nicoll, 2017a). However at the time of writing, January 2018, nothing has been announced to the community regarding the proposed redevelopment.

\subsection{Characteristics of the suburb of Johnsonville}

Johnsonville makes up one of the northern suburbs of Wellington and sits in a small basin, located above the Ngauranga Gorge as demonstrated by the red arrow in figure 3. The suburb was named and founded by Frank Johnson who established a timber mill which was located in the now central business district (Wellington City Council, 2008). 


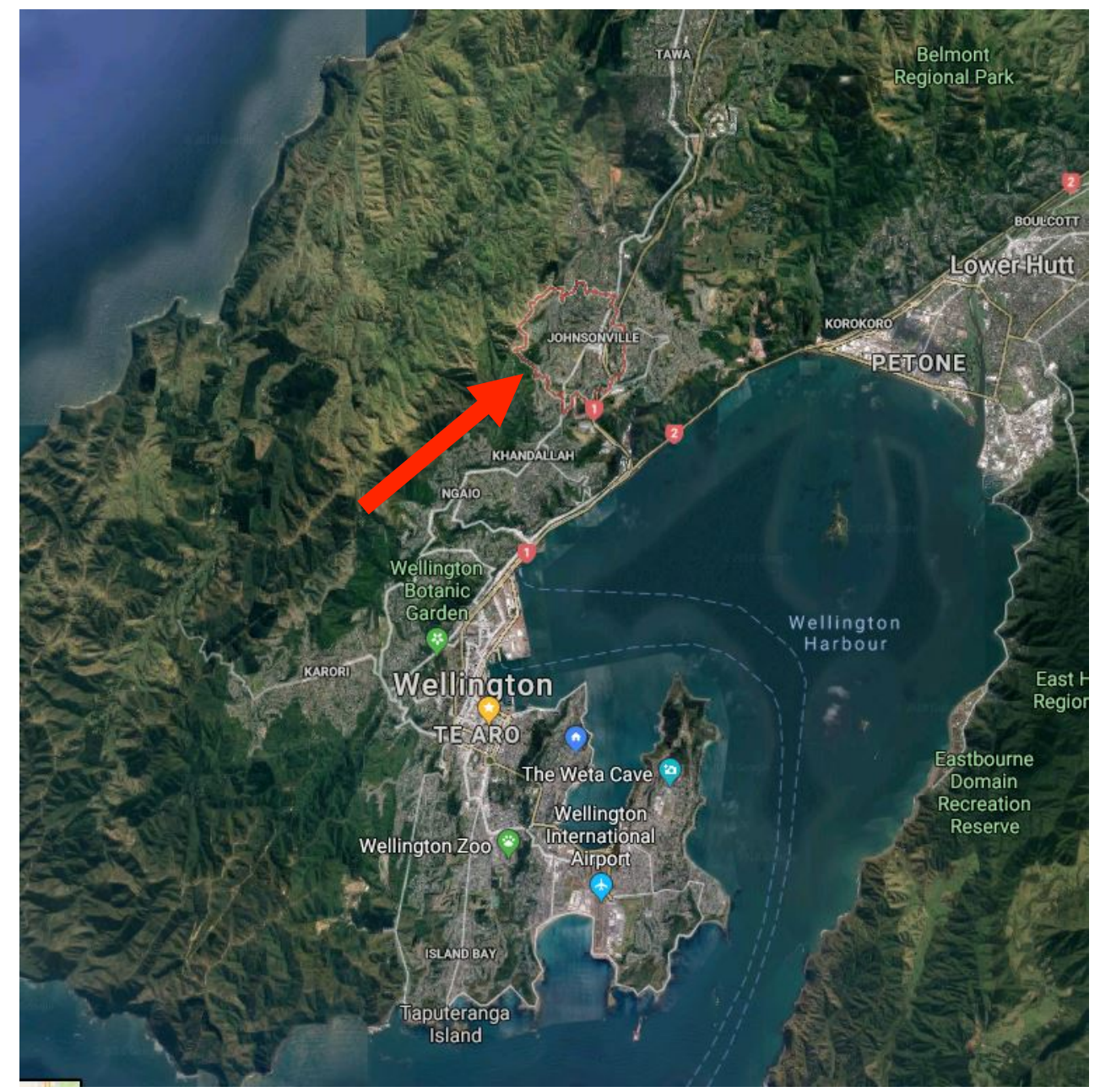

Figure 3. Map of Johnsonville (as indicated by the red arrow) in relation to the wider Wellington Region (Google Maps, 2018).

In the $19^{\text {th }}$ century it became a 'small rural; service town' (Maclean, 2007, p. 5) and due to its location being on the main train line from Manawatu and Wellington (1938) Johnsonville developed rapidly and amalgamated with Wellington in 1953 (Maclean, 2007; Wellington City Council, 2008). It is understood to be the "largest and most significant town centre in Wellington outside the central city and plays a key role in servicing the northern suburbs" (Wellington City Council, 2008).

According to census data from 2013, Johnsonville has a population of 10,239 residents (.id Consulting, 2013e). This population lives in 3,987 dwellings where the average number of occupants is 2.66 (.id Consulting, 2013e). As of 2013, Johnsonville's population was made up of $63.5 \%$ who identified as European, $8 \%$ who identified as Māori, 25.2\% Asian (.id Consulting, 2013b). Almost 100\% (94.3\%) of its population is employed with $76.2 \%$ being employed full time and the 
remaining percentage part-time (.id Consulting, 2013a). These employment figures are also tied to the age structure in the area (.id Consulting, 2013a). The number of people working in Johnsonville increased by 204 from 2006-2013 in relation to the increased labour force of 309 persons, however, this suburb is characterised by a large commuting workforce (.id Consulting, 2013a). Unfortunately, specific commuting statistics are unavilable through the New Zealand Census data. The most popular sectors for this work was in professional, scientific services which employed $14.1 \%$ of the residents of Johnsonville, $13.3 \%$ were employed within public administration and safety, and 8.4\% were employed in education and training (.id Consulting, 2013d). In terms of annual individual incomes, $8.7 \%$ of the population earned over 100,000, 11.3\% earned between 70,001-100,000, 15.35 of the population earned between 50,001 and 70,000 (.id Consulting, 2013c).

The Johnsonville Town Centre Plan which was adopted in 2008, provides a framework to guide the development of Johnsonville for the next 20 years (Wellington City Council, 2008). A strengths, weaknesses, opportunities and threats (SWOT) analysis was carried out in the consultation and community input phase of this plan. The results found that community members generally saw the continued population growth of the suburb as an advantage (Wellington City Council, 2008). The large town centre, affordable homes for families and a good range of community facilities were also highlighted as strengths of Johnsonville (Wellington City Council, 2008). Some of the opportunities for the suburb were seen to be related to the growth of Johnsonville in terms of housing, the newly proposed community hub and an opportunity to create a new central public space (Wellington City Council, 2008).

Major weaknesses highlighted by this analysis showed poor urban design quality such as the aesthetics of the suburb, where buildings and spaces in the town centre were considered to be "at best unremarkable and at worst of a very low quality" (Wellington City Council, 2008). Issues relating to public transport and congestion were also highlighted (Wellington City Council, 2008). Central public spaces are often important sites for public and civic events, however, Johnsonville lacks this accessible and central public space or community focal point (Wellington City Council, 2008). Respondents also highlighted the limited entertainment and night 
time facilities, advocating for developing a "wider range of town centre functions such as shops, entertainment and recreation and increasing and improving community facilities" (Wellington City Council, 2008). Major threats identified by residents related to the shopping centres redevelopment which has been significantly delayed, and the way the mall fails to relate well to its surroundings (Wellington City Council, 2008).

\subsection{The Johnsonville Shopping Centre}

The Johnsonville Shopping Centre was opened in the 1969 and was Wellington's first shopping mall, catering to both Johnsonville residents as well as attracting shoppers from other Wellington suburbs (Maclean, 2007). The mall and the attached Countdown supermarket currently account for $13,560 \mathrm{sqm}$ of the 55,830m of the commercial area available in Johnsonville, not including the 500 car parks available for mall customers and adjacent users (Wellington City Council, 2008). Figure 4 demonstrates the scale and also the location of the shopping centre in relation to the main retail area within Johnsonville. 


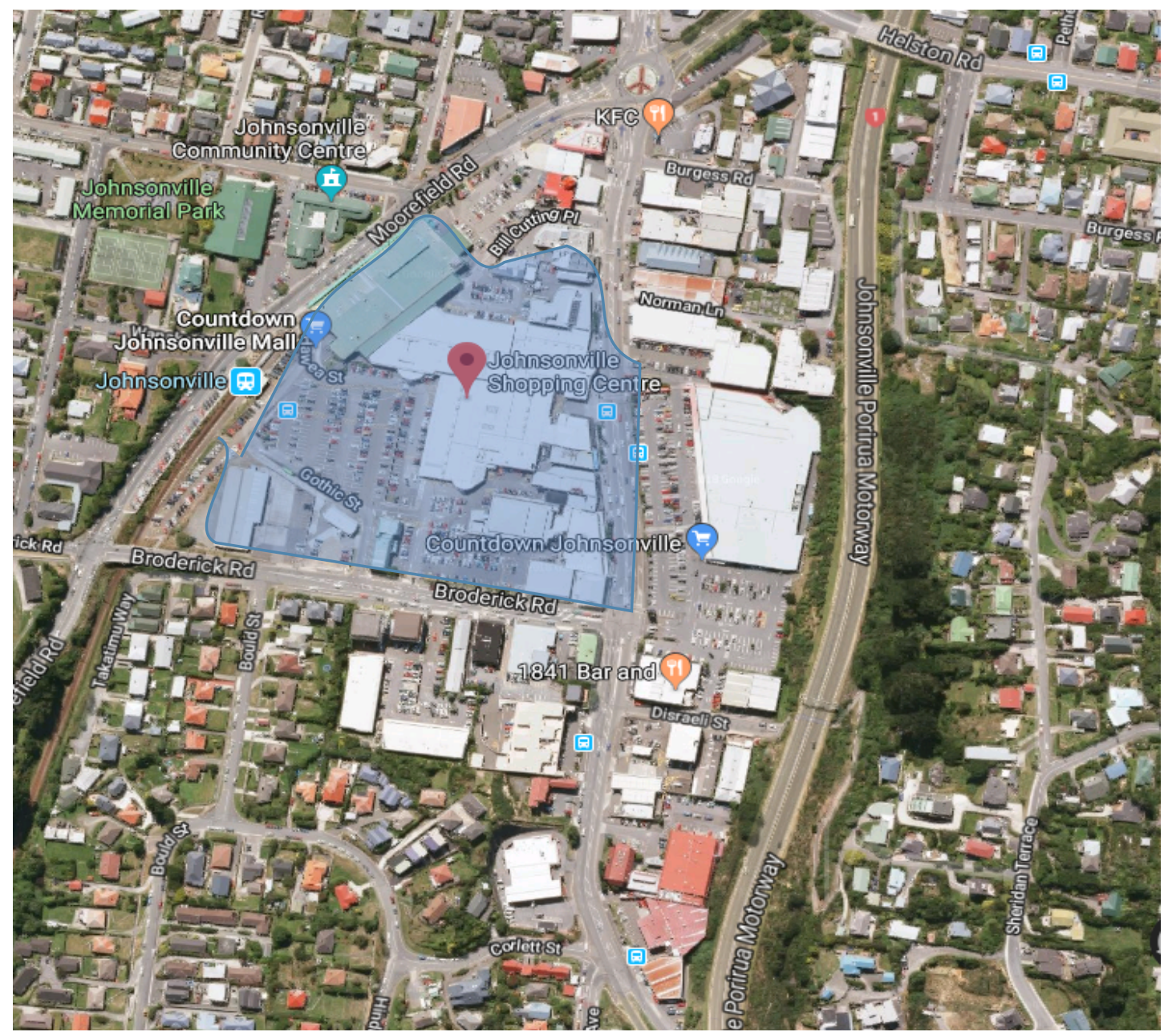

Figure 4. Map of Johnsonville retail area demonstrating the scale of the Johnsonville mall as highlighted in blue (Google Maps, 2008).

This centre is long overdue for redevelopment, and it has received substantial media attention regarding its decline. Media articles report that community members are also extremely frustrated and wary of any promises from the centre owner, Stride Property Ltd (MacAndrew, 2017b).

Customer numbers are said to have substantially declined and long-term tenants are leaving the mall (Forbes, 2016). Consent was granted for the redevelopment of this mall in 2009, which initially was set to result in a 32,000 square metre $\$ 300$ million dollar expansion (Devlin, 2016; Forbes, 2016). However the community is still waiting nine years later for the mall owners, Stride Property to decide on the future of the mall (Forbes, 2016). It has been said that the global financial crisis and earthquake damage to another Stride owned mall, made revisions to the proposed development necessary (Mason, 2017). A new resource consent was granted to 
Stride Property Ltd and Diversified NZ Property Trust for a smaller redevelopment in January 2017 (Wellington City Council, n.d.). This consent replaces the previous consent and "allows for the construction and redevelopment of shops, pedestrian areas, parking areas and vehicle access to service shops" (Wellington City Council, n.d.). Due to the proposal being a smaller version of the original consent, this was non-notified (Devlin, 2016). The revised proposal is for a $\$ 150$ million redevelopment, which is $26,000 \mathrm{~m} 2$ and set to include a cinema, 900 car parking spaces, 200 of which will be available to the general public (Nicoll, 2017b; Wellington City Council, n.d.). A new facade on Johnsonville, Broderick and Moorefields roads as well as better integration with other community sites will be included (Wellington City Council, n.d.). However, no date has been confirmed for when this will begin to take place (Nicoll, 2017b). Justin Lester, Wellington's mayor, stated that the redevelopment was a number one priority for those living in the northern suburbs and that the Council supported the redevelopment (Forbes, 2016).

Despite the community concern for the mall's decline, and the obvious political willingness for the redevelopment to happen, "Stride have refused a request to a meeting with residents concerned about the rundown state of the mall and lack of development" says Labour MP Ohariu candidate (2017), Craig O'Connor (MacAndrew, 2017a). A public meeting was held in May where 250 members of the community turned up to discuss the state of the mall, however, no one from Stride turned up (MacAndrew, 2017a). Greg O'Connor said "for Stride to refuse to even meet with locals, despite indicating they would be prepared to do so in a meeting with myself and the Mayor, is frankly disgraceful " (MacAndrew, 2017a). Simon Pleasants a resident in Paparangi appeared to agree with this sentiment stating, "there was a strong feeling of indignation that our town centre is being held back by cynical corporatists in a boardroom in Auckland" (MacAndrew, 2017b). The community frustration relating to the mall's decline and the delayed redevelopment was apparent across all media articles relating to this issue.

\subsection{Common themes throughout the case studies}

Both communities are characterised by a high commuting population, however, they also have differing socio-economic levels. While both malls are in decline, the 
Wainuiomata mall decline is more severe and both are at differing stages of redevelopment proposals. Despite this, it appears that in both locations these malls account for a large amount of the retail space within these suburbs. They have also been acknowledged in both to play an important role as community spaces. Evident within the previous section also, is the level of community frustration relating to both the malls decline, but also the communities apparent inability to influence the situation or decisions relating to these spaces. 


\section{Conceptions of public and private space in relation to shopping malls}

This chapter provides an overview of the central literature relating to this field of inquiry. It brings together key theories and concepts from a range of disciplines connected to this research. In doing so, it acts to illuminate key authors and academic works, contextualises this research and highlights the gap within the literature that this thesis seeks to answer. It will begin by addressing the categorisation of space and the binary and subsequent hierarchy of public and private within this. Global trends relating to increasing privatisation and the rise of shopping malls will also be addressed, as will the concerns regarding these trends. These will also be critiqued within the context of shopping malls, where these spaces are understood to provide an insightful opportunity to investigate the categorisation of space. Alternative ways of conceptualising space will also be discussed before linking these aforementioned arguments to the development of this research topic.

\subsection{Public and private space and the growing trend of privatisation}

As this thesis will demonstrate, the ways in which a society defines and categorises space has far-ranging implications (Bromley \& Thomas, 1995; Kohn, 2004). Based within western rational thought, this categorisation has typically relied on a binary (Waitt, 2010), defining space as either public or private (Kohn, 2004). Property rights are ascribed to a space dependent on this classification, which has "major societal and economic implications" (Guerin, 2003, p. 3). They ways in which societies and cities more generally attempt to negotiate these differing spaces is based on underlying ideologies and can differ widely (Carr, Francis, Rivlin, \& Stone, 1992; Madanipour, 2003). Nevertheless, the nature of these distinctions can be understood to shape the city and also the lives of the citizens within it (Madanipour, 2003).

Kohn (2004) explains that the everyday usage of the term 'public space' typically refers to a "place that is owned by the government, accessible to everyone without restriction, and fosters communication and interaction" (p. 11). Inherent within this conceptualisation is the idea that public spaces are sites of interactions, both planned 
and unplanned and are key sites for community cohesion (Kohn, 2004). They are understood by Carr et al. (1992) to generally take the form of streets, parks and squares which provide for peoples movement, communication and play. The importance of public spaces as a site for political expression and democracy, cultural expression and wider social tolerance has been acknowledged by a range of authors (Kohn, 2004; Lees, 1994; Parkinson, 2012 among others).

Public and private space has often been defined in opposition to one another (Weintraub \& Kumar, 1997). Whereas evidenced above, the term 'public space' evokes ideas of the state or a space which is owned by the government (Weintraub \& Kumar, 1997). Inherent within this definition also is the idea that public space is a space of sociability which fosters political community (Weintraub \& Kumar, 1997). In contrast, the term 'private space' is seen to relate to the domain of the family and also to the market economy and is often characterised by restricted access (Weintraub \& Kumar, 1997).

These definitions can be understood in relation to the property rights ascribed to these spaces. As Blomley (2004) argues, the dominant way of defining property has been through the ownership model. Within this model, property is understood to be primarily private, though public ownership is seen to be the exception to this (Blomley, 2004). As a result of a spaces ownership, a series of rights are seen to be attributed to the owner (Guerin, 2003). These three types of fundamental property rights are identified by Guerin (2003) as "the right to use (access or withdraw resources), possess (manage and exclude from) and dispose of (alienate) property" (Guerin, 2003, p. 5). These inalienable rights, given to a private property owner signifies their ability not only to restrict activities within spaces but also to exclude others from it. Concerns regarding the growing privatisation of public spaces relate to these private property rights, which appear to be in opposition to the civic liberties provided within public spaces.

Globally there has been a trend towards privatising public spaces, a process which is seen by Larner and Walters (2000) as the "quintessential expression of neoliberalism". The term privatisation broadly refers to the transfer of an asset from state to private ownership (Kohn, 2004). The underlying reasons for this trend can be 
found within neoliberal ideology, where the market is understood to be the preferred provider of 'public' goods and services (Larner \& Walters, 2000). This preference is based on efficiency, where the market is seen to provide public goods and services at a higher quality and lower price than the state (Larner \& Walters, 2000).

Privatisation has been justified by some, due to its ability to improve public services without needing to increase taxes (Larner \& Walters, 2000), nevertheless, many authors have expressed their concerns relating to this privatisation. Flinders (2005) argues that this is a 'faustian bargain', where despite efficiency gains, "these benefits may involve substantial political and democratic costs" (Flinders, 2005, p. 215). Concerns vary regarding this trend and include the implications for democracy and political expression (Kohn, 2004; Low, 2006), to the limiting of diverse ways of engaging in a space (Lippai \& Weberman, 2016). The limitations of these privatised spaces can be understood in relation to their inalienable property rights.

\subsection{The origin and growth of shopping malls}

Closely linked to the process of privatisation is the ubiquitous development of shopping malls. Shopping malls are increasingly taking on the functions of a town square by offering a range of public services such as post offices and banks, a trend which has caused alarm (Kohn, 2004). This trend is of particular significance when a shopping mall has become a communities defacto public space yet the mall begins to decline, leading to the subsequent decline of a communities 'public' facilities. However, in order to understand the impacts of this trend, an understanding of the social processes which led to the development and prevalence of shopping malls is necessary.

In New Zealand, department stores located in city and town centres were extremely popular in the later $19^{\text {th }}$ century. Originating from small drapery shops, they soon provided a range of goods and services and a unique atmosphere of leisure (Laurenson, n.d.-c). By the middle of the $20^{\text {th }}$ century, New Zealand saw the growth of suburbs, in part due to crowded city centres (Laurenson, 2018f). The city centre was seen to be aging and overcrowded, with increased automobile ownership contributing to significant congestion issues (Laurenson, 2018a). Laurenson (2018c) explains that after the Second World War a series of subdivisions were built throughout New Zealand and their distance from the city centre meant that 
department stores lost many of their customers to suburban retail. This suburbanisation was a major contributing factor in the decline of department stores and the rise of the suburban mall (Laurenson, 2018c). This suburbanisation was part of a global trend; one particularly prevalent in the United States of America (Parlette $\&$ Cowen, 2011). The large quantities of available land in suburban communities, coupled with a substantial customer base acted as a catalyst for the creation of shopping malls as a retail form (Laurenson, 2018e; Parlette \& Cowen, 2011).

Victor Gruen, an Austrian architect, is widely acknowledged to be the 'father' of the American style shopping mall (Gruen, 2017). Forced to flee Austria due to the Nazi regime, Gruen went to live in post-war suburban United States and was concerned by the lack of civic life in America's suburban communities compared to those of his home country (Gruen, 2017). He sought to "reproduce the vitality of the Vienna city centre" where commercial and private spaces were mixed. He saw this as the key to boosting civic life (Gruen, 2017, p. 12). The result of this philosophy was a project called 'Shopping Towns' which resulted in the first enclosed shopping mall (Gruen, 2017). The term indoor or enclosed shopping mall refers to a "conglomeration of retail stores linked together by enclosed walkways and corridors" (Jacobs, 1984, p. $4)$.

The first mall, Southdale Mall located in Edina, Minnesota aimed to "strengthen civic life in the atomised suburbs" (Gruen, 2017, p. IX). It was built in 1956 and was 74,000 square metres in size, hosting 72 retail tenants (Gruen, 2017). Gruen's designs focussed on facilitating community engagement, including a diversity of shops and a range of public services such as post offices and public gardens (Gruen, 2017). The design of shopping malls was hugely successful. They provided a variety of products in a convenient location with ample parking and a climate controlled environment (Gruen, 2017). They also expanded to become centres of entertainment and recreation offering things such as cinemas, gaming arcades and community events, and an opportunity to escape the noise and traffic related to other shopping venues (Bloch, Ridgway, \& Dawson, 1994)

Today, shopping centre sales currently account for approximately half of retail sales in the United States (Gruen, 2017). This has had a profound impact on the urban and 
suburban landscape surrounding malls (Jacobs, 1984). There are an estimated 18,000 shopping malls in the USA alone, occupying "almost thirteen billion square feet of floor space" (Gruen, 2017, p. 137). Their popularity as an urban form is not isolated to the United States, they are a prevalent retail form across the globe (Gruen, 2017). Within New Zealand, the American style of shopping malls were also seen as the best way to capitalise on the suburban market (Laurenson, 2018e). The first shopping mall opened in October 1963 in New Lynn, Auckland (Laurenson, 2018d). Mall developments have sprung up across New Zealand since (Laurenson, 2018d).

\subsection{Critiques of shopping malls as an urban form}

The criticisms of shopping malls are wide-ranging. In terms of public life, they are seen to restrict the "civic, political and religious activity that gave city centres their dynamism and variety" (Kohn, 2004, p. 2). This is attributed to their ability to limit behaviours and exclude certain people from these spaces due to their private property rights (Garrett, 2016; Kohn, 2004; Voyce, 2006). The rise of shopping malls has been attributed to a loss of space to voice political ideas and conversely be exposed to these (Kohn, 2004).

However, Kohn (2004) does not simply blame the developers of these spaces, instead acknowledging that one of the allures of shopping malls is the absence of 'any source of discomfort' such as political speech. The exclusion of people from these spaces has also been understood to reduce our opportunities for engagement across inequalities (Sennett, 2003), reducing the exposure communities have to different people they would normally encounter on the street (Kohn, 2004; Madanipour, 2016). Without this exposure, individuals are seen to miss the opportunity to understand one another, and it makes it unlikely that we would seek to change situations such as homelessness if we are not exposed to them (Kohn, 2004; Madanipour, 2016). While they were created to "counteract the desolation of the vast American suburbs" (Gruen, 2017, p. 140) subsequent designs by mall developers have largely focused on increasing profit and consumption often ignoring the key design principles which were key to Gruen's vision (Gruen, 2017). Shopping malls are now a much disparaged urban form, due to their uniformity, reliance on automobiles, neglect of downtown areas among many other factors (Gruen, 2017). In fact Gruen renounced his relationship to the shopping malls of today, despising what 
his vision had become, famously stating "I refuse to pay alimony for those bastard developments" (Hardwick, 2014, p. 216).

\subsection{Community functions of shopping malls}

Despite these critiques, the proliferation of shopping malls has led to an interest in understanding the social elements of this space. In fact, it has been argued that one of the factors which has allowed shopping malls to become so successful is their sociability (Feinberg, Sheffler, Meoli, \& Rummel, 1989, p. 49). Mall management often seeks to foster this within their respective enterprises (Bloch et al., 1994; Parlette \& Cowen, 2011) incorporating non-commercial elements such as community services and events (Parlette \& Cowen, 2011).

True to the original vision of Victor Gruen, these places have been understood by some as "an ecosystem unto itself, a combination of community and commercialisalism" (Sanburn, 2017, p. 1). In the United States, they are often viewed as the nation's version of a public square (Hopkins, 1991; Sanburn, 2017). While acknowledging that malls were designed for profit, Jacobs (1984) saw malls as having a latent function in their provision of public facilities such as space for older people to exercise, community events as well as libraries and other social services. It has been well documented that often indoor malls have been used in North America as space for exercise, a form of recreation termed 'mall walking' (Bloch et al., 1994; Duncan, Travis, \& McAuley, 1995; Parlette \& Cowen, 2011). This occurs particularly in extreme weather such as cold winters or hot summers (Bloch et al., 1994; Parlette \& Cowen, 2011).

A number of case studies from countries across the world demonstrate the ways in which these spaces have exceeded their designed function as spaces of consumption. In Hong Kong, a country which has one mall per square mile (A1, 2016), these sites act not simply as spaces of consumption but also of acculturation (Ng, 2009). Due to a lack of public spaces in Hong Kong, malls have become viewed as a node of social interaction, so much so that Nowek (2016) argues they should be referred to as 'leisure centres' or 'alternative community centres'. This link between the lack of space for socialisation and the importance of the mall can also be seen in 
Cairo, Egypt. Where a lack of public gardens contrasted with a high prevalence of shopping malls has meant that malls are popular, not only for shopping "but rather for youth to socialise and mix in groups" (Abaza, 2001, p. 101). Literature also suggests that the security and safety associated with shopping malls has also increased their sociability. As highlighted in the previous section, the security and exclusion of people from these spaces is one of the problematic features of shopping malls, but it also one of the reasons why people shop in malls. An example of this is in Mexico, where urban insecurity has meant that shopping malls are increasingly being used as public spaces (Lomnitz, 2012), while malls in the Czech Republic are marketed as safe and comfortable places for families (Pospêch, 2016).

\subsection{Community claims to private space}

In comparison to the malls in Hong Kong, the West Edmonton Mall (WEM) in Canada could also be considered a leisure centre with its indoor amusement park and pool and two hotels (West Edmonton Mall, 2018). This mall is approximately $500,000 \mathrm{~m} 2$ and boasts over 800 stores and services (West Edmonton Mall, 2018). While it is the 'number one tourist attraction' in the province, it also has been found to have an important community function. Research examining the social function of this mall demonstrated that it became the centre of the town in the cold winter months (Hopkins, 1991). It was understood to be an important place to mingle and socialise, so much so that over three-quarters of those Edmontonians surveyed perceived the mall to be public property (Hopkins, 1991). This community claim to a privately owned space, was also seen in Maryland, where the development of the Whiteflint Mall was seen to be providing a public space to the area, where there had previously not been one (Kowinski, 1985).

The extent of community claims on these spaces can be seen in instances when these sites have been threatened. One such example was the renovations of the New Town Plaza in Sha Tin, Hong Kong. This shopping centre was built in 1984 and quickly became adopted as the town centre of Sha Tin, leading to it becoming an incredibly successful mall (Chu, 2016). However, renovations occurred in the 2000's and left residents feeling that the area has lost important elements of its identity (Chu, 2016). In response to these changes, a number of residents started an initiative 'Help New Town Plaza' which aimed to stop any future changes to this space (Chu, 2016). 
While Chu (2016) was unsure whether this initiative would have an impact on the mall and influence future changes, the community campaign illuminated the importance of the mall for the community surrounding it (Chu, 2016). An interesting paradox is at play within this example, as in order to justify the mall development in 1984, narratives of community development were used (Chu, 2016). This space has now lived up to these narratives, and has become an essential part of the community, but now this is backfiring, as the community are fighting back, against what appears to be extractive corporatist strategies on behalf of the developer and are seeking to be able to shape 'their' space (Chu, 2016).

\subsection{The age of 'dead malls' and the loss of community space}

As demonstrated by the section above, shopping malls perform a variety of social and community functions outside of their role as a space of consumption. However, these roles are being threatened as a result of the global trend of 'dying' or 'dead malls'. While a uniform definition for these terms doesn't exist, Ferreira and Paiva (2017) explain that the term dead mall refers to malls which are closed or have a vacancy rate higher than $70 \%$. The Congress for New Urbanism refers to obsolete shopping malls as 'grey fields' (Bodzin \& Greenberg, 2001). Although these definitions refer to a singular mall's decline, these terms have also been used to refer to a wider retail trend characterised by the closure and decline of shopping malls evidenced globally, particularly in North America.

Media reports estimate that one in every four American malls could be closed by 2022 (Sanburn, 2017), while Dunham-Jones and Williamson (2017, p. 86) claim that "approximately one-third of enclosed malls in the US have died or are dying, covering over 13,000 hectares". The 2017 rate of retail closures in the USA is estimated to be higher than store closures during the Great Recession (Sanburn, 2017). This decline is not isolated to the United States, in fact, this trend has been occurring in shopping malls across the world. In Greater Lisbon (Portugal) alone, Ferreira and Paiva (2017) found 41 dead malls, representing over a quarter (27.3\%) of the malls they surveyed.

Bodzin and Greenberg (2001) found a number of characteristics which defined a mall in decline and also acted as indicators to the future health of a shopping mall. 
Overall the size of the mall was found to be the most significant predictor of its success, where the " 150 worst performing malls averaged 500,00 square feet while the best performing averaged 900,000 square feet" (Bodzin \& Greenberg, 2001, p. 79). Their study also demonstrated the need for continued investment, as the malls that were renovated most recently, performed best (Bodzin \& Greenberg, 2001). According to the life cycle of a shopping mall, they typically require a redevelopment within 20 years (Dunham-Jones \& Williamson, 2017). It is when these premises started to get old and run down, that there is an exodus of customers as well as leaseholders from the premises, leaving these massive retail premises empty (Dunham-Jones \& Williamson, 2017). Ferreira and Paiva (2017) identified four major factors impacting on the resilience of shopping malls, including the impact of innovation, the wider economic context, the relationship between urban cycles and retail cycles as well as the role that mall management plays. Shopping malls in less affluent neighbourhoods tended to be failing proportionally higher than those in wealthier areas, as did those surrounded by competition (Bodzin \& Greenberg, 2001). These results were corroborated by Ferreira and Paiva (2017) who found similar predictors in their study of shopping malls in the Greater Lisbon Region in Portugal.

Changing consumer tastes, widening inequality and E-commerce are some of the factors attributed to this decline (Sanburn, 2017). Big box retailers such as Walmart have also played a significant role, where their huge economies of scale have made it difficult for other retailers and shopping malls to compete (Parlette \& Cowen, 2011). In the United States, an oversupply of retail space is also seen to be of partial blame, where retail space reached a point of saturation in the mid-2000s and began to decline (Cohen, 2003; Parlette \& Cowen, 2011; Sanburn, 2017).

\subsection{Formal ownership vs spatial practice}

As demonstrated in the previous chapter, communities have responded to the mall decline with local activism however the wider issues of declining malls more generally has rarely been addressed by academic scholarship. Parlette and Cowen (2011) explain that "an entire category of urban space, albeit hardly recognised as such, is disappearing across North America" (Parlette \& Cowen, 2011, p. 798). However, they state that this trend has gone largely unnoticed by 
the academic community, attributing the apparent indifference to be based on conceptions of what community space is. Parlette and Cowen (2011) explain that this has led to a devaluing of community space in private spaces, where notions of ownership overpower the way in which space is being used and the claims towards it.

The community claims to the private mall space above challenge the traditional conceptions of how we understand public and private space. The protests over the closure of the Morningside Mall, demonstrate the importance of the understandings of these spaces. Where in spite of being widely recognised as a vital community space and the 'heart of the community', the mall was demolished to make way for big box retailers, shops which were catering to outside visitors and inaccessible to most of the local population' (Parlette \& Cowen, 2011). Despite community mobilisation and protest against the proposed changes, demolition plans continued facilitated with the help of the city (Parlette \& Cowen, 2011). This example showed that little consideration was given to the role of this mall for the community, a problem that the writers attribute to the formal categories of space. "Morningside Mall is a prime illustration of the conflict inherent in privatised public spaces - that despite collective voice and action the 'public' still had no impact on the fate of 'their' space" (Parlette \& Cowen, 2011, p. 807).

This case study demonstrates the need to consider other ways of looking at spaces if we are to maintain socially and economically vital suburbs. An alternative could be to analyse the uses and spatial practices enacted in malls, rather than emphasising the legal ownership of spaces (Parlette \& Cowen, 2011). The term spatial practice refers to the way in which a space is used, which typically exceeds the preconceived design of the space (Parlette \& Cowen, 2011). This was seen to be particularly true "in declining inner suburbs, where poor and racialized communities depend more heavily on malls for social reproduction as well as recreation and consumption" (Parlette \& Cowen, 2011, p. 794).

While the nature of the retail cycle is ever changing and new retail forms are replaced by others, Parlette and Cowen (2011) stress the need to question "the implications for community space that emerge through the loss of regional malls." 
(Parlette \& Cowen, 2011, p. 803). Due to the ways in which malls have been seen to act as community spaces, the loss of enclosed shopping malls can sometimes lead to the loss of any semblance of public space in a community, such as shown by the Morningside Mall example. While far from an unproblematic urban form, if we fail to take mall spaces seriously, instead only looking at 'pure public space', we risk failing to support community space and hinder opportunities to support flourishing public functions within these commercial spaces (Brill, 2001; Parlette \& Cowen, 2011). "When we are open to the myriad ways people make use of space in their everyday practice, we see a wealth of relations and contestations that would otherwise remain concealed by official categories of public space and private property" (Parlette \& Cowen, 2011, p. 807).

Often 'mono-dimensional views' of publicness are seen as relating to ownership, where the openness of public spaces is contrasted with the closed nature of private places (Carmona, 2015; Varna \& Tiesdell, 2010). However, this dichotomous view does not hold true when looking at urban spaces (Carmona, 2015; Varna \& Tiesdell, 2010). A number of scholars critique what they argue is an unrealistic perception of public space as open for all, questioning if public spaces have ever achieved this 'utopian vision' of publicness (Banerjee, 2001; Brill, 2001; Carmona, 2015; Day, 1999; Jackson, 1998; Varna \& Tiesdell, 2010). Day (1999) provides a gender lens to the idea of accessibility of public and private spaces, and challenges the idea that public spaces by virtue of their ownership are necessarily accessible to women. Banerjee (2001) also questions whether effective public life is necessarily related to the public realm.

Using a case study of London and analysing the trend of privatised spaces, Carmona (2015) argues that widespread concern over the privatisation of public spaces "are predicated on a normative notion of the public as an open and inclusive stage for social interaction, political action and cultural change" (Carmona, 2015, p. 376). Carmona (2015) argues that this clear-cut distinction fails to recognise the complexity of the situation, where a range of people relate to spaces in differing ways and asks the question is it possible to create a space for all? The reality is that "public space today is no longer (if it ever was) straightforwardly either open and public or closed and private but is instead full of complexity and contradictions that 
defy an overly restrictive view of what public spaces should be" (Carmona, 2015). His case study in London showed that public spaces were shaped through a myriad of complex relationships between the private and public sphere (Carmona, 2015). Indeed, Kohn (2004) challenges the way we understand public and private space and states that often places we share with strangers exists between these two in a grey area. It is often difficult to define a space as private and public due to these two elements being increasingly intertwined such as private plazas and the case of New York streets being cleaned and policed by private companies (Kohn, 2004).

Roy (2005) also advocates for a wider analysis of space, where the ownership of a space is seen as only one of the values we look at when considering space. Instead, we must acknowledge the political nature of space, which is the result of negotiations of power and knowledge (Lefebvre, 1991). How we choose to define space is inherently a political endeavour (Iveson, 2013; Vasudevan, 2015), and gets to the heart of Lefebvre's (1991) question, regarding the right to the city and who has this, and what it may mean for creating more democratic urban politics.

If we chose to instead examine spaces by other values rather than ownership, urban development may change radically. If citizens and how they use spaces were conceived of a part of urban development, there would be a need to focus on how spaces are used and created (the active production of space) rather than simply their legal category (Newman, 2011; Pickerill \& Chatterton, 2006). Vallance, Dupuis, Thorns, and Edwards (2017) also question the nature of public space, they argue that the way in which a space is used acts to determine a space, rather than a sites publicness being defined by ownership (Vallance et al., 2017). These different conceptions would have implications for the type of urban spaces we live in but also the decisions relating to these spaces and who gets to make these.

In line with these arguments, Brill (2001) critiques New Urbanism's focus on the revitalisation of 'pure public spaces' such as plazas and parks in order to facilitate interactions with strangers (Brill, 2001). The term New Urbanism refers to an influential movement within urban design that focuses on creating vibrant, walkable, sustainable and connected communities, often highlighting the importance of public spaces to create community connections and build social capital (Has, 2008). 
Brill says there is a disjuncture between the forms of place which are offered in communities and the social behaviour that is desired (Brill, 2001). Brill (2001) demonstrates that most people fail to distinguish between public life and community life, which he argues are very distinct and this has implications for how we design and live in our urban spaces. Public life is seen to be "spent in the occasional company of a diversity of strangers of whom we know little more than what we see" often these happen in locations all may use such as public spaces e.g. squares and parks along with privately owned spaces such as malls or nightclubs (Brill, 2001, p. 50). Community life (parochial life) is spent with neighbours or those acquaintances that you acknowledge such as shopkeepers and sporting group members, this typically occurs in a mix of semi-public and semi-private space such as streets, community functions or local bars (Brill, 2001).

He argues that we typically mourn the loss of these pure public spaces which may not have been as public as imagined and in doing this we fail to recognise other spaces for public life (Brill, 2001). "We discount the Public life that happens in spaces that are not publicly owned, and which are not the classical open spaces of the dense street, the enclosed square and the verdant park" (Brill, 2001, p. 53). In doing so, we fail to recognise and support the existing spaces we have for these interactions such as shopping malls or online networks (Brill, 2001).

\subsection{Synopsis}

This chapter has illuminated the ways in which dominant conceptualisations of space are based on a binary of public and private. As evidenced above, the way in which a space is defined dictates the rights ascribed to it based on the ownership model of property. As a result of these private property rights, there is growing concern over increasing privatisation which pits owners' rights over community rights. One form by which this privatisation has taken place has been shopping malls, which increasingly host a number of public functions. Despite the widespread criticism of this urban form, shopping malls have been understood to play important socialisation and community functions, particularly in communities which lack alternative forms of public space. However, shopping malls globally are in decline, and with them, communities risk losing an essential community space, one which is not recognised 
as such due to its private ownership. A number of authors, have spoken of the need to deconstruct this binary and model of property ownership, and instead reconceptualise this in order to support the forms of community space which do exist.

\subsection{Gaps in the literature}

As evidenced previously in this chapter, a number of authors have spoken of the community functions of shopping malls and instances by which communities have made ownership claims to these spaces. However, the majority of the literature relates to North America. Only one academic source was found which spoke of the impact of the privatisation of public spaces regarding malls in New Zealand and this architectural doctoral thesis focused solely on the implications for porosity and play (Moreno, 2010). Therefore, this research is the first to examine the community function that suburban shopping malls play in Aotearoa, New Zealand. This is significant because it seeks to make known a community space which has been widely ignored due to its private ownership. The second gap that this research addresses is understanding the ways in which a declining mall impacts on its surrounding community. The literature has spoken of the community resistance to these community spaces (malls) being altered or demolished, however a lack of research exists which comprehensively examines the impacts of a malls decline within a given location.

Numerous authors have also discussed the implications of inalienable private property rights accompanied with a growing trend of privatisation, particularly in terms of its significance for democracy. However, the work by Parlette and Cowen (2011) and Purcell (2002) is the only research that I came across which hinted at what this situation means for community decision-making. Other authors spoke of grass-roots resistance to the decline of local malls and other retail sites, however, there seemed to be an absence of discussion around formal decision-making frameworks and how different conceptions of these spaces might open up new opportunities to better allow for true urban democracy. 


\section{Shopping malls as community space and the impact of their decline}

This chapter analyses the results of the thematic analysis conducted on the 12 semistructured interviews and three focus groups which make up the qualitative research of this thesis. Larger themes have been selected to form the structure of this chapter, with a number of important sub-themes located within these. This chapter addresses the first two research questions of this study, the first being, 'what role can shopping malls play as community spaces and what are the elements within them which facilitate this role?' The second question asks 'what are the impacts on the community when the local mall declines?' In this chapter, I discuss the differing ways in which these mall spaces have become community spaces within their respective locations. Key commonalities and differences between the case study locations which have contributed to this function have also been explored. A brief explanation of the malls' decline is provided, accompanied by an analysis of the impacts of this decline

\subsection{Wainuiomata Mall as a site for socialisation and community building}

The Wainuiomata mall was referred to by one participant as the "heart of the community" (participant A). This statement exemplifies how participants responded to questions regarding the role that the mall played within their community. Their responses created an image of a community hub, which was 'packed', 'thriving' and 'full of people'. It was understood to be a place for all, where the community regularly met and engaged with one another, contributing to the overall sense of community within Wainuiomata.

Everyone went down there and mostly on a Friday night...I still remember what a great community resource the mall was, how it brought families together. You always sat down and talked, even my mum and dad always used to sit down and catch up with all the other families. So it was really good in creating a real community spirit (participant B). 
Within this dialogue this participant has attributed the physical space of the mall to being a 'community resource', asserting that this provision has allowed for the community to come together. The idea of the mall as being the key place where the community congregated to socialise was emphasised by numerous community members (participants A, B, C \& GWF participants 1,2,3). These social interactions were explained to be amongst community members, but also between families. Due to the mall being the gathering space for 'everyone', some participants spoke of casual and planned interactions with their families (GWF participants 1,2). One participant explained,

I remember my mum and dad, they always had meetings with whānau there... So it's stuff like that. It seemed to be the centre point for most of my whānau to go and meet, and I used to look forward to going down there because if I couldn't catch up with my aunty or my uncle, I knew where they were going to be" (GWF participant 2).

The mall was also understood to be a space which helped to build community connections, particularly for those new to the area. It provided opportunities to meet others while running errands due to its popularity as a community hub. One participant spoke of being new to Wainuiomata, "I didn't know very many people... so when I saw somebody and then they introduced me to somebody else it [the mall] was always a really good place to be" (GWF participant 1 ). This dialogue acknowledges the role that casual interactions can play in building community connections.

The popularity of the mall as a site for socialisation and community cohesion was attributed to a number of factors, one of which was its function as a community events facilitator and venue. Within the Wainuiomata focus group, participants discussed the range of events that were previously held in this space. These varied from community talent quests and the annual Christmas parade, to community service promotion events. Overall the mall was identified as the primary space within Wainuiomata where community functions occurred. One participant explained this event function,

I certainly remember the mall as a place where lots of people gathered, because there used to be lots and lots of events there, so it wasn't only about the shops, there 
were lots and lots of music shows and people advertising all of their wares, so it was a real gathering place for the community. So the mall itself was as much focussed on the shops as it was on the community events that occurred inside the mall (GWF participant 3).

Within this dialogue, this participant has demonstrated the significant role that the Wainuiomata Mall played as an event venue for the community and how this contributed to the mall's vitality. They have equated this community event function to the malls' retail function, demonstrating the extent to which the mall acted as a community resource.

Another element contributing to the mall's community role was the inclusivity and safety associated with this space. The majority of participants from Wainuiomata spoke of the mall as a safe place for all. It provided a space for old people to socialise and engage in the community, for families to catch up and also for youth to socialise with their peers (GWF participants 2, 4, 6, 13). Within the Wainuiomata focus group, multiple participants explained that due to the mall being a community hub, accompanied with the strong sense of familiarity amongst the community, youths hanging out in the area were socially surveilled (GWF participants $4,6,7$ ). Two focus group participants explained the role the mall played in their youth, so you saw everyone, so actually, you could get growled by someone you didn't know because you knew that person, who knew that person, who would then know your family (laughs) So that was what was good about it... (GWF participant 4). I think that is a key one, about safety for the whole whānau, when you went to the local mall (GWF participant 6).

This community surveillance role was dependent on strong community connections and was reliant on the mall being busy and occupied constantly.

However, participants explained that when the mall began to decline, community members no longer lingered in the mall nor did the youth (GWF participants 6,7). Therefore, they expressed that it was much harder to keep the youth safe without this venue and mechanism for community surveillance.

You know if the mall was there... we'd all be there, we'd all be part and parcel of the community making sure that we keep our kids safe, but its hard now (GWF participant 6). 
This quote emphasizes how the functioning mall space was understood to be a crucial element in the community's ability to protect their youth. The decline of the mall also led to the loss of other community functions within this space.

\subsection{Wainuiomata Mall decline and the loss of this socialisation role}

Participants spoke of some factors which have contributed to the mall's decline. The loss of local employment as a result of factory closures was understood to be a key contributing factor, where it was understood that if community members worked outside of Wainuiomata they tended to shop outside (participants A, B, C). While the changing nature of retail and the increasing prominence of e-commerce was also highlighted (participants A, C, I). The physical proximity of other larger retail sites, such as Queensgate were also understood to be a factor (participants A, K), as was the failure of the mall owners to redevelop the space. One participant explained that "one of the big factors was the mall owner not investing in the mall" (participant A).

The retail function of the Wainuiomata mall was understood to be crucial in ensuring its social function. Due to the increasingly limited goods and services offered within Wainuiomata, participants spoke of needing to shop outside of the community to meet their needs. This led to further reductions in the range of goods offered, and more people were shopping in neighbouring areas. Focus group participants spoke nostalgically of the stores they had previously had in the community, where they were able to get everything they needed from the mall (GWF participants $1,4,78$ ).

While once recognised as 'the' place to be, where 'everyone' went, participants now described the emptiness of the mall. It was no longer seen to have any social function, as there was no reason to linger in the mall or even be in the mall in the first place. The opportunities for casual interactions was perceived as rare. One participant explained,

there's no purpose for them to be down there, same for me why do I go down there for? Okay going to dash in there to get a milk, but that's about it, nothing else to attract me to the mall (GWF participant 4).

This idea of the mall as attracting people to it is significant. The shops within the mall was one attractor to the space, as were the community events. However, when 
the mall began to decline, so did these events. "There's very little if any community activities in the mall [now], which is sad because it's a HUGE space" (participant C).

The largest impact for the community of the mall's decline appears to be the loss of this social space. Since the mall's decline, participants explained that there is little opportunity to engage with other community members. This was understood to be a result of the lack of other community spaces within Wainuiomata. One participant summarises this idea,

there is still no other facility other than maybe the marae that does that, that you know people don't feel they're going down there just to buy something, they are going down there to catch up, they're going down there to watch you know their children, a concert all of that, I think, is what's been lost (participant B).

When asked where this community interaction now took place, focus group participants explained that this now occurs in the private sphere, "its homes, it's just are you home? I'm coming over put the jug on"' (GWF participant 4). They also spoke of using social media as a replacement for the physical social space that the mall had previously provided. Subsequently, focus group participants stated that they saw each other less around the community and this impacted on the sense of community spirit within Wainuiomata. One focus group participant explained, I live in Wainui, I haven't seen my friend for a year. It took me a whole year to finally... wow, are you still here! Because you just don't see anyone now, because everyone just stays home, you just don't go out, there is no reason to go out (GWF participant 1).

One participant did mention the local tavern and how it was trying to create a sense of community and provide a space for people to recreate and eat locally (participant C). However, they also noted that pokie machines and alcohol on the premises make it an unsuitable space for some. This lack of community space means that Wainuiomata residents have been restricted in the ways in which they can engage in their community. This was seen to have wider implications for community cohesion and the overall community spirit of the suburb. 


\subsection{Johnsonville Shopping Centre as a source of suburb identity}

In contrast to the findings from the Wainuiomata case study, participants within Johnsonville had less uniform ideas about the role of the mall as a community space. While they spoke of planned and casual socialisation occurring at the mall, this was typically associated with the consumption of food or drinks. Overall their dialogues did not reflect the strong community socialisation role of the mall as evidenced in Wainuiomata. The role of the mall as a community events venue was also significantly less prevalent in comparison to Wainuiomata. The Johnsonville Community Centre was understood to be the space where these events typically occurred (Participant E \& OJF Participant 2). When asked whether the mall played a role as a community space in Johnsonville, two older focus group participants clearly distinguished between shopping malls and the community centre. One participant claimed that "the community needs to get their community from the community centre" (OJF Participant). In fact, several participants argued that the actual mall itself provided nothing specifically targeted for the community. Instead, they claimed that the community function of the mall was created through the provision of facilities for the community to use, such as shops and cafes (OJF participants 1, 2, $4)$.

This distinction did not diminish the ways in which the value of the shopping centre was understood by community members. The vast majority of participants acknowledged that its community role exceeded that of a retail site. Their dialogues exemplify these sentiments well, "it is a bit of a hub. It is not just a mall it is a communal place, a community place" (participant D). Others referred to it as being 'a vital' and 'integral' part of the community (OJF participant $2 \&$ participant F). "It's the hub, it's the heart, it's the soul" (participant F).

The importance of the mall to the community seemed to centre on the suburbs identity, particularly as a result of the mall's central location and its large size. One participant explained, "it's like a universal reference point for the 25-35,000 people who live in that area" (participant G). This was further demonstrated to mean that not only did the Johnsonville population frequently pass through this space, but it also acted as the town centre. This role was attributed to the lack of community or 
public spaces within the suburb. However, two participants spoke of their desire for the mall to better represent a distinct identity for the Johnsonville suburb due to the significant role it played in representing the suburb (OJF participant $2 \&$ participant F).

Johnsonville participants spoke of some reasons for the decline of the mall. As with Wainuiomata, local employment opportunities were understood to be a contributing factor to people shopping outside of Johnsonville (participants E \& F, OJF participant 2). The physical proximity of other retail sites was also understood be an influencing factor, particularly in relation to the owners struggle to secure anchor tenants to go ahead with the redevelopment (OJF participant 2). E commerce was also mentioned as a reason for the delay in the redevelopment as was a recent earthquake damaging another one of Strides retail properties (OJF participant 1, 2, 3 \& GJF participants 1,2).

Unlike the reflections from Wainuiomata, Johnsonville participants did not generally speak of the previous nature of the mall when discussing the impact of its decline. Instead, they focussed on the current decline and how it had hindered their ability to engage within the community. The majority spoke of commuting into Wellington during the day and returning home once the mall was closed. This meant that had little ability to engage in the community during the week (GJF participants 2, 3, 6, 8). However, three participants also noted that they travel outside of Johnsonville on the weekends because the mall did not have what they wanted or needed (GJF participants 2,3,7). They expressed their frustration that they had to leave their community to fulfil their needs and how this lack of engagement had hindered an ability to feel like part of the community One participant explained the overall group's sentiment well,

I don't feel like a part of the Johnsonville community. Maybe it's because I wasn't born and raised here, I don't go here for coffee, I don't eat here, I don't, I try to avoid doing my supermarket shopping, I go to Pak-n-Save in Petone or I go to Moore Wilsons in town... at the moment I don't feel like part of the community. I walk into Johnsonville mall and I'm like, I know this sounds awful, these aren't my people (people murmuring agreement) ( GJF participant 3). 
This statement demonstrates the extent to which being able to do simple things such as buying a coffee at a café or shopping for gifts could have the potential to contribute to one's sense of belonging in a community. Within both case studies, the retail function was crucial to ensuring the community function of the mall. It was evident that when this space was in decline, so too was the ability for these communities to come together and engage.

\subsection{Suburban shopping malls as a source of community pride}

Closely related to the previous theme, a number of participants in both locations also spoke of how the mall influenced the pride they felt for their community. The strength of community pride in Wainuiomata was emphasised throughout the focus group discussion. The mall had previously played a significant role in this. One participant spoke of its opening in Wainuiomata and what a big deal it was for the community. "We didn't have anything like it, a department store or anything like that, we had never experienced having the big stores in Wainui"'(participant B). Another participant also expressed their surprise that their community was the chosen location for this large shopping centre,

to choose Wainuiomata for the mall, was, you know, huge for the local people, given it was a town full of young families...So it was a place full of people that actually had big families and then we got this flash mall and it was like, you know, why choose us I guess? (GWF participant 3).

From both of these reflections, there was a real sense that the mall was a cherished part of the community. This was accompanied with a strong sense of surprise, that their community, with such a large proportion of young families, was being given this 'flash mall'.

Two other Wainuiomata participants spoke of the community's previous focus on supporting local businesses. One participant explains, "there was a real loyalty back then to buying local. That's what I remember...There was a real pride in buying local" (participant B). However, due to the decline of the mall, this participant explained that this loyalty to the local mall and shops had been lost. They lamented this loss and said they were sad that their grandchildren had no pride in the mall because it had previously been a huge source of community pride. This link between the mall and pride was also made by focus group participants. They explained that 
the mall's decline had influenced how other people perceived the area and the Wainuiomata community. One participant expanded on this idea stating "people see us as a joke because we have a big empty mall (murmurs of agreement)" (GWF participant 7). A general discussion was then had within the group about a recent online article, which named Wainuiomata as one of the worst towns in New Zealand. They expressed disbelief that Wainuiomata was included within this list, attributing their inclusion to the mall, "that's because of the mall... we keep getting judged by our empty mall” (GWF participant 7).

The link between the mall's decline and the reputation of Wainuiomata was understood by one participant to be far-reaching. They explained that a proposed retirement village almost withdrew from the community due to bad press relating to the mall (participant A). This negative press was seen to impact on the broader image of Wainuiomata, and this participant expressed their frustration that despite all of the good things occurring within the community "all you read about is you know the mall and is Wainuiomata dying?" (participant A). A retailer from Johnsonville also expressed their frustration with the media regarding the mall's decline as they attributed these articles to further reducing the number of people coming into the mall. They spoke about a previous newspaper article detailing the mall's decline, "one month we were quiet because of that, the media is not helping either" (participant $\mathrm{H}$ ).

Within Johnsonville, participants did not speak of prior pride in this retail site but instead spoke of the current mall as a source of embarrassment. One participant claimed, "I hardly want to be seen there" (GJF participant 5). When guests came from out of town, general focus group participants stated that they did not take them to the Johnsonville Shopping Centre and instead went to nearby areas such as Churton Park. Criticism was not only related to the retail function but also to the aesthetics of the mall and how it reflected on their community sentiment. Words such as 'freaking ugly' 'embarrassing' 'shabby' and 'depressing' were used to refer to the mall. One participant spoke of the extent of their engagement with the mall, I try to avoid going there at all costs. If I do go to it, I go to Countdown and I enter through one of the side doors because I find it really depressing and I think that's a real shame (GJF participant 3). 
The decline of the mall was also seen to impact on the wider community spirit within Johnsonville. One participant spoke of conversations with other parents in the area, claiming that these were full of negativity towards Johnsonville, relating to the situation with the mall.

one of the conversations that always came up was you know when are they going to do something about the mall, there's nothing happening in Johnsonville, it's boring here and just a lot of negative talk (participant F).

They explained that continued unfulfilled promises for a redevelopment and the further decline of the mall exacerbated this community sentiment. In fact, two participants spoke of being influenced to move to the area based on the promise of the mall redevelopment (GJF participants $3 \& 6$ ). However, the extent of unfulfilled promises related to the mall was exemplified by one participant, who spoke of recently opening a time capsule from 25 years ago. They explained that they had put a Herald newspaper into it at the time, and when they opened it up they "had a look [at the newspaper] and it said mall development to go ahead, 25 years ago!" (participant D). The level of community frustration with the situation can be attributed to such a lengthy unfulfilled promise for a mall redevelopment.

\subsection{The importance of local shopping malls for specific populations}

In both case studies, it was apparent that local retail amenities such as the shopping mall, played an important role for older people. The mall was understood to be a safe space for older members to exercise, recreate and socialise. The act of going to the mall, was considered to be a form of recreation, providing a destination or trip to leaves one's house (OJF participant 1). The mall was also used as an indoor space to exercise, particularly in bad weather (OJF participant 2). Another participant spoke of using the mall as a place to counter loneliness. They explained that after a series of bereavements and intense feelings of loneliness, they had gone down to the mall to just be surrounded by people (participant 1 ).

The Wainuiomata Mall was also mentioned as being particularly significant to the older members of the community. Two participants within the focus group explained that older Māori men were noted to congregate within the mall making use of the 
seating and also enjoying the mall heating (GWF participant $8 \& 9$ ). The mall space acted to facilitate these interactions.

The social nature of the shopping mall was seen to provide opportunities for engagement while accessibility issues relating to age made the availability of basic goods and services within a community increasingly important. These participants explained that when these needs cannot be met locally, older people are forced to travel elsewhere leading to issues relating to transport accessibility and increased transport costs. One participant explains,

as the city [Wellington] has become larger and busier, it makes the local shopping more important, and particularly for older people who can have difficulty getting around for a whole range of reasons (OJF participant 1).

Accessibility issues relating to the decline of the local mall were also highlighted as an issue for the general population. Participants within the Johnsonville focus group spoke of the increased costs of shopping outside of the community, while in the Wainuiomata focus group, participants spoke of the inadequacy of public transport to service this need. In Wainuiomata, the frequency of the bus services was understood to have reduced substantially since the mall's decline, from services operating every 15 minutes to now operating once an hour (GWF participant 9). The transport linkages were also not seen to be sufficient,

so there is nothing directly from Wainui to Pak-n-Save, Petone. They did provide both of those after the earthquake to take people over to shop and they were all packed, but there is nothing. Public transport out of Wainui is nothing. It's all cars, or friends or families (GWF Participant 10).

Within this theme, participants spoke of the disproportionate impact that the mall's decline can have on a population around issues of accessibility. This situation can create inequities for those who don't have easy access to private vehicles, community connections or good quality public transport options.

\subsection{Summary}

This chapter has demonstrated the extent to which both the Wainuiomata Mall and the Johnsonville Shopping Centre played important community functions within their respective locations. Despite these functions being conceptualised in different 
ways, both of these extended well beyond the traditional notion of a mall as a retail space. These spaces were understood to be sources of suburban pride and identity, key sites for socialisation and community safety as well as playing a particularly important role for older community members. These roles were partly attributed to the lack of other community spaces within these suburbs. However, this chapter demonstrated that as a result of the malls' decline, these community functions have deteriorated. This is particularly significant as no other space has been able to replace these roles within either communities. Community members spoke of an inability to engage in their communities as a result of the malls' decline, contributing to a lack of community spirit and cohesion. The mall's decline was also attributed to issues regarding inequities of accessibility for basic goods and services. 


\section{Contextualising this community function within the literature}

The previous chapter has demonstrated the ways in which the spatial practice within both case study malls, has far exceeded that which is acknowledged by its private property status. This chapter aims to contextualise these research findings comparing and contrasting them with the literature. It does so, in order to advance an argument that despite the private ownership of shopping malls, they can play a vital community role. This role is increasingly evident when these malls' decline, and these community functions are lost.

\subsection{The notion of a shopping mall as a community space}

The idea that a retail site, no less a shopping mall can act as an important community space, may initially be confronting. As mentioned previously, this urban form has been widely criticised. Nevertheless, a number of authors have also recognised the role that shopping malls can play as community spaces, particularly in communities lacking other forms of community infrastructure. As evidenced in the previous chapter, both Wainuiomata and Johnsonville are suburbs characterised by limited public space. Participants in both locations attributed the social importance of the local mall to this lack of alternative space, coupled with the mall's central location and size. These findings acted to support the work of Parlette and Cowen (2011), who claimed that often in suburbs, like Scarborough, the local mall provided the closest thing to a community facility. Cowen (2005) proposes that this lack of community space is characteristic of suburban landscapes in the United States. This lack of community space also been seen in cities such as Hong Kong, where shopping malls have also become key sites for socialisation due to a lack of public space (A1, 2016; Ng, 2009; Nowek, 2016). These findings indicate the importance of understanding the broader spatial and contextual nature of a community in order to be able to categorise the function of a space.

The previous chapter spoke of the immensely important role that the Wainuiomata mall played as a site for community building and socialisation. The ways in which participants from Wainuiomata spoke of this social function, seemed to reflect Victor 
Gruen's original vision for shopping malls. As mentioned earlier, he envisioned shopping malls as a way to socialise in suburban neighbourhoods, where interactions were typically relegated to the private sphere (Gruen, 2017). The consequences of the malls' decline also corroborate this assessment, as community interactions were forced back into individual homes or online as a result of this decline.

Gruen's designs also focussed on facilitating community engagement and providing a range of services for both consumers and the public (Gruen, 2017). One of these services could be seen to be the community events hosted by the Wainuiomata Mall. As mentioned previously, the mall acted as the key community events venue within the suburb. The inclusion of community events and activities has long been understood as a mechanism for mall management to improve the sociability of shopping centres and foster a sense of community (Bloch et al., 1994; Parlette \& Cowen, 2011). Others have critiqued the authenticity of this sense of community within malls, due to its perceived construction by mall management (Lewis, 1990). Yet, the ways in which participants used and claimed ownership of the Wainuiomata mall demonstrated that their connection to the mall went far beyond one of a corporate constructed strategy. This sense of community ownership to a local mall is not unique to the Wainuiomata case study. As noted earlier, this sentiment has been seen in a number of instances, such as with the West Edmonton Mall (Hopkins, 1991) and the Morningside Mall (Parlette \& Cowen, 2011) where these spaces were conceived of as public and community space.

\subsection{Potential reasons for differing conceptions of community space}

The previous chapter demonstrated the ways in which the two case study locations conceptualised the community function of their mall. For Wainuiomata, it seemed that the mall functioned almost as a community living room, where people were able to come together and socialise. As my previous research, and others (White et al., 2017) found, Wainuiomata is characterised by a very strong sense of community. Some of which is attributed to its geographical isolation due to the hills surrounding it. In comparison to Johnsonville residents, the majority of Wainuiomata participants had also lived within the area significantly longer. This length of residence may have impacted on the community function that the mall played due to strong existing community connections in the area. Saville-Smith and James (2003) explain that 
length of tenure and wider residential mobility can affect community attachment to a place. Participants from Johnsonville who had lived in the area for a long time discussed the strong community spirit in Johnsonville. However, this sense of community spirit was not evident amongst discussions with any of the participants who had lived in Johnsonville for less than 10 years. As evidenced in prior chapters, the Johnsonville mall has been waiting for redevelopment for over 25 years. It is possible that this larger community role of the mall was not in the memories of the majority of participants due to their short tenure in the suburb.

The community centre was also understood to have a relatively strong role in Johnsonville and it is possible that this reduced the community's expectation of the mall to provide this service. In Wainuiomata the 'hub' or community centre was only mentioned by two participants affiliated with council. This space was not even mentioned when participants spoke of the lack of alternative community infrastructure apart from the mall. This is possibly related to the structured nature of this space, where services and events are planned and this is not just a space to meet one another. The image that the Wainuiomata participants built of the mall as the hub of Wainuiomata was not related to any formal structures, but instead, it appeared that it was the way in which one was able to go into the mall and socialise in both planned and unplanned ways which were significant.

It is possible that the importance of the mall could be attributed to the socioeconomic status of Wainuiomata, which was lower than that of Johnsonville as demonstrated in the case study chapter. Parlette and Cowen (2011) made a link between the importance of malls to communities with lower socio-economic status saying that they "depend more heavily on malls for social reproduction as well as recreation and consumption" (Parlette \& Cowen, 2011, p. 794). This idea may be further corroborated by the way in which participant's spoke of their surprise in being given the mall, particularly given the young nature of the suburb. 


\subsection{The community function of the mall relied on the success of its retail function}

Within both case studies, the retail function was crucial to ensuring the social nature of these malls. The decline of these two spaces had an obvious impact on the goods and services available within their respective suburbs and whether these met the needs of their community members. In Wainuiomata due to the lack of shops within the mall, participants explained that the community saw there to be no reason to go to the mall and therefore the strong social role that the mall once held in Wainuiomata declined.

These findings contrast with research by Parlette and Cowen (2011) on the Morningside Mall. They found that when the retail element of the mall declined, its importance as a community space grew (Parlette \& Cowen, 2011). As shops shut down, more community groups entered the mall, accompanied with an increase in ad hoc community uses such as "an informal place for a men's cards club" (Parlette \& Cowen, 2011, p. 795). The authors explained that these were "uses that persisted long after the decline of the core retail function." (Parlette \& Cowen, 2011, p. 795). Neither of the case study locations have seen the replacement of empty retail sites with community services as seen in this example. Nevertheless, this idea was floated by the Hutt City Council, when attempting to aid the failing mall. They proposed the idea of moving the library into the Wainuiomata Mall, however, the community resisted this due to the library being located in a purpose made building already. This could potentially be the difference between these two findings because the community around the Morningside Mall did not have these services elsewhere, where in the case study locations they did.

Instead of going to the mall, participants spoke of these interactions now occurring in private homes or online. Pattison (2015) also noted this trend between declining local shops and the limited opportunities for incidental and casual social interactions. Instead, the interactions which did occur in the community had to be planned (Pattison, 2015) as demonstrated in the Wainuiomata case study. However, casual interactions are understood to be important for both individuals and wider communities. They provide opportunities to engage with a wide range of people and foster the building of social capital (Lochner, Kawachi, \& Kennedy, 1999). They 
have also been linked to increasing community tolerance (Madanipour, 2016) and helping to prevent feelings of social isolation (Travis, Duncan, \& McAuley, 1996).

Both case study locations have high commuting populations, therefore, as expressed by participants, there was already a limited ability to engage with their respective communities. This situation was further exacerbated by the malls' decline. This idea was particularly prevalent amongst Johnsonville participants who spoke of their frustration in not being able to engage and how it hindered any sense of connection to the suburb. The link between community satisfaction and community services was identified by Filkins, Allen, and Cordes (2000) in their study in rural Nebraska. Their results found that consumer services, along with education and local government had the highest influence on how satisfied people were with their community. Another element tied to a sense of attachment to a community was a 'congruence or compatibility 'of a community and its inhabitants (J. Kim \& Kaplan, 2004). This means that participants lives are compatible with what is on offer within the community and the "environment facilitates people's everyday lifestyle" (J. Kim $\&$ Kaplan, 2004, p. 316). It seems obvious from participant's explanations of the impacts of the malls' decline that their communities are not currently compatible with their lifestyles. This compatibility plays a significant role in how satisfied participants are with their communities as well as the pride they have for these.

\subsection{Community identity and pride as represented by a local shopping mall}

Johnsonville participants spoke of being embarrassed by the mall, due to both its outdoor aesthetics and the provisions within. This situation was understood to impact on how they felt about their community, how they engaged in it and the general Johnsonville community spirit, leading to a lot of negativity within the community. Notions of identity were not explicitly mentioned in Wainuiomata, however, participants spoke of how the decline of the mall impacted on others' perceptions of the area, and also the pride within their community. As the previous section demonstrated, the Wainuiomata mall was once a great source of pride for the community, however now the most commonly used adjective to refer to this space was 'sad'. 
The idea of neighbourhood characteristics impacting on pride and broader community identity had been explored by Nowell, Berkowitz, Deacon, and FosterFishman (2006). Their research found that physical characteristics within a community "communicated messages about the value and character of the community and its residents" (Nowell et al., 2006, p. 29). They were understood to impact on both what insiders thought and how they felt about their community, as well as how outsiders perceived the community and its inhabitants (Nowell et al., 2006, p. 37). Participants in their study spoke of the shame that community members felt being associated with run down elements of a depressed neighbourhood, and conversely how physical features within the community could provide pride and a sense of belonging. These findings were demonstrated in both Wainuiomata and Johnsonville. The declining malls were seen as a source of community embarrassment, and a negative factor influencing their reputation to outsiders.

The notion of community pride within a retail space has previously been explored by West and Orr (2003). They examined the impact of a new mall development within a depressed community, to understand whether it would influence community pride. This research found that the mall development "heightened civic pride" and improved community spirit (West \& Orr, 2003, p. 193). While this thesis is not looking at malls within cities or declining urban cores, nor new mall developments (the context for West \& Orr's study), West and Orr's piece demonstrates how community facilities can impact on resident's pride of place. Their research futher demonstrates that malls as an urban form are capable of influencing civic pride and supports the findings of this thesis. These findings highlight the importance of maintaining key community facilities, including malls.

\subsection{Safety and a place for all}

The mall was described as a safe place for people of all ages to gather. In both Wainuiomata and Johnsonville, it was mentioned as a site for youth to meet and socialise. This use was also recognised amongst youth in Cairo, Egypt (Abaza, 2001) which highlights a cross-cultural similarity amongst this age group. The importance of safety in the mall has been recognised by a number of writers and is seen as one of the features attributed to the success of the mall as a retail form (Lomnitz, 2012; 
Pospêch, 2016). However, the way in which the safe nature of the Wainuiomata mall was conceptualised by participants was distinct from the literature.

For Wainuiomata participants, the safety associated with the mall was attributed to its role as a community space and its tight-knit community. Participants spoke of the community surveillance which occurred within the mall, where mall users would look out for youths and ensure they behaved but also that they were safe. There was no mention of other forms of security and surveillance typically attributed to malls. This is despite it being a dominant criticism of shopping malls and privatised public spaces more generally (Low, 2006; Parlette \& Cowen, 2011; Voyce, 2006). The absence of this is possibly a result of the demographics of participants who contributed to this study, but also could be related to the characteristics of the suburbs or mall management policies. Safety, at least in Wainuiomata was achieved through the creation of natural, self-surveilling opportunities rather than CCTV cameras, for example.

\subsection{The specific role of the mall dependent on age}

This research found that suburban shopping malls, or particularly local shopping centres were important for older people. A relatively large body of literature exists examining the relationship of older people to local amenities and shopping malls, (Bromley \& Thomas, 1995; Duncan et al., 1995; Harrell, Lynott, Guzman, \& Lampkin, 2014; Pattison, 2015; Travis et al., 1996) to name a few. The findings of this research corroborate these studies.

In terms of providing for basic needs within the community, this research found that there were accessibility issues for older participants within Johnsonville if these needs couldn't be met locally. This finding was supported by Sidenvall, Nydahl, and Fjellström (2001) who also found that local shops played an important role for older populations, the importance of which varied depending on age, level of strength and living arrangements.

The mall as a site for socialisation for older people was also a theme that was highlighted in this research. One participant spoke of using the mall to counter feelings of loneliness a usee that has been acknowledged in the literature (Y. K. Kim, 
Kang, \& Kim, 2005). This finding was also supported by Tauber (1972) who found that an individual may visit a mall looking for social contact when they feel "bored, lonely or depressed" (p. 46). Pattison (2015) has linked these uses specifically to the social life of older people, where a shopping trip is understood to reinforce community connections and to meet a number of social needs.

The last age-specific role of local shopping malls was related to its role as a space for exercise. The phenomenon of mall walking is relatively well researched (Bloch et al., 1994; Duncan et al., 1995; Parlette \& Cowen, 2011) and its rise is credited to the proliferation of indoor shopping malls across North America (Travis et al., 1996). The indoor nature is seen to protect from extreme weather such as hot summers or cold winters (Bloch et al., 1994; Parlette \& Cowen, 2011). Mall walking has been understood as not only a form of exercise but also as providing opportunities for social connection, which typically diminishes as one ages and is no longer employed (Duncan et al., 1995). In the case of Johnsonville, there was no formal mall walking, however, the social interactions appeared to provide the same positive impact that is reported in the literature. This section demonstrates how older community members relate to neighbourhood shops differently and the necessity of considering these different uses when these malls are in decline.

\subsection{Summary}

This chapter has linked the findings from the first two research questions of this thesis with the broader literature within this field of inquiry. It has demonstrated that these two case studies are not anomalies. Elsewhere shopping malls have been recognised as important community spaces and their link to community cohesion, sense of pride and identity have been noted elsewhere, as have the impacts of their decline. 


\section{Community decision-making in privately owned commercial spaces}

Due to the community role that these spaces play and the impact of this decline, it seems crucial to understand the ways in which community members are informed and able to have a say in the decision-making relating to these malls. The second section of this thesis will seek to answer the following two research questions, 'to what extent are community members able to influence decision-making regarding this space? And 'what strategies might be employed to enable stronger community engagement in decision-making processes?' This chapter will address the relationship between mall owners and communities, the desire for greater community agency around decision-making and the ways in which the private ownership of the mall is understood to hinder this. Finally, it will examine potential solutions to these issues.

\subsection{The failure of the mall owners to sufficiently engage with the affected communities}

Communication is widely understood to be a key feature in decision-making (Hirokawa \& Poole, 1996). However, when participants were asked about their ability to influence decision-making within their respective malls, the lack of communication and broader disengagement between the mall owners and the community was a strong theme which was evident in both case studies. Within Johnsonville, participants spoke of the few instances that the mall owners, Stride, had made contact with the community. The extent of this communication was in the form of a "newspaper advertisement and being quoted in the paper occasionally" (participant E). This newspaper article was identified as part of the "begrudging stuff' (GJF participant 2) that Stride released after a meeting with members of the council which sought to improve the company's engagement and communication with the Johnsonville community (participant E). This article spoke of the reasons for the delay in the redevelopment and their future plans for the mall. Nevertheless, 
there was a general desire for the owners to be upfront with the community and for engagement to be more comprehensive. One councillor expressed their disappointment with Stride's approach stating that "they should have been face-toface. In my view, I just think that would have been good public relations" (participant E). Another participant attributed this lack of communication and engagement to a growing animosity between the Johnsonville community and the mall owners. "It's just creating a massive divide and the more they don't talk to us [the community], the more there is a massive divide" (participant F).

The desire for the mall owners to be open with the community was also apparent in the Wainuiomata case study. When asked about the relationship between the Wainuiomata community and the mall owners, one councillor highlighted the lack of community engagement stating "umm well for one, they wouldn't come to Wainui, and that's the big one" (participant A). For this participant, visiting the community was understood to be a small but important way in which the mall owners could show their commitment to Wainuiomata. They also spoke of the consistent failure of the owners to communicate with the community. This idea was apparent within the Wainuiomata focus group, where participants spoke of their information sources relating to the mall. These appeared to be based on rumours from one community member to another, the odd media article and also a community Facebook page called Nui Natter.

Nevertheless, one instance of consultation was mentioned by Wainuiomata focus group participants and the previous mall owners, which addressed their future development plans. However, participants explained that this consultation process was never enacted upon. "They did come and talk to the community, and then nothing happened, and then the next thing we heard was that Countdown had brought them" (GWF participant 12). They spoke of their frustration at this process and the fact that they had given up their time, yet the owners were not able to keep them informed about decisions that were being made.

Prior to the mall being brought by Progressives, one participant affiliated with council spoke of their attempt to encourage the mall owners to come and talk to the community (participant A). They spoke of the detrimental impact of the malls' 
decline on the community spirit and also the wider reputation of Wainuiomata, as mentioned in previous chapters. As a result of the owner's failure to respond to correspondence from local councillors, this participant chose to take the unusual action of flying up to Auckland to approach the owners face to face. As a member of council they sought to encourage the owners to visit and talk to the community about their future plans for the mall. Despite the owners initially agreeing, they later changed their minds. A change of heart which was attributed to concerns regarding the potential animosity of the community (participant A). However, this was understood to be another example of the community being let down by the owners who were unwilling to come and speak to them (participant A).

Local retailers in both locations also spoke of the mall owner's lack of communication. This idea was particularly strong amongst retail participants from Wainuiomata, possibly as a result of the severity of the mall decline and the new owners. One participant from Wainuiomata discussed this situation, "there has been no communication, no nothing at all...”(participant I). For this participant, any communication which did occur in the last three and a half years was the result of them ringing the owners to try and understand what was happening. While this situation related to the previous owners, two retail participants said nothing had changed since Progressive Enterprises purchased the mall at the beginning of 2017 (participants I, K ). They had been unable to talk to the new owners, despite their repeated attempts to contact them. However, one participant had been consulted over future plans and where their shop could fit within these (participant J). Nevertheless, they ultimately decided to leave the mall, mainly as a result of not trusting that the redevelopment would occur in the timeframe and manner that had been promised (Participant J). It was unclear from participants why one had been consulted with, and others had not.

The retail participants in both locations emphasised the insecurity that this lack of communication and unfulfilled promises for a redevelopment had on their ability to run their business. It was seen to have impacted on their business growth, their ability to have a retail space within their community and also opportunities to sell their businesses (participants I, K, H, J, D). None of the retail participants expressed a desire or expectation to contribute to the decision-making regarding the nature of 
the redevelopment, instead, they spoke of simply wanting to know what was happening in order to be able to plan ahead. One Wainuiomata retailer explained this common sentiment well, "communication is everything isn't it... It's like anything if you have answers you can handle it. If you don't have answers you can't do anything" (participant I).

These conversations with community members and also retailers highlighted the extent to which the mall owners had failed to engage and communicate with those affected by their decisions. It seemed that the vested interest that these groups had within the mall and the future of this space, was either not recognised by the mall owners, or it was ignored. The council's involvement in attempting to improve this engagement and communication in both locations demonstrates the insufficiency of this situation.

\subsection{Community desire to be recognised as key stakeholders by mall owners}

As expressed above, participants in both locations spoke of their discontentment relating to the ways in which the mall owners have acted towards the communities affected. Within Johnsonville, there was a particularly strong sense that the owners did not care about the wider community and instead the extent of their engagement in Johnsonville was understood to be relating to making a profit (participants G, E, F \& GJF participants $2,3,7$ ). One participant explicitly referred to this treatment, claiming that the community was seen by Stride as 'commodities' and 'resources' to extract (participant $G$ ). These sentiments aid in understanding the magnitude of frustration amongst Johnsonville community members in relation to the delayed redevelopment and subsequent decline of the mall.

Participants acknowledged that there may be legitimate reasons for this situation, tough they also spoke of the need for Stride to demonstrate that it had an interest in Johnsonville outside of its commercial benefit. One participant envisioned this to take the form of the mall hosting a community event or facilitating an activity within the mall space (participant F). Another participant linked this need to demonstrate care for the community, to changing business practice norms. "Business today is not just about going into a community and making money out of it- it's actually, it's 
being part of the community" (participant E). From the previous participants' accounts, it is clear that Stride has failed to do this well.

Within Wainuiomata, several focus group participants and interviewees also questioned the extent to which the new mall owners (Progressive Enterprises) would care for and contribute to the community (GWF participants 7,8,13, \& participants A, C). This scepticism was related to the nature of Countdowns previous operation in Wainuiomata. This was understood to be substandard, in terms of management, community engagement, the physical shop and also the quality and range of food available. One participant demonstrated the general sentiment amongst participants well,

Countdown is quite notorious for doing what they like in Wainui...I feel like they have never gone out to seek any feedback from the Wainuiomata community about the shop and things (participant B).

This participant spoke of a desire to be able to provide feedback and input to Countdown, a shop which was understood to be vital to the community due to it being the only supermarket. However, they expressed their dismay that there had been no opportunity to provide input, linking this to the Countdowns lack of care for the community.

In both locations, participants struggled to reconcile the ways they have been treated versus the role they play in ensuring the success of the mall. In fact, several participants from the Johnsonville general focus group claimed that Stride has obligations to the community due to this role (GJF participants 2, 3). One of these participants expressed their frustration that Stride did not seem to be aware of or acknowledge this obligation. "It still feels like they have failed to even consider that they have any responsibility to the community, that we are an inconvenience to them, rather than the people who actually make this work" (GJF participant 2). From this dialogue, it is clear that there is a discrepancy between the community's expectations of the mall owner and the ways in which the mall owners conceptualise their obligations to the community.

Another way in which this discrepancy was understood was when shops began to close in the Wainuiomata mall. Two participants spoke of the sudden closure of 
certain shops, expressing their frustration that they were not made aware of their potential closure (GWF participants 7, 12). In relation to the loss of the New World supermarket, one participant stated, "there was no consultation with the community about actually could we support it to stay open" (GWF participant 7). It was evident from their dialogue that they believed that the community would have banded together to support this retail space, however, they were given no opportunity to do so. It seems that the mall owners did not recognise this supporting role. The idea of the community actively seeking to support shops they identified as important, was also acknowledged within the general Johnsonville focus group. Two participants spoke of consciously choosing to shop locally to try and support the local retailers left in the shopping centre (GJF participants 1,2).

When participants were asked how they would like to contribute to decisionmaking, one major theme was identified. They wanted to feel like their opinions mattered and for the owners to recognise their role in this situation. One participant from the Johnsonville general focus group explained, "just to be asked in the first place, that we are seen to be valued enough to be asked" (GJF participant 2). This statement hints at the extent of frustration but also the level of disempowerment felt within the community. There was a general desire, particularly within the Johnsonville general focus group to be given opportunities to contribute to decisions regarding the mall redevelopment.

In fact, a significant proportion of the dialogue within the focus group centred on what the community wanted to have within this space. The basic tenants of this vision were that they wanted a place for people to come together which was community orientated and included elements such as cafes and restaurants and wider entertainment facilities such as cinemas and theatres. This space was envisioned to be unique, creative and a representation of the community. It was also described as a place where everyday community needs could be met without having to go to the city. Participants spoke of the ways in which they would like to voice this vision. Some explained that they would be happy to form a consumer reference group or focus groups with the mall owners to express their desires for the space. 
The desire to be able to express one's opinion and contribute to some element of decision-making was also apparent in Wainuiomata. One participant spoke of the need for the mall owners to call a community meeting to demonstrate that they want the communities input. This was to ensure that a new development is not forced onto the community, but it's something they can have say in. This idea of community ownership was mentioned by another participant affiliated with Hutt City Council. This participant explained that in the case of new developments, gaining community ownership is often the hardest part (Participant L). The way in which this was seen to be achieved was through investing time into the community, building connections and offering opportunities to influence the decisions.

\subsection{Private ownership as a limiting factor to community engagement and input into decision-making}

As noted in the previous section, there was a strong desire from both of these communities to be informed, recognised as important actors and have the ability to contribute to decision-making regarding these spaces. Despite this, discourses surrounding the private ownership of the mall pervaded almost all of the conversations with participants when asked about their ability to have a say in the decision making processes regarding these malls.

Many felt that as a result of the mall's private ownership, the owners were not obligated to communicate, consult or engage with the community. The majority of participants spoke in a frustrated but also defeated tone and expressed their concern relating to the private nature of this space. This was exemplified by a comment made by a participant in relation to the Wainuiomata Mall, "it's like our community facility. Now we don't have any say in it" (participant B). This statement contains two key elements. Firstly it demonstrates the extent to which this participant sees the community claiming ownership of the mall. It also demonstrates a perceived sense of community powerlessness in relation to the decisions regarding this space.

As mentioned in the previous section, GJF participants spoke in detail about how they envisioned consultation. However, during this dialogue, one participant criticised these ideas as being 'utopian visions' and unlikely to happen. "We are talking about a commercial organisation like they give a shit and let's be honest, they 
probably don't (murmurs of agreement)" (GJF participant 7). Based on an awareness that Stride was not obligated to consult with them, participants spoke of the ways in which they could market their input. They spoke of doing so by equating their input with offering 'free ideas' and 'data' to the company. "I think we need to sell it to the company, as not an opportunity for 'we want to have a say', it's for them to do some data mining as well" (GJF participant 3). From this conversation, it appeared that incentivising their participation was one of the only ways in which these participants envisioned any form of input.

To understand the broader ways in which communities had agency, participants affiliated with the council were asked how council could influence decision-making within these private spaces. Their responses also centred on the fact that the malls were private property and therefore the council's ability to influence them was very limited. Although, they did mention ways in which the existing regulatory framework could influence aspects of a development (participants A, C, E). The two mechanisms mentioned were district planning rules and the resource consent process. These were seen to guide developments in certain directions to ensure that it creates some 'public good' outcomes (participant E). However, it was also acknowledged that these mechanisms had a limited ability to influence decisionmaking. Participant A explains this situation,

You know it's very difficult for us to influence what is built on the site. Um or what is done. I mean there's rules again in the District Plan you can say that there is going to be $\mathrm{x} y \mathrm{z}$ to cater for $\mathrm{x} y \mathrm{z}$. And, they have got to build to those standards. But yeah it's a little bit tricky

This comment shows that provided that a development conforms to broad land use plans and the confines of their resource consent, council has little influence over other aspects of the development.

In relation to the recent sale of the Wainuiomata Mall, these participants were asked if the council had played a role in deciding who the new owner would be or the nature of the redevelopment. One participant spoke of the council attempting to lobby the owners to influence their decision (participant A), however, this was the only direct mechanism mentioned. Instead, another council affiliated participant explained "with it being in private ownership, council has had no control over any of 
it, no control over timing, no control really over what it is and what should be put in there" (participant C). These participants expressed their frustration with this lack of influence they had relating to the mall's decline (before its recent purchase). In fact, two participants spoke of a conversation which was held at Hutt City Council regarding the council buying the mall (participants $\mathrm{A}, \mathrm{C}$ ). This idea was broached due to the severe impact the mall's decline was having on the community, coupled with councils inability to change the situation. However, it was decided that "owning malls is not core business of council" (participant $\mathrm{C}$ ) and there were fears regarding the financial risks of council owning private property, particularly for a mall which was in decline (participants A, C).

Instead, the council chose to expand some of their development policies in order to incentivise a redevelopment in Wainuiomata (participant $\mathrm{C}$ ). These incentives are called the Business Stimulus Package and Economic Development Grant and include "rates remissions for a certain number of years" (participant C). It was hoped that these would ensure a redevelopment occurs. The use of incentives was also mentioned by a Johnsonville participant affiliated with council. They spoke of the vast amount of money that the Wellington City Council had invested into Johnsonville in order to improve the suburbs infrastructure to aid in the mall's redevelopment (participant E). However, they also noted that despite this investment, the mall was not legally obligated to realise this development. Participant E described this situation, "so council has gone ahead to make Johnsonville in a fit state to accept a mall, in good faith really. And, now it wouldn't be unreasonable to expect the mall to go ahead with their side of the moral bargain at least". This participant has highlighted the lack of formal influence that the council had within this context, that despite this significant investment they may not be able to obtain the desired results because the mall is privately owned.

For both community members and council, their influence and opportunity to have input in decision-making regarding these spaces has been diminished because of the private nature of these malls. Few mechanisms appear to exist to protect these communities. 


\subsection{Community frustration over councils lack of influence}

In the general Johnsonville focus group, there was a large amount of frustration over the current situation with the mall. This was directed at the mall owners, but also at the council. There was a strong sense that the council was not adequately supporting the community with the issue of the mall. Recalling the recent elections, one participant argued that a number of councillors and also an MP had been elected due to their rhetoric around pushing for the redevelopment of the Johnsonville Shopping Centre (GJF participant 3). However, they argued that there has been a lack of follow through on these political promises. In response, another participant spoke of a community event they had attended recently, where a council planner had outlined their inability to do anything with the mall situation due to it being a 'commercial venture' (GJF participant 2). This statement corroborates the council's previous stance as detailed by participants above.

Two participants within this focus group did not perceive this argument to be sufficient (GJF participants 3, 7). Instead, they claimed that council should be able to have a greater influence in these decisions, in spite of the mall's private ownership. This argument was related to council's representational role and the power dynamics of this situation. One participant explained, "there is an extreme power differential, a mismatch at the moment in terms of what developers have and what councils have, and what the communities have" (GJF participant 7). They proposed that council needed to step up and take a greater role in the decision-making process regarding this space in order for them as community members to feel heard in this situation.

This negative perception towards council was also seen to have been enhanced by the past role that the council had played in delays relating to the Johnsonville Shopping Centre. Several participants, both from focus groups as well as individual interviewees, mentioned the fact that the Wellington City Council had previously stopped a redevelopment of the mall, due to concerns that it would take retail away from Wellington (GJF participants 1,5,6 \& participant F).

There was a plan that went to Wellington City Council years ago, and Wellington City Council got scared stiff that it would take people away from the city and gave it a no (OJV participant 3). 
Despite the council having changed their stance significantly since then, there still seemed to be a lingering sense of distrust. This section has demonstrated that there is a strong community desire to be active and contributing members within their communities. However, they expressed their frustration relating to councils lack of influence within these decisions since it is the role of council to represent communities and their interests. The designation of a space as private property was not understood to be sufficient to exclude council from fulfilling this role.

\subsection{Rebalancing power dynamics}

In response to participants' frustration at not having their voices heard, either as community members or through their representatives, council, a number of suggestions were made in how to remedy this power differential. There was a very strong desire from participants in both locations to be able to contribute to the decisions relating to their city centre development, of which these malls sit at the heart.

One way in which this was conceptualised was the need to create a form of legislation which would act to increase the influence that the council could have within these situations. This mechanism was suggested as a result of previous conversations with council, where the council had spoken of the legislative restrictions on them regarding their ability to influence the mall owners. One participant hoped that if a legislative mechanism was put into place, it would allow the council to "play more of a lead role, or have an upper hand" in the decisions regarding these private spaces (GJF participant 7). A participant from Wainuiomata also echoed this sentiment, expressing that due to the strong community function of the mall, there needed to be legislation which put restrictions on what occurred within this space (participant B). These also needed to stipulate the obligations to private owners around community engagement and participation in decision-making. They explained their justification for these measures,

I do think there needs to be some form of legislation, I mean it's almost like if someone came and took over the Wainui marae and then decided to do whatever they wanted with it and it had nothing to do with providing a cultural facility for the community, then that is just not right. They could do anything with it really, so the community is powerless. You know we haven't got any say with what happens with 
what used to be the hub of Wainui. So I think there does need to be some form of legislation that clearly outlines responsibilities around the community and what that means in the way of that space (Participant B).

This statement highlights the vulnerability of the community within this situation stressing the need for protective measures. This participant has also linked the community claim to the mall space and attributed it to community rights.

Amongst GJF participants, there did not seem to be a concern relating to the larger issue of privatisation within their suburb. Instead, participants spoke of ways to ensure that these private powers were limited in certain ways. This was particularly well communicated by one participant who summarised the group's sentiments well,

I am picking up from the group and it's in my own thoughts, it's that I don't actually think there is anything wrong with private companies owning land. Property development is fine, but it also sounds like we all want some limitations on what they can do and that is an appropriate role for, well for councils, and above that for central government (GJF participant 7)

As communicated by this dialogue, there was a general desire to ensure that no matter the ownership of the mall, that they as community members and council could still influence these spaces. Indirectly, these focus group participants have critiqued the inalienable rights ascribed to private property.

Aside from legislative and regulatory mechanisms, there were two other main options that communities conceived of to change the power dynamics of this situation. One was to look to the public sector for the provision of a space which fulfilled the social role that the mall had previously played. The second was creating public-private partnerships with the mall owners in order to have a stake in decisionmaking due to this financial contribution.

\subsection{Public provision of community spaces}

One participant said that the Wainuiomata mall had played a "huge, huge role" (participant C) as a community space and in the wake of this loss, they explained the ways in which this space provision had changed. Refreshments and food were available at the Tavern in Wainuiomata, and public services such as the library were 
increasingly being used to supplement this lack of community space. They explained,

our library is no longer just a place of learning where you go read a book. It is becoming very much a community hub space as well...So no, the Council still has a very key role in what we are calling our Community Hubs. We've taken on that role (Participant C).

This example demonstrates that council are attempting to provide the facilities which were once available at the mall. Several participants mentioned the 'Community Hubs initiative' developed by council which aims to rejuvenate community facilities in the Hutt (participant L). Construction on Johnsonville's new community hub is set to start this year, with plans being developed for Wainuiomata also (Participant C). However, despite one participant acknowledging their excitement about the upcoming hub, they also stated that the "retail aspect needs to be backing it up" (participant F). This correlates to these research findings where while some of the functions of the mall were purely community-based, a lot were also about the provision of goods and services within this space and how this contributed to opportunities for community.

\subsection{Public-private partnerships}

Public-private partnerships were understood as one way in which council could gain influence in decision-making regarding these malls. The idea inherent within these suggestions was that by the council or the community having a financial stake in the development, their participation in decision-making could be secured. One Wainuiomata participant affiliated with the council spoke of their desire for the new mall development to connect well to the other retail sites on Queen Street. They spoke of meeting with the mall owners to see whether there is an option for council purchasing a sort of line of, a line of sight or like a path right through the centre of the Strand..., where council can have sort of you know a bit more of a stake in the ground (participant A).

From this statement, it is clear that this participant attributes ownership of a portion of this property to an increased council influence in relation to this space. One OJF participant also attributed partial ownership to increased decision-making influence, where it was suggested that the community needed to have a financial investment in the development in order to get what they desired (OJF participant 4). However, 
another participant was quick to respond that by giving their income, in the form of retail consumption, this should act as encouragement for the owners to provide the shopping centre and engage with the community (OJF participant 2). Inherent within all of these suggestions, was a desire to ensure they are consulted, fairly represented and given a voice in the decisions regarding these spaces.

\subsection{Summary}

This chapter has demonstrated that there has been a lack of communication and engagement between the mall owners and the community. This has meant that community members have been unable to contribute to decision-making regarding what they consider to be their community space. Participants voiced their frustration with this situation, arguing that they have a right to be recognised for the important role they play in supporting and sustaining the mall. The private ownership of the mall was seen to diminish this right, where community, as well as their representatives in council had few mechanisms to influence the decisions made regarding the mall space. A number of solutions were sought to balance out the uneven power differentials between the mall owners, council and the community. These responses included owning a portion of this land in order to gain influence as well as regulatory and legislative measures to ensure that private owners had some ingrained obligations to the communities affected. The following chapter will examine these findings in relation to the literature and provide some high-level policy recommendations that respond to these findings. 


\section{Property rights vs community rights in privatised 'public' spaces}

As demonstrated in the previous chapter, community members have had little ability to participate in decisions regarding what they conceive of as their community space. This situation is the direct result of the private ownership of this space. The conception of 'private space' based on legal ownership, fails to recognise the ways in which communities use and interact with these spaces. This chapter provides a critique of the notions of 'public' and 'private' space in relation to theories of property rights and decision-making, in order to advocate for improved community decision-making within privatised community spaces.

\subsection{Disempowered suburban communities in decision-making}

By referring to these private malls as 'their' community space, community members made an ownership claim on these sites. As a result of these claims, participants had set expectations of the mall owners, which could be understood as the 'rights' attributed to their ownership. At the most basic level, there was a desire to be consulted with and have an opportunity to be included in decision-making regarding the future of these spaces. Despite this strong community claim, participants spoke of their struggle to reconcile the lack of engagement that the mall owners had with the community, in comparison to the important role communities play in ensuring the success of the mall. Unfortunately, Berry (2003) argues that this situation is not unique to these case studies, instead, community are often left out of decisions which impact them. He states that "community is often taken for granted by corporate decision makers, to be dealt with through public relations or community outreach after corporate decisions are made" (p. 3).

This is despite communities being a primary stakeholder in corporations. According to Freeman (1984), the term stakeholder refers to "any group or individual who can affect or is affected by the achievement of an organisation's objectives" (p. 46). The category of primary stakeholder refers to owners, employees, customers, suppliers and community; essentially the groups that make a successful business possible. Despite this important role, Berry (2003) argues that as long as corporations operate 
within the set laws and regulations, "the community ordinarily has little power to refuse corporate strategies and initiatives" (p. 3). This lack of community agency in decision-making appears to conflict with council's role as stipulated in the Local Government Act 2002. This role centres on advocating and representing their respective communities, encouraging participatory decision-making and conducting democratic local decisions on the communities behalf (Department of Internal Affairs, 2011a). Despite this overarching remit, these case studies highlight how individual private land ownership is privileged, over broader collective outcomes. In both of these cases, the council seems to have felt hamstrung to be able to fulfil these roles.

One decision-making mechanism was mentioned where communities and council were able to influence private development plans. This was through the resource consent process. This process is guided by the Resource Management Act 1991 (RMA) which holds public participation to be a core principle (Ministry for the Environment, 2015). This RMA examines the extent to which proposed activities affect individual participants, groups or communities and provides opportunities for decision-making based on this evaluation (Ministry for the Environment, 2015). It guides the initial construction or redevelopment of a site, and once this has been granted any obligations for consultation ends unless provided for within the resource consent stipulations.

This process provided no opportunities for the case study communities to engage in decision-making. This was due to the fact that the promised redevelopment in Wainuiomata had not occurred and the mall was continuing to function as before, meaning that a new resource consent was not needed. In Johnsonville, as mentioned previously a new resource consent had been granted. However, this was based on the previous resource consent which had expired (participant $G$ ). The owners plan for the development was smaller than the original plans and therefore this consent was granted as non-notified, meaning that community members were unable to have a say in these plans (Devlin, 2016). Participants expressed their frustration with this process, as the previous consultation had occurred over 10 years ago, and they didn't believe the new plans from the mall owners would meet the community's needs or desires (participants F, G). 
Processes for council consultation are set out in the Local Government Act 2002. These explain that council are obligated to provide access to information for anyone who may be impacted or is interested in a future decision that they make (Department of Internal Affairs, 2011b). It also stipulates that "these people should be encouraged to express their views to council”, be given a sufficient opportunity to do so, and for council to give due consideration to these views when making decisions (Department of Internal Affairs, 2011b, p. 1). These guidelines state the obligations to council relating to the nature of public decision-making, however, these fail to provide any framework for decisions relating to privately owned spaces in key community nodes such as suburban town centres. There are no such guidelines for companies working with communities, instead, limited options are available for community input, which are typically through self-regulation and market-driven mechanisms such as Corporate Social Responsibility. This relies on the goodwill and willingness of corporate entities to consider more than just economic outcomes (Schwartz, 2009).

As demonstrated by the descriptions of these processes, how a space is categorised as public or private influences the ways in which communities are able to contribute to decision-making. If the mall space was public, changes would be subject to lengthy and comprehensive public consultation processes. This idea can be exemplified in examining the difference in consultation processes regarding the Johnsonville hub project compared to the mall. Despite the mall being acknowledged in the Johnsonville Town Centre Plan as a major threat and weakness to the community, there was no opportunity for community members to provide input into this space. Whereas in comparison, they were offered a number of opportunities to contribute to the community hub development. Because shopping malls are understood to be 'private spaces' based on the nature of its ownership, community's informal claims on space often fail to get traction in terms of decision- making power (Parlette \& Cowen, 2011).

\section{2 'Public' and 'private' spaces and the impact of this designation}

The ways in which we conceptualise space and attribute property rights based on this categorisation is at the core of this issue. Clear binaries exist which pit public against private, with private ownership sitting at the top of an ideological hierarchy of space 
management in our towns and cities. The ownership model was spoken about earlier in this thesis, where a series of inalienable property rights are given to the owner of a space. Because this ownership model provides a series of rights to the owner, it also limits the way in which the state can intervene (Blomley, 2004). This intervention is only undertaken if it appears that by using these rights, property owners will cause harm to others (Blomley, 2004). Therefore within this model, "the rights of the private owner are seen as trumping those of the collective, and are deemed both anterior and superior. This places a heavy burden on those seeking to regulate or limit the property right" (Blomley, 2004, p. 3). The weight of this burden can be understood within the context of this research. Particularly when participants affiliated with council spoke of their inability to use any 'heavy-handed' options to change the situation, such as altering zoning and taxation. They explained that this could not be done as these would impact on the property rights of the mall owners. Their hesitation to interfere with these rights can also be understood within the context of local governments attempting to attract private investment to suburban centres given the lack of public resources.

One major issue with this ownership model of property is that it fails to acknowledge community's interests and claims to space (Blomley, 2004). This is because it only provides rights to the legal owner of the space, which is recognised as being strictly private or public. Community claims to these spaces cannot be reconciled with this model as it acts to render "certain other claims to land especially those of a more collective nature- marginal, or even invisible, denying them legal standing and rights status" (Blomley, 2004, p. 27). The dominance of this ownership model is exemplified in both case studies.

Despite widespread recognition that these malls were crucial community spaces, few participants explicitly demanded rights to this space. Instead, they spoke of their desires to be involved in decision-making, before resigning themselves to the fact that the owners were under no obligation to do so. Blomley (2004) also noticed a similar pattern while speaking to anti-gentrification activists, he attributed this to "a pragmatic realisation that such a claim would not be very successful given prevailing legal opinion; alternatively, it may reflect the prevailing blindness of such claims" (p. 37). 
Some community responses to this issue can be understood within the ownership model. In recognition that their claim to the mall space did not fit within either of the two categories stipulated in this model, a number of participants sought to base their claim to these mall spaces on ownership. Public-private partnerships were understood to be a way by which community and council could ensure decisionmaking influence, as a result of them having a financial 'stake' in the space. Another option was seen to be the public provision of these spaces. These responses to this issue demonstrated the dominance of the ownership model, as did the fact that the Hutt City Council discussed owning the mall in order to be able to influence the space and make decisions regarding it. Whereas no council affiliated participant suggested limiting the private property rights of these spaces.

As shown in these examples, the way in which space is categorised as public or private greatly affects the rights available to communities. These proposals to effect community agency are understood to be mechanisms through which community members could achieve an element of decision-making, a right which would be available to them if this community space was publically owned.

\subsection{Spatial justice, property rights and democracy}

As illuminated in this research, the nature of space provision within one's community either fosters or hinders opportunities for self-determination and participation in decision-making. According to Purcell (2002), Lefebvre noted this link and was concerned by the trend towards neoliberal global restructuring and the rise of corporations. This was due to the inalienable property rights associated with these corporations, meaning that they were not controlled by councils or government (Purcell, 2002). His concern focussed on how growing corporate ownership would limit democracy and citizens decision-making abilities, reducing urban residents ability to shape their cities, which he theorised as the right to the city (Purcell, 2002). This very instance that had preoccupied Lefebvre can be seen in both of these case studies, where Harvey (2003) has argued, "human rights in general and such specific claims as the right to the city become subordinated to the primacy of the rights to property" (p. 45). 
The right to the city can also be understood within the context of the theory of participatory democracy. This form of democracy seeks to extend citizens political participation beyond voting in elections (Michels \& De Graaf, 2010). Instead, it stresses that citizens should participate in decision-making more widely, including in spaces such as local communities and workplaces (Michels \& De Graaf, 2010). This improved participation in community decision-making has been attributed to a stronger sense of community belonging (Michels \& De Graaf, 2010) and community pride (Morrison, 2016). It has also been recognized as an important element for strong and socially connected communities (Wellington Regional Council, 2011).

However, these objectives appear to be in conflict with the growing trend of privatisation and inalienable property rights as demonstrated by this thesis. Instead private ownership has been associated with decreased opportunities for decisionmaking and an inability for communities to shape their spaces. In fact, a number of participants spoke of feeling powerless to influence the situation with the mall. This sentiment of powerlessness has been characterised by Young (1990) as a form of injustice. She explains that this refers to the "draining away for some of any sense of political power, participation, representation and capacity for self-expression" (p. 21). As has been demonstrated in the previous chapters of this thesis, all of these elements have been apparent in both case study locations. While these injustices have occurred on the individual and community level, this lack of community decision-making can also be linked to wider issues of spatial injustice.

The term spatial justice, refers to the idea that "justice, however it may be defined has a consequent geography" (Soja, 2010, p. 1) and the geographies in which we choose to live our lives can have negative or positive effects. As demonstrated by this research and wider literature, dependent on the nature of space provision within one's community, community members may or may not be able to participate in decisions relating to their community space. In Wainuiomata and Johnsonville this community space was privately owned and therefore the community was denied the right to self-determination and decision-making. However, for people who live in communities with large quantities of publically owned spaces, they would be provided with these opportunities. This research shows that there is a geography of injustice as a result of urban planning and private property rights. Spatial injustice is 
understood by Soja (2010) to be "rooted in the sanctification of property rights and privileges"(p. 44). Within the New Zealand Urban Design Protocol, a key attribute recognised of a successful town or city was that they "encourage people to participate in making decisions that affect them" (Ministry for the Environment, 2005). However, one must question how this is able to be realised when the decisions that affect communities are being made by private companies.

This idea also demands a greater inquiry into whether this situation affects different populations disproportionately. While it is outside the remit of this thesis, if suburban sites are key locations for the provision of affordable housing options outside of city centres, this lack of agency in contributing to community spaces may be disproportionately affecting those in lower socio-economic communities. So far, this thesis has demonstrated the detrimental impact that inalienable private property rights have on communities and their ability to self-determine, and the implications this has for broader democracy and spatial justice. The following section will argue the need to reconceptualise the way we understand space, advocating for a shift from the ownership model to a framework which is more inclusive and just.

\section{The need to reconceptualise these terms and spaces}

This research seeks to disrupt dominant discourses relating to private property rights and public and private space in order to challenge existing forms of decision-making which are based in these discourses. As mentioned earlier in the literature review of this thesis, a number of scholars have critiqued 'monodimensional' conceptions of space. As evidenced by the role that the shopping mall has played within these case study communities, these shopping malls do not fit into the traditional category of private space. In fact, Kohn (2004) argues that few spaces can be defined as solely public or private, with most existing between these two categories.

Based on theories by Foucault (1970) linking knowledge to power, it can be seen that the binary between public and private, as well as the ownership model of property, have been constructed and maintained as a result of power relations. Foucault rejected the idea that inherent truths exist and instead argued that certain pieces of knowledge become accepted 'truths' as a result of power (1970). These dominant ideas are understood to limit or constrain or even naturalise certain things 
(Waitt, 2010). This limiting process can be seen in relation to this research, where the lack of council and community influence in decision-making was justified by private property rights, in itself a constructed notion along with the constructed notion of a spaces categorisation.

However, Foucault also acknowledges that these dominant or normative ideas, attitudes and practices are not permanent and are able to be changed (Waitt, 2010). They have only been temporarily fixed as 'truths' (Waitt, 2010). This can be shown in relation to the distinction between private and public space, where numerous academics and even court cases are seeking to create new 'truths' in terms of what constitutes private and public space (Kohn, 2004). This idea is expanded on in the following section. Understanding existing discourses, how they are constructed and maintained is crucial in order to disrupt meanings and potentially change these meanings or 'truths' (Davies \& Gannon, 2005). The previous sections of this thesis have aimed to illuminate the nature of these discourses.

Despite presenting itself as fixed and unchanging, the ownership model of property is shaped by a range of factors and reflects the nature of the society in which it is based (Guerin, 2003, p. 10). This model has been recognised as flawed by many, however, it is understood to be so pervasive due to the clarity and certainty it provides (Blomley, 2004). Yet, Blomley (2004) argues that as result of the constructed nature of these property rights they are flexible and can be changed. Property relations can be configured as exclusionary, violent and marginalising. They can also be a means by which people find meaning in the world, anchor themselves to communities, and contest dominant power relations. To get at these multiple possibilities, we need to unsettle dominant treatments and recognise property's diverse meanings and often unsettled politics (Blomley, 2004, p. 156). This statement reflects the real potential that societies have to create property relations which are just and democratic.

The way in which we conceive or define a space is argued to be a political endeavour (Iveson, 2013; Vasudevan, 2015), one which is the result of negotiations of power and knowledge (Lefebvre, 1991). Fraser (1990) also argues for the need to unpack the classifications of private and public space and the mechanisms that surround 
them. She argues that these "are powerful terms that are frequently deployed to delegitimise some interests, views, and topics and to valorise others" (Fraser, 1990, p. 73). As seen in both the Wainuiomata and Johnsonville case studies, notions of private space have resulted in the exclusion of community members and council from decision-making, despite the significant impact that these decisions will have on the community in particular.

Fraser argues that when something is relegated to the private sphere, it acts to exclude people from public debate. "The issues in question here are cast as impersonal market imperatives or as "private" ownership prerogatives or as technical problems for managers and planners, all in contradiction to public political matters" (Fraser, 1990, p. 73). A number of authors have articulated other ways of understanding space, whereby ownership is only one factor amongst others (Roy, 2005). For Vallance et al. (2017), the ways in which a space is used is understood to provide a more accurate definition of a space.

If we chose to instead examine spaces by other values rather than ownership, urban development may change radically. If the needs and desires of the collective citizenry were central to urban development policy and practice there would be a need to focus on how spaces are used and created (the active production of space) rather than simply their legal category (Newman, 2011; Pickerill \& Chatterton, 2006). This would mean that the Wainuiomata and Johnsonville malls would be conceived of as important sites of community cohesion, community identity and pride formation and hence the decision-making mechanisms around these spaces would reflect this broader role.

As mentioned previously, participants spoke of needing to own a portion of a development in order to ensure decision-making influence. However Lefebvre's approach goes further suggesting that in order to achieve true democracy, communities should have a seat at the corporate decision-making table irrespective of needing to financially invest into this space. Lefebvre argues that democracy should not be confined to state decisions, but instead that it should "apply to all decisions that contribute to the production of urban space" (Purcell, 2002, p. 102). He argues that there needs to be a restructuring of power relations which "underlie 
the production of urban space, fundamentally shifting control away from capital and the state and toward urban inhabitants"(Purcell, 2002, p. 102). Reframing decisionmaking processes in order to give communities an 'as of right' direct voice in any decision that relates to their urban space (Purcell, 2002) whether it is in private ownership or not, empowers communities in radical ways to be central to key decisions made about their neighbourhoods, towns and cities.

\subsection{Moving toward 'just' community spaces}

There is a growing set of challenges both to this binary of space and the inalienable property rights attached to this demarcation. This challenge has come in many forms. One of these forms is through community protest and wider activism, which have sought to challenge the 'truths' regarding space. Activist groups globally have sought to oppose this binary and the hierarchy of power it produces. Instead, they publically create alternative realities for space, confusing these strict categories and in doing so reduce the "the authority of the people who own it" (Blomley, 2004, p. 32). Previous events have included picnics in the entrance halls of banks and privatised parks (Blomley, 2004).

A series of court cases in the United States have also sought to challenge these inalienable private property rights and broader conceptions of what a public or private space is. The first time that the US courts addressed this issue of individual versus private rights was in Marsh v Alabama in 1946 (Kohn, 2004). The context of this case was that a Jehovah witness was arrested for handing out religious pamphlets in a town which was company owned. However, his arrest was challenged as it was seen to be a violation of his first amendment right to religious freedom (Kohn, 2004). The ruling found in favour of the individual distributing the pamphlets, emphasising the rights of citizens over the companies private property rights (Kohn, 2004). The Justice of this decision stressed the rights of citizens, which should be available to all regardless of whether a public or a private organisation owns one's town (Kohn, 2004).

While the company involved in this case based their argument on the rights they had as owners of private property, the judge declared that "the right to private property is not absolute" (Kohn, 2004, p. 71). This decree was based on the argument that when 
a private company is performing public functions, such as in this case, then "it opens itself up to greater government scrutiny and regulation" (Kohn, 2004, p. 71). Because the town was accessible to the public and invited people in, it meant that it had 'quazi public obligations'. The court argued that "the more an owner, for his advantage, opens up his property for use by the public in general, the more do his rights become circumscribed by the statutory and constitutional rights of those who use it" (Kohn, 2004, p. 71). This case has challenged the binaries of public space and inalienable property rights and instead sought to understand the function of the space and allocated rights based on this. It also addressed ideas of spatial justice, as it sought to provide equal opportunities for religious freedom independent of the ownership of the town.

Another court case, acknowledged the function that shopping malls play beyond retail and instead sought to limit private property rights to ensure vital spaces for democracy. This case was called New Jersey Coalition Against the War in the Middle East et al. v. J. M. B. Realty Corporation et al and related to a group of organisations seeking to be able to hand out leaflets in a number of malls (Maniscalco, 2015). There was a concern that if the law did not provide a mechanism to support civic society and opportunities for free speech within these spaces, democracy would be severely restricted (Maniscalco, 2015). The justice argued, that due to the "unprecedented growth of shopping centres throughout the state...their owners now shared a civic responsibility with urban municipalities" (Maniscalco, 2015, p. 190). He argued that free speech was still compatible with commercial operations and sought to create spaces for political expression within shopping malls (Maniscalco, 2015). However, as a result of political pressure these were limited to providing restricted opportunities for political engagement within shopping malls (Maniscalco, 2015). Despite this, this case acknowledged the civic role that malls played within this state, the ruling justice chose "to look at spatiality and functionality over property and title" (Maniscalco, 2015, p. 190). 
In recognition of these court cases and the wider impacts of shopping malls on democracy, five states have placed restrictions on the private property rights of these malls. In New York, a law ensures that privately owned complexes with a minimum of 20 shops and larger than 250,000 square feet have to have a place in which citizens can engage in non-disruptive political discussion (Kohn, 2004). This is in order to ensure that privatisation still allows for an active civic life (Kohn, 2004). However amongst these five, New Jersey was the only state which was understood to "interpret the constitution broadly enough to apply to social places that are not owned by the state" (Kohn, 2004, p. 134).

Nevertheless, the court cases described above have been understood as 'outliers' and cases before and since these have reverted back to ideas of inalienable private property rights. In fact Maniscalco (2015) has argued that "state action doctrine has consistently proven hostile to the practice of public space in privately owned malls" (p. 202). Both Kohn (2004) and Maniscalco (2015) argue that society has changed immensely since laws relating to private spaces were created. Particularly in relation to the prevalence of shopping mall and the growing privatisation of public spaces. Maniscalco (2015) argues, "ultimately the laws that govern property and space will expand or encroach on the legitimacy of public practices within a community" ( $p$. 204). Expanding this idea, he claims,

I believe that shopping centres- whether they are appointed with indoor or outdoor mall and common areas- ought to be treated by courts as publically functional places, where new suburbanites are legally permitted to advance their claims of diverse identity and ideology in the open, as well as visibly negotiate them in representational space (Maniscalco, 2015, p. 221).

These cases from the US, focus primarily on wider issues of democracy. However, their arguments can also be transferred to the ideas of community decision-making guiding this thesis. As noted by the Johnsonville focus group participants they didn't see private ownership as inherently bad, but instead they saw a need for restrictions to private property rights. These court cases and state-based restrictions demonstrate that restrictions within these spaces are possible and can be justified based on the function of these shopping malls. Lefebvre argued that growing capital accumulation and its accompanied power acted as a threat to liberal democracies (Purcell, 2002). 
He argued for checks to this power, which current conceptions of public and private did not allow for, but which inhabitants as decision makers would (Purcell, 2002). In the chosen case studies, this way of acknowledging the inhabitants of the space would allow for a development which would work for all. Sanoff (2005) also argues that in order to achieve true participatory democracy, decision-making within local and also private organisations needs to be fully democratised in order to even attempt true democracy on the national level. These court cases demonstrate that an alternative conceptualisation of property rights and space is possible.

\subsection{Summary}

This section has demonstrated the ways in which private property rights and the binary of space categorisation has acted to disempower citizens and communities. The implications of which have been discussed in relation to broader issues of spatial injustice. However, this chapter has also revealed the ways in which these discourses around space and property have been created, and how another construction is possible. One which is crucial if we are to achieve any semblance of a true urban democracy. The aforementioned court cases provide indications of how these theoretical arguments have been put into practice, where the function of a space is understood to be a central consideration when ascribing property rights. 


\section{Conclusions}

This thesis found that despite their private ownership and primary retail function, shopping malls can also play an important community role. This function is particularly pronounced in communities which lack public or community space such as the case study locations, Wainuiomata and Johnsonville. However, despite this important community function and the impact of the decline of the malls, community members have been unable to contribute to decision-making regarding this space. This lack of agency is attributed to the private ownership of these spaces, and the property rights that accompany them. Because the dominant model for defining space is based on ownership rather than everyday use, these community claims to space have been silenced. This thesis challenges this silencing, highlighting the implications that this has for community self-determination, spatial justice and broader ideas of participatory democracy. It instead argued for a more inclusive way of conceptualising space, one which recognises spatial practice and attributes rights based on this.

This concluding chapter will recount the main arguments of this thesis based on both the research findings and the broader literature. It will reiterate the significance of this research area as well as present some of the limitations of this thesis. During this research, a range of additional research avenues became apparent. These have also been detailed as have a series of policy recommendations that seek to alleviate or remedy concerns relating to the role of the mall in suburban communities.

\subsection{Conclusion of findings}

The overarching objective guiding this research was to understand the role that suburban shopping malls can play as community spaces, and to examine the extent to which communities are able to shape decisions regarding these spaces. This objective has been met throughout the different chapters in this thesis.

The second chapter of this thesis provided a detailed explanation of both the philosophical underpinnings of this research and the methods by which the research 
questions were answered. The constructivist epistemology guided all elements of this thesis from both its conception, data collection and analysis.

The third chapter of this thesis introduced the case study locations of Wainuiomata and Johnsonville. Both were characterised by years of unfulfilled promises relating to a mall redevelopment and community frustration over the mall's subsequent decline.

The academic context of this field of inquiry was addressed in chapter 4 . This chapter presented the dominant ways in which space is defined and how property rights are ascribed to these categorisations. It contextualised concerns regarding the privatisation of public space in relation to these rights, which pit owners' rights over those of the community. Shopping malls were then introduced as a key urban form synonymous with this trend. The literature demonstrated that despite the widespread criticisms relating to these spaces, a number of which are a result of their private property rights, shopping malls have been understood to play important socialisation and community functions. This role is particularly prevalent in communities which lack alternative forms of public space. However, this chapter explained that globally shopping malls were in decline, and communities were losing an important community space without it ever being recognised as such. A number of authors critiqued the dominant ways of understanding space and instead spoke of needing to reconceptualise this, in order to support existing forms of community space. Finally, this section demonstrated a gap in the literature which this thesis responded to. This was in understanding not only the community role of suburban shopping centres in Aotearoa, New Zealand but also in understanding the decision-making frameworks regarding these spaces more generally.

This research answered this objective by splitting this thesis into two sections. The first section, which included chapters five and six, addressed the first two research questions. These questions asked 'what role can shopping malls play as community spaces and what are the elements within them which facilitate this role? And 'what are the impacts on the community when the local mall declines?' Chapter five details the findings from the thematic analysis which was conducted on the interview and focus group transcripts. It demonstrated that while the community function that the 
mall performs varies across the case studies, in both spaces these shopping malls had become more than spaces of consumption and instead were understood to be proxy community spaces. In Wainuiomata, the mall was identified as a site for socialisation and community building, while in Johnsonville it was seen to be a source of suburban identity and the spatial equivalent of a town square. A key element which facilitated these roles was the lack of alternative public space within these communities. This chapter also addressed the decline of these malls, and how this impacted on their community function. It found that a successful retail function was crucial to ensuring the community function of the mall. As a result of less foot traffic and reduced goods and services, fewer people used these spaces. This lead to a loss of this socialisation role in Wainuiomata, and an inability for community members to engage within their community in both locations. This in turn impacted on the pride they felt for their communities and also reduced opportunities to build social connections. The malls' decline was also seen to disproportionately affect those with mobility restrictions, particularly the elderly. Chapter six related these findings to the literature demonstrating that these two case studies are not anomalies, and instead spoke of wider community uses of these spaces more generally.

Based on the findings from research question one and two, namely that the mall played a crucial community role and its decline had a severe impact on the community, the subsequent two research questions sought to understand the ways in which community members were able to contribute to decisions relating to these spaces. The research questions for chapters seven and eight were, 'to what extent are community members able to influence decision-making regarding this space?' and 'what strategies might be employed to enable stronger community engagement in decision-making processes?' Chapter seven demonstrated the insufficiency of the mall owner's engagement and communication with the affected communities. This had led to a sentiment that the mall owners did not care about either community. There was a strong desire for the owners to be more upfront and for the community to be recognised as a key stakeholder, who not only support the mall but are impacted by its decline. Within this, participants expressed their frustration that neither they nor their representatives, council, could influence decisions relating to this space. This exclusion was linked to the private ownership of the mall and the power imbalance within this situation. Participants then sought mechanisms to 
change this balance in order to ensure they were able to contribute to the decisions relating to these spaces. Legislative and regulatory mechanisms were spoken of, as were potential opportunities for public-private partnerships or the public provision of community facilities.

The following chapter then linked the key themes from the previous chapters to demonstrate the need to critique notions of public and private space and the property rights attributed to them. It discussed the way in which these designations acted to disempower communities, reducing their ability to contribute to the decisions which most affect them. This chapter argued that this lack of community agency in decision-making linked to wider issues of spatial injustice, leaving some communities unable to self-determine while others could, solely dependent on the ownership of their community spaces. This chapter sought to dismantle these strict binaries of space, instead suggesting a definition based on the way in which these spaces are used, and attributing rights to these spaces in relation to this.

\subsection{Policy recommendations}

This thesis has shown the need to reconceptualise spaces within local government policy and practice based on the ways in which they are used, and not simply within the binary of 'public' and 'private'. Community claims to space and their subsequent rights to engage in decision-making are important areas to acknowledge in order to ensure spatial justice and equal opportunities for participatory democracy. There are a number of mechanisms which could be put in place to ensure that despite some communities living in areas which are predominantly owned by a corporate, they still have as much opportunity as others for self-determination.

1. When issuing resource consents for key sites and large developments such as shopping malls, stipulations must be made to the site owners of their obligations to the community.This should form part of a legally binding contract. Community members should set these obligations.

2. An analysis for how each private space is used in a community should be conducted in order to determine the extent to which communities can participate within decision-making regarding the space. 
3. If large sections of a community are being sold to a single developer, negotiations need to occur prior to reach a compromise. In order to meet the communities ability to self-determine coupled with meeting business interests.

4. When a development declines, rather than before it is developed, it is also necessary to have protective mechanisms in place for this eventuality. The resource consent process could provide this by the inclusion of a timeframe by which a development must begin to be constructed.

\subsection{Academic contribution}

The most significant way in which this research has contributed to the literature is that it has made visible a form of community space within New Zealand, which normally would not be recognised as such. By raising an awareness of the roles that suburban shopping malls can play as community space, it makes visible community claims to space and challenges the existing framework of property rights and subsequent wider community exclusion from decision-making.

\subsection{Limitations of this study}

Two case studies were used in this research, in order to provide a more comprehensive analysis of this phenomenon as well as increase the generalisability of these findings. However, these case studies are both located in the Wellington Region. It would be beneficial to expand this research using case studies across New Zealand in order to understand the extent of the issue throughout New Zealand in different local government jurisdictions.

The research disappointingly does not include the perspective of the mall owners. Unfortunately, the mall owners and management of both case studies declined to take part in this research after repeated attempts to engage with them. Their involvement in this research would have contributed to a more holistic piece of work. So while this research has attempted to engage a variety of people from differing contexts, unfortunately, one side of this story is not told here.

Another significant limitation is the nature of the ways in which my focus groups were conducted. Due to being an outsider to these case study locations, two of the 
three focus groups participants were pooled by outsiders. This meant that these groups were not wholly representative of the general population. Also, the use of social media solely as a recruitment tool would have influenced the subset of people who formed the general Johnsonville focus group.

The final limitation of this research is the order in which I conducted this research. I spoke to key participants before conducting the focus groups. This was beneficial in terms of allowing me to understand the context of the situation and meant that I was able to ask relevant questions in the focus groups. However, it also meant that some things were brought up in the focus group that I would have liked to explore further in depth with the relevant key informants. Due to the time restrictions of this thesis and busy timetables for the interviewees, this was unable to happen.

\subsection{Further research avenues}

As a response to the findings from this thesis, a number of research avenues have been illuminated and are deemed worthy of exploration

1. The availability of goods and services in one's local community was closely tied to issues of accessibility and spatial justice. In a time of neoliberalism and increasing efficiency, a number of social services are being centralised and consolidated, such as banks and post offices. What are the impacts of this, and are they felt disproportionately amongst the different population and socio-economic groups who tend to sit on the margins of cities away from such centralised services?

2. While this research has used shopping mall case studies, the basic argument of this thesis revolved around how private interests and community interests within a space can be negotiated. It would be interesting to see how community planning projects such as the Karori project (Wellington) were able to negotiate these private interests. Relatedly, the differences in decision-making involvement for lower socio-economic communities versus higher income communities would be of interest to compare.

3. It would be important to explore models of decision-making that enable a community to be involved more directly and how these could be applied to phenomenon such as privatised public spaces. 
4. Finally, the extent of this privatisation of key central across New Zealand would be important to map, not simply in terms of shopping malls, but other large-scale developments or property ownership which monopolise towns or cities. A global comparison, particularly to North America could provide insightful findings.

\subsection{Conclusion}

Using case studies of suburban shopping malls, this thesis has demonstrated the need to reconceptualise the way in which we categorise space and the property rights ascribed to these. This is particularly important within the context of increasing privatisation, where the nature of public service provision is changing. In relation to this change, property rights and spatial categories need to be addressed in order to ensure the formation of 'just' and equitable communities. 


\section{References}

.id Consulting. (2013a). Johnsonville: Employment status. Retrieved from http://profile.idnz.co.nz/wellington/employment-status?WebID $=200$ .id Consulting. (2013b). Johnsonville: Ethnic groups. Retrieved from http://profile.idnz.co.nz/wellington/ethnic-group?WebID=200 .id Consulting. (2013c). Johnsonville: Individual income. Retrieved from http://profile.idnz.co.nz/wellington/individual-income? WebID $=200$ .id Consulting. (2013d). Johnsonville: Industry sector employment. Retrieved from http://profile.idnz.co.nz/wellington/industries?WebID $=200$ .id Consulting. (2013e). Johnsonville: Population, dwellings and ethnicity. Retrieved from http://profile.idnz.co.nz/wellington/population?WebID=200 Abaza, M. (2001). Shopping malls, consumer culture and the reshaping of public space in Egypt. Theory, Culture \& Society, 18(5), 97-122.

Al, S. (2016). Mall City: Hong Kong's Dreamworlds of Consumption. Hong Kong, China: University of Hawai'i Press.

Alexander, V. (2000). Tales from the Swamp. Wainuiomata, New Zealand: Wainuiomata Historical Museum Society.

Banerjee, T. (2001). The Future of Public Space: Beyond Invented Steets and Reinvented Places. Journal of the American Planning Association, 67(1), 924.

Barbour, R., \& Schostak, J. (2005). Interviewing and Focus Groups. In B. Somekh \& C. Lewin (Eds.), Research Methods in the Social Sciences (pp. 41-48). London, UK: SAGE Publications.

Barry, C. (2016). The mall is not a Wainuiomata problem; it's a mall problem. Retrieved from http://campbellbarry.co.nz/the-mall-is-not-a-wainuiomataproblem-its-a-mall-problem/

Baxter, P., \& Jack, S. (2008). Qualitative Case Study Methodology: Study Design and Implementation for Novice Researchers. The qualitative report, 13(4), 544-559.

Bedford, T., \& Burgess, J. (2001). The Focus-group Experience. In M. Limb \& C. Dwyer (Eds.), Qualitative Methodologies for Geographers: Issues and Debates (pp. 121-135). New York, NY: Arnold. 
Berry, G. R. (2003). Organizing Against Multinational Corporate Power in Cancer Alley: The Activist Community as Primary Stakeholder. Organization \& Environment, 16(1), 3-33.

Bloch, P. H., Ridgway, N. M., \& Dawson, S. A. (1994). The shopping mall as consumer habitat. Journal of Retailing, 70(1), 23-42. doi:https://doi.org/10.1016/0022-4359(94)90026-4

Blomley, N. K. (2004). Unsettling the city: Urban land and the politics of property. London, UK: Routledge.

Bodzin, S., \& Greenberg, E. (2001). What to do with Greyfields. Places, 14(1).

Braun, V., \& Clarke, V. (2006). Using thematic analysis in psychology. Qualitative research in psychology, 3(2), 77-101.

Brill, M. (2001). Mistaking Community Life for Public Life. Places, 14(2).

Bromley, R. D., \& Thomas, C. T. (1995). Small town shopping decline: dependence and inconvenience for the disadvanged. International Review of Retail, Distribution and Consumer Research, 5(4), 433-456.

Byrne, M. M. (2001). Linking philosophy, methodology, and methods in qualitative research. AORN journal, 73(1), 207-210.

Cameron, J. (2010). Focusing on the Focus Group. In I. Hay (Ed.), Qualitative Research Methods in Human Geography (pp. 152-172). Ontario, Canada: Oxford University Press.

Carmona, M. (2015). Re- theorising contemporary public space: a new narrative and a new normative. Journal of Urbanism: International Research on Placemaking and Urban Sustainability, 8(4), 373-405.

Carr, S., Francis, M., Rivlin, L., \& Stone, A. (1992). Public space. Cambridge, UK: Cambridge University Press.

Chacko, E. (2004). Positionality and Praxis: Fieldwork Experiences in Rural India. Singapore Journal of Tropical Geography, 25(1), 51-63.

Chu, C. (2016). Narrating the mall city. In S. Al (Ed.), Mall city: Hong Kong's dreamworlds of consumption (pp. 83-93). Hong Kong: Hong Kong University Press.

Cohen, L. (2003). A Consumers' Republic: The Politics of Mass Consumption in Postwar America. New York, USA: Random House Inc. 
Conradson, D. (2005). Focus Groups. In R. Flowerdew \& D. Martin (Eds.), Methods in Human Geography: A Guide for Students Doing a Research Project (pp. 128-143). London, UK: Pearson Education.

Costantino, T. (2008). Constructivism. In L. Given (Ed.), The SAGE Encyclopedia of Qualitative Research Methods (Vol. 1). London, UK: SAGE Publications.

Cowen, D. (2005). Suburban citizenship? The rise of targeting and the eclipse of social rights in Toronto. Social \& cultural geography, 6(3), 335-356.

Crayton-Brown, B. (2016, 11/07/2017). Wainuiomata Mall loses another tenant, with Warehouse closing in February. Stuff. Retrieved from http://www.stuff.co.nz/business/82259892/Wainuiomata-Mall-loses-anothertenant-with-Warehouse-closing-in-February

Creswell, J. W. (2014). Research Design: Qualitative, Quantitative, and Mixed Methods Approaches (4th ed.). London, UK: SAGE Publications

Davies, B., \& Gannon, S. (2005). Feminism/Postructuralism. In B. Somekh \& C. Lewin (Eds.), Research Methods in the Social Sciences (pp. 318-325). London, UK: SAGE Publications.

Day, K. (1999). Introducing gender to the critique of privatized public space. Journal of Urban Design, 4(2), 155-178.

Department of Internal Affairs. (2011a). Councils' roles and functions. Retrieved from http://www.localcouncils.govt.nz/lgip.nsf/wpg_url/About-LocalGovernment-Local-Government-In-New-Zealand-Councils-roles-andfunctions

Department of Internal Affairs. (2011b). How councils should make decisions. Retrieved from http://www.localcouncils.govt.nz/lgip.nsf/wpg url/AboutLocal-Government-Local-Government-In-New-Zealand-How-CouncilsShould-Make-Decisions?OpenDocument

Devlin, C. (2016). New plans for $\$ 150 \mathrm{~m}$ redevelopment of Johnsonville Shopping Centre. Stuff. Retrieved from http://www.stuff.co.nz/business/84688796/newplans-for-150m-redevelopment-of-johnsonville-shopping-centre

Dowling, R. (2010). Power, Subjectivity and Ethics in Qualitative Research. In I. Hay (Ed.), Qualitative Research Methods in Human Geography (pp. 26-39). Ontario, Canada: Oxford University Press. 
Duggan, M., \& Brenner, J. (2013). The Demographics of Social Media Users, 2012. Retrieved from Online:

http://boletines.prisadigital.com/PIP SocialMediaUsers.pdf

Duncan, H., Travis, S., \& McAuley, W. (1995). The Meaning of and Motivation for Mall Walking Among Older Adults. Activities, Adaptation \& Aging, 19(1), $37-52$.

Dunham-Jones, E., \& Williamson, J. (2017). Dead and Dying Shopping Malls, ReInhabited. Architectural Design, 87(5), 84-91.

Dunn, K. (2010). Interviewing. In I. Hay (Ed.), Qualitative Research Methods in Human Geography (pp. 101-138). Ontario, Canada: Oxford University Press.

Edwards, J., \& Shadwell, T. (2016). Wainuiomata residents fear mall's struggle could spell disaster for suburb. Stuff. Retrieved from http://www.stuff.co.nz/business/industries/76022228/wainuiomata-residentsfear-malls-struggles-could-spell-disaster-for-suburb

England, K. V. (1994). Getting personal: Reflexivity, Positionality, and Feminist Research. The Professional Geographer, 46(1), 80-89.

Feinberg, R. A., Sheffler, B., Meoli, J., \& Rummel, A. (1989). There's something social happening at the mall. Journal of Business and Psychology, 4(1), 4963.

Ferreira, D., \& Paiva, D. (2017). The death and life of shopping malls: an empirical investigation on the dead malls in Greater Lisbon. The International Review of Retail, Distribution and Consumer Research, 27(4), 317-333.

Filkins, R., Allen, J. C., \& Cordes, S. (2000). Predicting Community Satisfaction Among Rural Residents: An Integrative Model. Rural Sociology, 65(1), 7286.

Flinders, M. (2005). The Politics of Public-Private Partnerships. The British Journal of Politics and International Relations, 7(2), 215-239.

Flowerdew, R., \& Martin, D. (2005). Methods in Human Geography: a Guide for Students Doing a Research Project. London, UK: Pearson Education

Forbes, M. (2016). Fears for the future of Wellington's Johnsonville mall as retailers pack up. Stuff. Retrieved from http://www.stuff.co.nz/business/80360674/fears-for-the-future-ofwellingtons-johnsonville-mall-as-retailers-pack-up 
Foucault, M. (1970). The order of things: An archaeology of the human sciences. New York, NY: Random House USA INC.

Fraser, N. (1990). Rethinking the public sphere: A Contribution to the Critique of Actually Existing Democracy. Social text, 25(26), 56-80.

Freeman, R. E. (1984). Strategic Management: A Stakeholder Approach. Cambridge, UK: Cambridge University Press.

Garrett, B. (2016). The privatisation of cities' public spaces is escalating. It is time to take a stand. The Guardian. Retrieved from https://www.theguardian.com/cities/2015/aug/04/pops-privately-ownedpublic-space-cities-direct-action

Gruen, V. (2017). Shopping Town: Designing the City in Suburban America (A. Baldauf Ed.). Minneapolis, MN: University of Minnesota Press.

Guerin, K. (2003). Property Rights and Environmental Policy: A New Zealand Perspective. Retrieved from Online: https://treasury.govt.nz/publications/wp/property-rights-and-environmentalpolicy-new-zealand-perspective-wp-03-02-html

Hardwick, J. (2014). Mall Maker: Victor Gruen, Architect of an American Dream. Philidelphia, PA: University of Pennsylvania Press.

Harrell, R., Lynott, J., Guzman, S., \& Lampkin, C. (2014). What is Livable? Community Preferences of Older Adults. Retrieved from Online: http://www.ifa-fiv.org/wp-content/uploads/2014/07/what-is-livable-reportAARP-ppi-liv-com.pdf

Harvey, D. (2003). The right to the city. International Journal of Urban and Regional Research, 27(4), 939-941.

Harvey, D. (2016). The Right to the City. In R. LeGates \& F. Stout (Eds.), The City Reader. New York, NY: Routledge.

Hass, A. (2008). New Urbanism and Beyond: Designing Cities for the Future. New York; Rizzoli.

Hennik, M., Hutter, I., \& Bailey, A. (2011). Qualitative Research Methods. Los Angeles, CA: SAGE Publications.

Hirokawa, R. Y., \& Poole, M. S. (1996). Communication and Group Decision Making (Vol. 77). London, UK: SAGE Publications.

Hopkins, J. S. (1991). West Edmonton Mall as a centre for social interaction. The Canadian Geographer/Le Géographe canadien, 35(3), 268-279. 
Iveson, K. (2013). Cities within the City: Do-it-Yourself Urbanism and the Right to the City. International Journal of Urban and Regional Research, 37(3), 941956.

Jackson, P. (1998). Domesticating the Street: The Contested Space of the High Street and the Mall. In N. Fyfe (Ed.), Images of the Street: Planning, Identity and Control in Public Space (pp. 176-191). London, UK: Routledge.

Jacobs, J. (1984). The Mall: An attempted escape from everyday life Chicago, IL: Waveland Press.

Jolliff, E. (2017). Wainuiomata Shopping Centre gets new lease on life Newshub. Retrieved from http://www.newshub.co.nz/home/newzealand/2017/03/wainuiomata-shopping-centre-gets-new-lease-of-life.html

Kim, B. (2012). Social Cnstructivism. Emerging perspectives on learning, teaching, and technology, 1(1), 16.

Kim, J., \& Kaplan, R. (2004). Physical and Psychological Factors in Sense of Community: New Urbanist Kentlands and Nearby Orchard Village. Environment and behavior, 36(3), 313-340.

Kim, Y. K., Kang, J., \& Kim, M. (2005). The relationships among family and social interaction, loneliness, mall shopping motivation, and mall spending of older consumers. Psychology \& Marketing, 22(12), 995-1015.

Kobayashi, A. (2001). Negotiating the personal and the political in critical qualitiative research In M. Limb \& C. Dwyer (Eds.), Qualitative Methodologies for Geographers: Issues and Debates (pp. 55-70). Ontario, Canada: Oxford University Press.

Kohn, M. (2004). Brave New Neighborhoods: The Privitisation of Public Space. New York, NY: Routledge.

Kowinski, W. (1985). The Malling of America: An inside look at the Great Consumer Paradise. New York, NY: William Morrow and Company.

Larner, W., \& Walters, W. (2000). Privatisation, governance and identity: the United Kingdom and New Zealand compared. Policy \& Politics, 28(3), 361-377.

Laurenson, H. (2018a). Decline and survival Te Ara- the encylopedia of New Zealand. Online: Te Ara.

Laurenson, H. (2018b). Department stores and shopping malls- New Zealand's main malls Te Ara- The encycloedia of New Zealand. Online: Te Ara. 
Laurenson, H. (2018c). Mall and department store culture Te Ara- the encylopedia of New Zealand. Online: Te Ara.

Laurenson, H. (2018d). New Zealand's main malls Te Ara- the encylopedia of New Zealand. Online: Te Ara.

Laurenson, H. (2018e). The rise of shopping malls Te Ara- the encylopedia of New Zealand. Online: Te Ara.

Laurenson, H. (2018f). Story: Department stores and shopping malls Te Ara- The encylopedia of New Zealand. Online: Te Ara.

Lees, L. (1994). Urban Public Space and Imagined Communities in the 1980s and 1990s. Journal of urban history, 20(4), 443-465.

Lefebvre, H. (1991). The Production of Space. Hoboken, NJ: Blackwell Publishing

Lefebvre, H. (1996). Writings on Cities. Malden. MA: Blackwell Publishers.

Lewis, G. (1990). Community Through Exclusion and Illusion: The Creation of Social Worlds in an American Shopping Mall. Journal of Popular Culture, 24(2), 121-136.

Ley, D., \& Mountz, A. (2001). Interpretation, representation, positionality: issues in field research in human geography. In M. Limb \& C. Dwyer (Eds.), Qualitative Methodologies for Geographers: Issues and Debates (pp. 234247). Ontario, Canada: Oxford University Press.

Lochner, K., Kawachi, I., \& Kennedy, B. P. (1999). Social capital: a guide to its measurement. Health \& place, 5(4), 259-270.

Lomnitz, C. (2012). Urban insecurity has made public spaces of Mexico's shopping malls. Retrieved from http://www.publicspace.org/en/post/urban-insecurityhas-made-public-spaces-of-mexico-s-shopping-malls

Low, S. M. (2006). The Erosion of Public Space and the Public Realm: paranoia, surveillance and privatization in New York City. City \& Society, 18(1), 4349. doi:10.1525/city.2006.18.1.43

MacAndrew, R. (2017a). Fears for future of Johnsonville mall as McDonald's and OPSM become latest to leave. Stuff. Retrieved from http://www.stuff.co.nz/dominion-post/business/commercialproperty/93951972/fears-for-future-of-johnsonville-mall-as-mcdonalds-andopsm-become-latest-to-leave

MacAndrew, R. (2017b). Lack of Johnsonville Mall progress angers residents left in the dark over redevelopment plans. Stuff. Retrieved from 
http:/www.stuff.co.nz/dominion-post/business/commercial-

property/92957818/Lack-of-Johnsonville-Mall-progress-angers-residents-

left-in-the-dark-over-redevelopment-plans

Maclean, C. (2007). Wellington places- Northern suburbs Te Ara- the Encyclopedia of New Zealand. Online

Madanipour, A. (2003). Public and Private Spaces of the City. London, UK: Routledge.

Madanipour, A. (2016). Culture and Tolerance in Public Space Space and Pluralism: Can Contemporary Cities Be Places of Tolerance (pp. 35-54). Budapest, Hungrary: Central European University Press.

Maniscalco, A. (2015). Public Spaces, Marketplaces, and the Constitution: Shopping Malls and the First Amendment. Albany, NY: State University of New York Press.

Mason, B. (2017). You SHALL go to the mall... Retrieved from https://talkwellington.org.nz/2017/you-shall-go-to-the-mall/

Michels, A., \& De Graaf, L. (2010). Examining Citizen Participation: Local Participatory Policy Making and Democracy. Local Government Studies, $36(4), 477-491$.

Ministry for the Environment. (2005). New Zealand Urban Design Protocol.

Retrieved from Online: http://www.mfe.govt.nz/publications/towns-andcities/new-zealand-urban-design-protocol/2-attributes-successful-towns-and

Ministry for the Environment. (2015). An everyday guide: Consultation for resource consent applicants. Retrieved from Online:

http:/www.mfe.govt.nz/publications/fresh-water/everyday-guideconsultation-resource-consent-applicants/everyday-guide

Mohammad, R. (2001). 'Insiders' and/or 'outsiders': positionality, theory and praxis. In M. Limb \& C. Dwyer (Eds.), Qualitative Methodologies for Geographers, Issues and Debates. Ontario, Canada: Oxford University Press

Moreno, M. (2010). "Porosity and play: sustaining public life in New Zealand's suburban shopping centres". Master's thesis, Victoria University of Wellington.

Morrison, P. S. (2016). Pride and the city. Region, 3(2), 103-124.

Newman, S. (2011). Postanarchism and space: Revolutionary fantasies and autonomous zones. Planning theory, 10(4), 344-365. 
Ng, J. (2009). Paradigm City: Space, Culture, and Capitalism in Hong Kong. Albany, NY: State University of New York Press.

Nicoll, J. (2017a). Makeover on the cards as Countdown owner buys ailing Wainuiomata mall Stuff. Retrieved from http://www.stuff.co.nz/dominionpost/business/commercial-property/90101961/Makeover-on-the-cards-asCountdown-owner-buys-ailing-Wainuiomata-mall

Nicoll, J. (2017b). Revamp of Wellington's Johnsonville Shopping Centre gets resource consent. Stuff. Retrieved from http://www.stuff.co.nz/business/90292179/Revamp-of-WellingtonsJohnsonville-Shopping-Centre-get-resource-consent

Nowek, A. (2016). The Prescience of Malls. In S. Al (Ed.), Mall City: Hong Kong's Dreamworld's of Consumption. Hong Kong, China: University of Hawai'i Press.

Nowell, B. L., Berkowitz, S. L., Deacon, Z., \& Foster-Fishman, P. (2006). Revealing the Cues Within Community Places: Storiesof Identity, History, and Possibility. American journal of community psychology, 37(1-2), 63-76.

Parkinson, J. (2012). Democracy and Public Space: The Physical Sites of Democratic Performance. Oxford, NY: Oxford University Press.

Parlette, V., \& Cowen, D. (2011). Dead Malls: Suburban Activism, Local Spaces, Global Logistics. International Journal of Urban and Regional Research, 35(4), 794-811.

Pattison, C. (2015). Village gossip-stories of Napoleon Street and the evolving community role of local shopping. Oral History Australia Journal, 1(37), 7.

Phoenix, A. (1991). Social Research in the Context of Feminist Psychology. In E. Burman (Ed.), Feminsts and Pyschological Practice (pp. 89-103). London, UK: SAGE Publications.

Pickerill, J., \& Chatterton, P. (2006). Notes towards autonomous geographies: creation, resistance and self- management as survival tactics. Progress in Human Geography, 30(6), 730-746.

Piper, H., \& Simons, H. (2005). Ethical Responsibility in Social Research. In B. Somekh \& C. Lewin (Eds.), Research Methods in the Social Sciences (pp. 56-63). London, UK: SAGE Publications.

Pospêch, P. (2016). Urban or Family-Friendly? The Presentation of Czech Shopping Centres as Family-Friendly Spaces. Space and Culture, 20(1), 68-80. 
Purcell, M. (2002). Excavating Lefebvre: The right to the city and its urban politics of the inhabitant. GeoJournal, 58(2-3), 99-108.

Roy, A. (2005). Urban Informality: Toward an Epistemology of Planning. Journal of the American Planning Association, 71(2), 147-158.

Sanburn, J. (2017). Why the Death of Malls is About More than Shopping. TIME.

Sanoff, H. (2005). Community participation in riverfront development. CoDesign, $1(1), 61-78$.

Saville-Smith, K., \& James, B. (2003). Building Attachment in Families and Communities Affected by Transience and Residential Mobility: New Research Programme. Paper presented at the Social Policy Research \& Evaluation Conference.

Schwartz, M. (2009). Corporate Social Responsibility. London, UK: Routledge. Sennett, R. (2003). Respect in a World of Inequality. New York: WW Norton \& Company.

Sidenvall, B., Nydahl, M., \& Fjellström, C. (2001). Managing food shopping and cooking: the experiences of older Swedish women. Ageing \& Society, 21(2), 151-168.

Sixsmith, J., Boneham, M., \& Goldring, J. E. (2003). Accessing the Community: Gaining Insider Perspectives From the Outside. Qualitative health research, 13(4), 578-589.

Smith, S. (2001). Introduction: doing qualitative research in geography. In M. Limb \& C. Dwyer (Eds.), Qualitative Methodologies for Geographers: Issues and Debates (pp. 23-35). Ontario, Canada: Oxford University Press.

Soja, E. (2010). Seeking Spatial Justice. Minneapolis, MN: University of Minnesota Press.

Stark, S., \& Torrance, H. (2005). Case Study. In B. Somekh \& C. Lewin (Eds.), Research Methods in the Social Sciences (pp. 33-40). London, UK: SAGE Publications.

Statistics New Zealand. (2013). Wainuiomata. Retrieved from https://www.stats.govt.nz/topics/population/

Tauber, E. M. (1972). Why Do People Shop? The Journal of Marketing, 36(4), 4649.

Te Ara. (2016). Eastern ranges. In Te Ara: the encyclopaedia of New Zealand (Ed.), Te Ara: the Encyclopaedia of New Zealand, . Online Te Ara. 
Travis, S. S., Duncan, H. H., \& McAuley, W. J. (1996). Mall walking: An Effective Mental Health Intervention for Older Adults. Journal of Psychosocial Nursing and Mental Health Services, 34(8), 36-38.

Valentine, G. (2005). Tell me about ...: using interviews as a research methodology. In R. Flowerdew \& D. Martin (Eds.), Methods in Human Geography: A guide for students doing a research project (pp. 110-127). Essex, England: Pearson Education.

Vallance, S., Dupuis, A., Thorns, D., \& Edwards, S. (2017). Temporary use and the onto-politics of 'public' space. Cities, 70, 83-90.

Varna, G., \& Tiesdell, S. (2010). Assessing the Publicness of Public Space: The Star Model of Publicness. Journal of Urban Design, 15(4), 575-598.

Vasudevan, A. (2015). The autonomous city: Towards a critical geography of occupation. Progress in Human Geography, 39(3), 316-337.

Voyce, M. (2006). Shopping malls in Australia: The end of public space and the rise of 'consumerist citizenship'? Journal of sociology, 42(3), 269-286.

Waitt, G. (2010). Doing Foucauldian Discourse Analysis- Revealing Social Realities. In I. Hay (Ed.), Qualitative Research Methods in Human Geography. Ontario, Canada: Oxford University Press.

Weintraub, J., \& Kumar, K. (1997). Public and Private in Thought and Practice: Perspectives on a Grand Dichotomy. Chicago, IL: University of Chicago Press.

Wellington City Council. (2008). Johnsonville Town Centre Plan. Retrieved from Online https://wellington.govt.nz/ /media/your-council/plans-policies-andbylaws/plans-and-policies/a-to-z/johnsonville/files/jville-plan.pdf?la=en

Wellington City Council. (n.d.). Johnsonville Mall redevelopment Retrieved from https://wellington.govt.nz/your-council/projects/johnsonvilleprojects/johnsonville-mall-redevelopment

West, D. M., \& Orr, M. (2003). Downtown Malls as Engines of Economic Development, Community Spirit, and Political Capital. Economic Development Quarterly, 17(2), 193-204.

West Edmonton Mall. (2018). About WEM. Retrieved from http://www.wem.ca/about-wem/overview

White, D., Dougall, K., Mawer, C., Meachen, R., \& Kiddle, R. (2017). Profile of Wainuiomata Community. Unpublished work. 
Yin, R. K. (2013). Case Study Research: Design and Methods. New York, NY: SAGE publications.

Young, I. (1990). Justice and the Politics of Difference. Princeton, NJ: Princeton Univeristy Press. 


\section{Appendices}

\section{Appendix 1: General interview guide for both case study locations}

1. Could you begin by explaining your connection to Wainuiomata / Johnsonville or the wider area?
a. What is your connection to the mall?
b. What are your main activities while you are there?
c. How frequently do you visit?

2. Could you please explain what has been happening with the mall over the last decade?

3. What role does the mall hold in the Wainuiomata/ Johnsonville community?

4. Do you think that the mall has a role in supporting the Wainuiomata/ Johnsonville community/ the wider community around it?

5. Have you had an opportunity to participate in any decision making processes or provide input relating to the state of the mall and its future redevelopment plans?

6. If so, in what way was this possible? Who provided these opportunities?

7. If not, would you have liked to be included? In what way do you envision this inclusion process?

8. What role has council played within this issue?

9. What are your opinions on privately owned spaces?
a. Benefits of this?
b. Disadvantages?
c. Future- are there concerns around what may happen again to this space in the future?

10. Any additional comments you would like to make? 


\section{Appendix 2: General interview participant recruitment email}

Tēnā koe...

My name is Chantal Mawer and I am a student at Victoria University, working towards a Masters of Environmental Studies. I am conducting research for my thesis into the role that malls can play as community spaces. In particular, this research project aims to explore the role that the Johnsonville/ Wainuiomata Mall plays within the community, while also examining how community members can participate in decision making relating to this space. This research is part of a larger government funded research project, which focuses on building better homes, towns and cities. I am interested in the declining nature of the Wainuiomata/ Johnsonville Mall and how this situation has been experienced by its surrounding community.

I was wondering whether you would be interested in including your perspective into this research, and as such, would you be willing to be interviewed? Questions would be related to the role of the mall in Wainuiomata/ Johnsonville, its previous decline and the ways in which the community are able to contribute to decisions regarding this space. Alternatively if you believe there is somebody better suited to answer these questions, I would appreciate any suggestions.

I have attached documents with further information about this research. I understand that this is a busy time of the year, however if you were interested I would be really keen to complete interviews within September or October if possible. Obviously you are very busy and I would aim to only take an hour of your time. I would happily come to you at your convenience, or if you would prefer we have office space at Victoria University also.

If you are interested in talking to me or would like to hear more about this project, please contact me. I look forward to hearing from you soon,

Ngā mihi nui,

Chantal Mawer 


\section{Appendix 3: Human ethics approval}

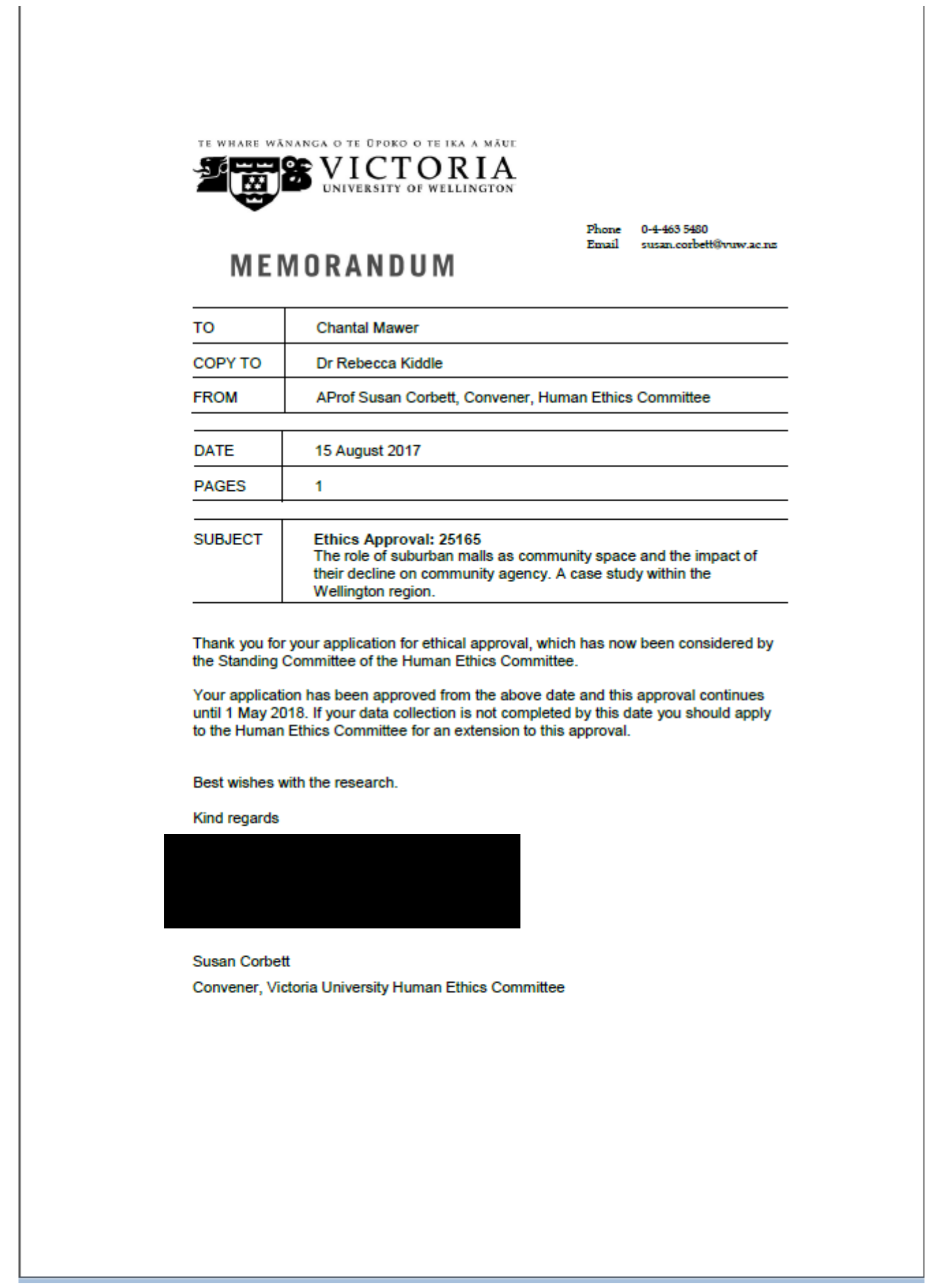




\section{Appendix 4: Interview Information Sheet}

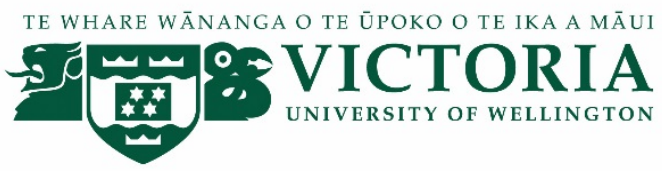

\section{'Suburban Malls as Community Spaces' \\ INFORMATION SHEET FOR POTENTIAL INTERVIEWEES}

Thank you for your interest in this project. Please read this information before deciding whether or not to take part. If you decide to participate, thank you. If you decide not to take part, thank you for considering my request.

\section{Who am I?}

My name is Chantal Mawer and I am a Masters student in Environmental Studies at Victoria University of Wellington. This research project will contribute towards my thesis.

\section{What is the aim of the project?}

This research project aims to explore the role of malls as community places and examine how community members can participate in decision making. It hopes to encourage better processes for community decision making.

This research has been approved by the Victoria University of Wellington Human Ethics Committee 0000025165.

\section{How can you help?}

If you agree to take part, the interview can be arranged at a time and location, which best suits your needs and availability. I will ask you questions about your local mall and your wider community. The interview will take approximately 1 hour. I will audio record the interview with your permission and write up our conversation afterwards. You can choose to not answer any question or stop the interview at any time, without giving a reason. You can also withdraw from the study by contacting me at any time before the 30th of November, 2017. If you withdraw, the information you provided will be destroyed or returned to you.

\section{What will happen to the information you give?}

Your identity will be kept confidential unless you choose to be identified and named in the research. This means that the two researchers named below will be aware of your identity but the research data will be aggregated and your identity will not be disclosed in any reports, presentations, or public documentation if you do not 
choose so. However, you should be aware that in small projects your identity might be obvious to others in your community.

Only the research team will read the direct research notes and see your responses. The data collected will be kept securely and destroyed 5 years after the research ends. However, if you are happy to be named, we would like to attribute the information to you.

\section{What will the project produce?}

The information from this research will be used to construct a Masters thesis and possible academic journal publications. It is hoped that this thesis may in the future, act as an aid to inform best practice for community decision making in privately owned community spaces. It is possible that this research may also be presented at an academic conference.

\section{If you accept this invitation, what are your rights as a research participant?}

You do not have to accept this invitation if you don't want to. If you do decide to participate, you have the right to:

- $\quad$ choose not to answer any questions;

- $\quad$ ask for the recorder to be turned off at any time during the interview;

- withdraw from the study before the 30th of November

- $\quad$ ask any questions about the study at any time;

- $\quad$ receive a copy of your interview recording

- $\quad$ read over and comment on a written summary of your interview

- be able to read any reports of this research by emailing the researcher to request a copy.

\section{If you have any questions or problems, who can you contact?}

If you have any questions, either now or in the future, please feel free to contact either my supervisor or me:

\section{Student:}

Name: Chantal Mawer

Chantal.Mawer@vuw.ac.nz
Supervisor:

Name: Rebecca Kiddle

Role: Lecturer

School: School of Geography, Environment and Earth Sciences

Phone: 044636119

Rebecca.Kiddle@vuw.ac.nz

\section{Human Ethics Committee information}

If you have any concerns about the ethical conduct of the research you may contact the Victoria University HEC Convenor: Associate Professor Susan Corbett. Email susan.corbett@vuw.ac.nz or telephone+64-4-463 5480. 


\section{Appendix 5: Interview consent form}

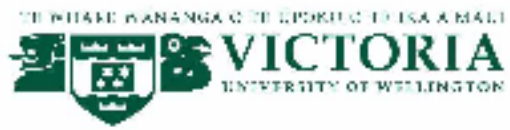 \\ 'Suburban Malls as Community Spaces' \\ CONSENT TO INTERVIEW}

This consent form will be held for 5 years.

Researcher: Chantal Mawer, School of Geography, Environment and Earth Sciences, Victoria University of Wellington.

- I have read the Information Sheet and the project has been explained to me. My questions have been answered to my satisfaction. I understand that I can ask further questions at any time.

- I agree to take part in an audio recorded interview.

I understand that:

- I may withdraw from this study at any point before the $30^{\text {th }}$ of November, 2017, and any information that I have provided will be returned to me or destroyed

- If I remain in the study the identifiable information I have provided will be destroyed on the $1^{\text {ts }}$ of May, 2023.

- Any information I provide will be kept confidential to the researcher and the supervisor if I choose.

- I understand that the results will be used for a Masters thesis, potential academic publications and presentations at academic conferences.

- I am happy for my name to be used in relation to this research Yes $\square$ No $\square$

- I would like to receive a copy of the recording of my interview Yes $\square$ No $\square$

- I would like a summary of my interview $\quad$ Yes $\square$ No $\square$

- I would like to receive a copy of the final report $\quad$ Yes $\square$ No 


\section{Appendix 6: Johnsonville general focus group recruitment advertisement}

\section{FOCUS GROUP PARTICIPANTS WANTED}

Hi all, my name is Chantal Mawer and I am a Masters student at Victoria University. I am looking for 10 Johnsonville residents between the ages of 18-55 to participate in a focus group to discuss the Johnsonville Mall. This focus group is part of a study aiming to explore the role of malls as community places and examine how community members can participate in decision making. This is your chance to have a say regarding the mall.

The focus group will last approximately 60-80 minutes, in exchange for your time, snacks and a $\$ 20$ Countdown voucher will be provided. Any information you contribute will be kept confidential.

Please email me on Chantal.Mawer@vuw.ac.nz or private message me if you are interested in taking part. This focus group will be held sometime in mid Novembera time and date will be set with those interested in taking part and will be held at the Johnsonville Community Centre. I am happy to send through more information for those who are interested.

I look forward to hearing from you, Chantal 


\section{Appendix 7 Focus group information sheet}

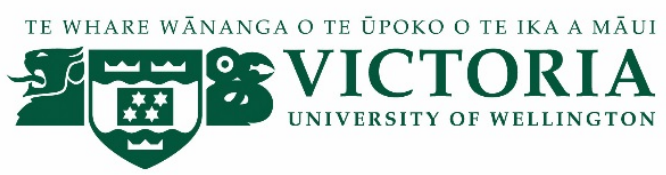

\section{'Suburban malls as Community Spaces' INFORMATION SHEET FOR PARTICIPANTS IN FOCUS GROUPS}

Thank you for your interest in this project. Please read this information before deciding whether or not to take part. If you decide to participate, thank you. If you decide not to take part, thank you for considering my request.

\section{Who am I?}

My name is Chantal Mawer and I am a Masters student in Environmental Studies at Victoria University of Wellington. This research project will contribute towards my thesis.

\section{What is the aim of the project?}

This research project aims to explore the role of malls as community places and examine how community members can participate in decision making. It hopes to encourage better processes for community decision making.

This research has been approved by the Victoria University of Wellington Human Ethics Committee 0000025165.

\section{How can you help?}

If you agree to take part you will be part of a focus group, the time and location is yet to be decided. I will ask you and other participant's questions about your local mall and your wider community. The focus group will take between 1 and 1.5 hours. I will audio record the focus group with your permission and write it up later. You can withdraw from the focus group at any time before the focus group begins. You can also withdraw while the focus group it is in progress. However it will not be possible to withdraw the information you have provided up to that point as it will be part of a discussion with other participants.

\section{What will happen to the information you give?}

Your identity will be kept confidential unless you choose to be identified and named in the research. This means that the two researchers named below will be aware of your identity but the research data will be aggregated and your identity will not be disclosed in any reports, presentations, or public documentation if you do not 
choose so. However, you should be aware that in small projects your identity might be obvious to others in your community.

Only the research team will read the direct research notes and see your responses. The data collected will be kept securely and destroyed 5 years after the research ends. However, if you are happy to be named, we would like to attribute the information to you.

\section{What will the project produce?}

The information from this research will be used to construct a Masters thesis and possible academic publications. It is hoped that this thesis may in the future, act as an aid to inform best practice for community decision making in privately owned community spaces.

\section{If you accept this invitation, what are your rights as a research participant?}

You do not have to accept this invitation if you don't want to. If you do decide to participate, you have the right to:

- $\quad$ choose not to answer any question;

- $\quad$ ask for the recorder to be turned off at any time during the focus group;

- withdraw from the focus group while it is taking part however it will not be possible to withdraw the information you have provided up to that point;

- $\quad$ ask any questions about the study at any time;

- $\quad$ read over and comment on a written summary of the focus group

- be able to read any reports of this research by emailing the researcher to request a copy.

\section{If you have any questions or problems, who can you contact?}

If you have any questions, either now or in the future, please feel free to contact either my supervisor or me:

\section{Student:}

Name: Chantal Mawer University email address:

Chantal.Mawer@vuw.ac.nz 0272453663

\author{
Supervisor: \\ Name: Rebecca Kiddle \\ Role: Lecturer \\ School: School of Geography, \\ Environment and Earth Sciences \\ Phone: 044636119 \\ Rebecca.Kiddle@vuw.ac.nz
}

\section{Human Ethics Committee information}

If you have any concerns about the ethical conduct of the research you may contact the Victoria University HEC Convenor: Associate Professor Susan Corbett. Email susan.corbett@vuw.ac.nz or telephone +64-4-463 5480. 


\section{Appendix 8 Focus group consent form}

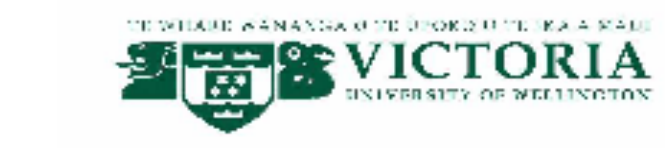

\section{'Suburban Malls as Community Spaces' CONSENT TO PARTICIPATE IN FOCUS GROUP}

This consent form will be held for 5 years.

Researcher: Chantal Mawer, School of Geography, Environment and Earth Sciences, Victoria University of Wellington.

- I have read the Information Sheet and the project has been explained to me. My questions have been answered to my satisfaction. I understand that I can ask further questions at any time.

- I agree to take part in an audio recorded focus group.

I understand that:

- I can withdraw from the focus group while it is in progress however it will not be possible to withdraw the information I have provided up to that point as it will be part of a discussion with other participants

- If I remain in this study, the identifiable information I have provided will be destroyed on the $1^{\text {st }}$ of May, 2023.

- Any information I provide will be kept confidential to the researcher and the supervisor unless my consent is given

- I understand that the results will be used for a Masters thesis, potential academic publications and presentations at academic conferences.

- I am happy for my name to be used in relation to this research

Yes $\square \quad$ No

- I would like a summary of the focus group:

Yes $\square \quad$ No

- I would like to receive a copy of the final report and have added my Yes No email address below.

Signature of participant: 


\section{Appendix 9: Focus group guide}

Introduction: Hello and welcome to this focus group, thank you so much for coming. My name is Chantal Mawer and I am a masters student at Victoria University and my research for this thesis focuses on Johnsonville mall/

Wainuiomata mall as one of my case studies. Our task today is to get a conversation going about the Johnsonville mall/ Wainuiomata Shopping centre and have your input on this space. This research project aims to explore the role of malls as community places and examine how community members can participate in decision making. It hopes to encourage better processes for community decision making.

I am asking for your perspectives to this because you are all community members who have no doubt been influenced by the situation with the mall and I want to hear your perspective about what's been happening. Too often only some people get to be heard about community issues and this research aims to open this up. You are the experts in the situation and I am here to learn from you.

I will be taking notes later on, but I would also like to audio tape what you are saying so that I don't miss anything important and so that I can go back to the information and revisit it if I need to.

\section{Housekeeping:}

The total length of time of the focus group meeting is expected to be about an hour and 15 minutes.

As far as the focus groups are concerned, there are a few "ground rules"

I might move you along in conversation. Since we have limited time, I'll ask that questions or comments off the topic be answered after the focus group session

I'd like to hear everyone speak so I might ask people who have not spoken up to comment

Please respect each other's opinions. There's no right or wrong answer to the questions I will ask. We want to hear what each of you think and it's okay to have different opinions.

I ask that you not discuss other participants' responses outside of the discussion. However, because this is in a group setting, the other individuals participating will know your responses to the questions and we cannot guarantee that they will not discuss your responses outside of the focus group.

Please help yourselves to food and drinks.

\section{Any questions so far?}

Again your participation here today is totally voluntary. So if you are okay with moving forward, we would like to get your consent. (HAND OUT CONSENT FORMS/ CHECK THAT ALL HAVE HANDED IN). 


\section{Question guide}

1. Each group member to introduce themselves- names and also your connection to Johnsonville and also the mall?

2. How do you use the mall?

3. What role do you think the mall holds in the Wainuiomata/ Johnsonville community?

4. What role do you think the mall has in supporting the Wainuiomata/ Johnsonville community/ the community around it?

5. What has been happening with the mall/ how do you feel about it?

6. Have you been able to participate in any decision making/ or express your thoughts/ concerns about the state of the mall and its future

8. If so, in what way was this possible?

9. If not, how would you have liked to be included?

10. What do you think about the concept of privately owned public space?

11. Do you see any benefits/ problems with this idea?

12. Any additional comments you would like to make?

I think we've come to the end of our questions. Let me be the first to say thank you for your honest opinions - you were tremendously helpful.

Again, thank you very much for your participation today. I really appreciate your help. 
